\title{
ESTUDO DE CESTAS PROTENDIDAS PELA TÉCNICA DO MEIO CONTÍNUO
}

Enga. RITA A. DAVID

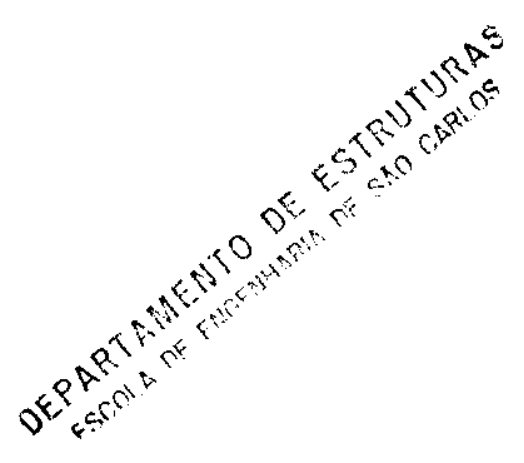

\begin{abstract}
Dissertação apresentada à Escola de Engenharia de São Carios, da Universidade de São Paulo, como parte dos requisitos para obtenção do Título de Mestre em Engenharia de Estruturas.
\end{abstract}

ORIENTADOR: Prof. Dr. Roberto L. A. Barbato

São Carlos

1995 


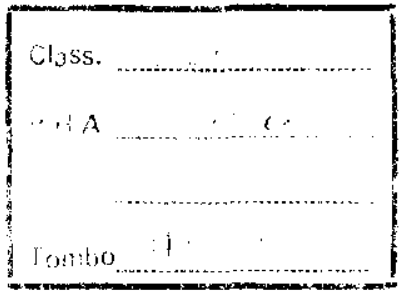

D275e

David, Rita Aparecida

Estudo de cestas protendidas pela técnica do meio contínuo/Rita Aparecida David.- São Carlos, 1995.

$102 p$.

Dissertação (Mestrado)-Escola de Engenharia de São Carlos-Universidade de São Paulo, 1995.

Orientador: Prof.Dr. Roberto L. A. Barbato

1. Coberturas pênseis. I. Título. 
À minha mãe, Almerinda, pelo seu exemplo de vida, com minha eterna gratidão. 


\section{AGRADECIMENTOS}

Especialmente ao Prof.Dr. Roberto Luiz de Arruda Barbato, pela dedicada orientação e sobretudo pela amizade e incentivo a todo instante.

Ao Departamento de Engenharia e Tecnologia Civil - UNESP Campus de Bauru por proporcionar condições favoráveis para $O$ andamento deste trabalho.

Ao meu irmão Antonio e à minha cunhada-irmã Arlene pela confiança e por terem viabilizado economicamente meus estudos possibilitando de alguma maneira que eu chegasse até aqui.

Às minhas tias Adair, Guiomar e Beatriz pelo amor, apoio, confiança e amizade que sempre me dedicaram.

Ao Johnny pela confiança e apoio incondicionais.

Aos meus sempre amigos Silvete e Kira pela ajuda e incentivo.

Aos funcionários do Departamento de Estruturas da Escola de Engenharia de São Carlos especialmente ao Sr. Antonio Valdair Carneiro pela digitação, ao Sr. Francisco Carlos Guete de Brito pelos desenhos e à Sra. Maria Nadir Minatel por sua colaboração na pesquisa bibliográfica.

A todos aqueles que, de alguma forma, contribuem e me incentivam no dia a dia na busca de tempos melhores. 


\section{SUMÁRIO}

\section{LISTA DE FIGURAS}

LISTA DE TABELAS

LISTA DE SÍMBOLOS

iii

RESUMO

iv

ABSTRACT

vii

\section{ABSTRACT}

1. INTRODUÇÃO

01

1.1- Histórico

01

1.2- Conceitos Básicos 03

1.2.1- Sistemas Estruturais $\quad 04$

1.2.1.1- Cestas não Protendidas 04

1.2.1.2- Cestas Protendidas 06

1.2.1.3-Cabos-Treliça 08

1.2.1.4- Cabos de Aço e seus Acessórios 10

1.2.2- Sistema Vedante 16

1.3- Aplicações de Cestas Protendidas em Coberturas 19

1.3.1- Arena da Feira Estadual em Raleigh 19

1.3.2- Pavilhão do Rio Grande do Sul 21

1.3.3- Ginásio de Esportes de Milão 22

1.3.4- Ringue de Patinação no Gelo em Munique 24

1.4- Conteúdo do Trabalho 25

2. ESTUDO DE CESTAS PROTENDIDAS 27

2.1- Equações Gerais 27

2.1.1- Fundamentos Geométricos 27

2.1.2- Condições de Equilíbrio 32

2.1.3- Condições de Elasticidade 34

2.1.4- Componentes Horizontais dos Esforços 40

2.1.5- Equações Diferenciais 43 
2.2- Resolução do Sistema Final de Equações 48

2.2.1- Condições de Contorno 48

2.2.2- Estudo dos Termos Geométricos 52

2.2.3- Estudo dos Termos de Carregamento 54

2.3- Determinação dos Deslocamentos e dos Esforços nos Cabos $\quad 57$

3. ESTRUTURA DO PROGRAMA COMPUTACIONAL 59

3.1- Programa CARACT.FOR 59

3.2- Programa MATRIZ.FOR $\quad 59$

3.3- Programa RESULT.FOR 60

3.4- Fluxogramas 60

3.5- Entrada de Dados 66

3.6- Saída de Resultados 69

3.7- Exemplo de Aplicação Numérica 70

4- EXEMPLOS NUMÉRICOS

4.1- Exemplo 2

4.2- Exemplo $3 \quad 82$

5- CONSIDERAÇÕES FINAIS $\quad 85$

$\begin{array}{ll}\text { 6- BIBLIOGRAFIA } & 88\end{array}$

$\begin{array}{ll}\text { 7- APÊNDICE } & 91\end{array}$ 


\section{LISTA DE FIGURAS}

Página

Figura 1.1- Esquemas de cestas não protendidas 04

Figura 1.2- Esquemas de cestas não protendidas (continuação) 05

$\begin{array}{ll}\text { Figura 1.3- Esquemas de cestas protendidas } & 07\end{array}$

Figura 1.4- Esquemas de cabos-treliças 08

Figura 1.5- Esquemas de sistemas estruturais compostos por cabos-treliça

Figura 1.6- Esquemas de sistemas estruturais compostos por cabos-treliças (continuação) 10

Figura 1.7- Formação de um cabo de aço 11

Figura 1.8- Construções mais usuais 12

Figura 1.9- Torção dos cabos de aço 13

Figura 1.10- Soquetes e sapatilhas protetoras $\quad 15$

Figura 1.11- Sapatilhas protetoras; sentido de colocação dos grampos 16

Figura 1.12- Fixação das placas de argamassa ou de concreto armado

Figura 1.13- Fixação das telhas de aço ou de alumínio 17

$\begin{array}{ll}\text { Figura 1.14- Fixação de chapas lisas } & 18\end{array}$

Figura 1.15- Fixação de lâminas de plástico ou de náilon 18

Figura 1.16- Detalhe do encontro da vedação com o fechamento lateral

Figura 1.17- Vista externa e planta da Arena da Feira Estadual em Raleigh

Figura 1.18- Pavilhão do Rio Grande do Sul 
Figura 1.19- Ginásio de esportes de Milão 24

Figura 1.20- Ringue de patinação no gelo em Munique 25

Figura 2.1- Notação geométrica das superfícies 29

Figura 2.2- Elemento de membrana com dimensões e esforços atuantes.

Figura 2.3- Elemento de membrana submetido a esforços de tração

Figura 2.4- Curva do contorno como função de y 51

Figura 2.5- Curva do contorno como função de x 52

Figura 2.6- Contorno da superfície em planta e reticulado adotado

Figura 2.7- Analogia de viga para estudo dos termos de carregamento

Figura 3.1- Fluxograma do programa CARACT.FOR 63

Figura 3.2- Fluxograma do programa MATRIZ.FOR 65

Figura 3.3- Fluxograma do programa RESULT.FOR 68

Figura 3.4- Planta da cesta protendida com dimensões principais, poligonal do contorno e malha adotadas. Exemplo $1 . \quad 73$

Figura 4.1- Características geométricas e malha arbitrada.

Exemplo 2.

Figura 4.2- Deslocamentos obtidos para $y=0,40 m$

Figura 4.3- Deslocamentos obtidos para $y=0,72 m$

Figura 4.4- Deslocamentos e acréscimos de esforços para $x=0 m \quad 83$

Figura 4.5- Deslocamentos e acréscimos de esforços para y=0m 84

Figura 4.6- Características geométricas e malha arbitrada.

Exemplo 3.

Figura 4.7- Deslocamentos obtidos para $x=0 m$ 


\section{LISTA DE TABELAS}

Página

Tabela 3.1- Identificação do arquivo de dados ARQ1.DAT 70

Tabela 3.2- Identificação do arquivo de dados ARQ2.DAT 72

Tabela 3.3- ARQ1.DAT; Exemplo 1

Tabela 3.4- ARQ2.DAT; Exemplo 1

Tabela 3.5- Deslocamentos e esforços devido ao carregamento permanente 76

Tabela 3.6- Esforços finais nos cabos na direção do eixo x

Tabela 3.7- Esforços finais nos cabos na direção do eixo y 78

Tabela 4.1- Deslocamentos e esforços obtidos através da Análise do Meio Contínuo, e deslocamentos por MØLLMANN \& MORTENSEN (1966)

Tabela 4.2- Deslocamentos e componentes horizontais dos esforços 


\section{LISTA DE SÍMBOLOS}

$A_{s}$

$A_{x}, A_{y}$

$d A$

$\overline{\mathrm{d}} \mathrm{A}$

ds

$\overline{d s}$

$d s_{0}$

$D_{x}, D_{y}$

$e_{x}, e_{y}, e_{z}$

$E_{x}, E_{y}$

$e_{1}, e_{2}, e_{3}$

$\overline{\mathrm{e}}_{1}, \overline{\mathrm{e}}_{2}, \overline{\mathrm{e}}_{3}$

$H_{0}, H_{p}$ área da seção transversal dos cabos da cesta protendida

área equivalente da seção transversal dos cabos da cesta protendida nas direções dos eixos $x$ e y respectivamente.

área infinitesimal do elemento de superfície inicial.

área infinitesimal do elemento de superfície deslocada.

comprimento inicial; módulo do vetor obtido pela variação do vetor posição $r$.

comprimento final; módulo do vetor obtido pela variação do vetor posição $\bar{r}$.

comprimento de referência

funções de rigidez que dependem somente da geometria e das propriedades mecânicas da cesta protendida.

versores das direções $x, y$ e $z$.

módulo de elasticidade longitudinal dos cabos nas direções dos eixos $x$ e y respectivamente.

versores tangentes e normal à superfície inicial em um ponto genérico.

versores tangentes e normal à superfície deslocada em um ponto genérico.

componentes horizontais dos esforços devido à protensão e às ações externas respectivamente; por unidade de comprimento. 
$H_{x}, H_{y}$ : componentes horizontais dos esforços $T_{1}$ e $T_{2}$ respectivamente; por unidade de comprimento.

$\ell_{x}, \ell_{y}$

distância em planta entre cabos nas direções dos eixos $x$ e $y$ respectivamente.

m

vetor deslocamento de um ponto genérico da superficie; $m=f$ $(u, v, w)$.

$M_{x}, M_{y} \quad$ : representação dos momentos fletores, obtidos por analogia de viga, no estudo dos termos de carregamento da cesta protendida.

$N_{x}, N_{y} \quad: \quad$ representação dos esforços normais, obtidos por analogia de viga, no estudo da variação de temperatura.

$p \quad: \quad$ vetor carregamento, $p=f\left(p_{x}, p_{y}, p_{z}\right)$ por unidade de área.

$p_{x}, p_{y}, p_{z}:$ carregamentos atuantes no elemento de superfície, nas direções dos eixos, $x, y$ e $z$ respectivamente.

$\mathrm{p}_{\mathrm{x}}^{*}, \mathrm{p}_{\mathrm{y}}^{*}, \mathrm{p}_{\mathrm{z}}^{*} \quad: \quad$ termos considerados como carregamentos adicionais nas direções dos eixos $x, y$ e $z$ respectivamente.

vetor posição da superfície inicial; $r=f(x, y, z(x, y))$.

$\bar{r}$

vetor posição da superfície deslocada; $\bar{r}=f(x+u, y+v, z+w)$

$T_{0}, T_{p}$

forças devido a protensão e devido às açōes externas respectivamente; por unidade de largura do elemento de superficie.

$T_{1}, T_{2} \quad$ : forças atuantes por unidade de largura do elemento de superfície, nas dierções de $e_{1}$ e $e_{2}$ respectivamente. 
$u, v, w$

deslocamentos de um ponto genérico da superfície segundo as direções $x, y \in z$ respectivamente.

$v_{x}, v_{y}$

representação dos esforços cortantes obtidos por analogia de viga no estudo dos termos de carregamento da cesta protendida.

$x, y, z(x, y) \quad: \quad$ coordenadas cartesianas.

$\alpha \quad$ : coeficiente de dilatação térmica do material que compõem os cabos da cesta protendida.

$\beta(x, y)$ : função de carregamento obtida pela integração das equações diferenciais de equilíbrio da cesta protendida.

$\beta^{*}(x, y)$ : função de carregamento adicional obtida a partir da linearização das equações de equilíbrio da cesta protendida.

$\Delta t \quad$ : variação de temperatura.

$\Delta_{\mathbf{x}}, \Delta_{\mathrm{y}} \quad$ : distância em planta entre os elementos da malha arbitrada, na direção dos eixos $x$ e y respectivamente.

$\varepsilon_{1}, \varepsilon_{2} \quad$ : deformações específicas em um ponto genérico do elemento de superfície nas direções de $e_{1}$ e $e_{2}$ respectivamente. 


\section{RESUMO}

DAVID, R.A. Estudo de cestas protendidas pela técnica do meio contínuo. São Carlos, 1995. Dissertação (Mestrado) - Escola de Engenharia de São Carlos, Universidade de São Paulo.

Neste trabalho apresenta-se um estudo do comportamento estrutural de cestas protendidas, tendo em vista a sua utilização em coberturas pênseis de grandes áreas livres. A partir da Técnica do Meio Contínuo obtêm-se as equações que permitem analisar as cestas protendidas quanto a esforços e deslocamentos. Fazem-se considerações sobre o sistema de equações encontrado visando a sua resolução mediante o emprego de programa computacional como instrumento de cálculo. Apresentam-se exemplos numéricos e os resultados são comparados com os obtidos em outros trabalhos. Fazem-se algumas considerações a respeito do projeto $\mathrm{e}$ do cálculo de cestas protendidas, além de algumas indicações sobre a continuidade da pesquisa.

Palavras chaves: cabos; coberturas pênseis; estruturas protendidas. 


\section{ABSTRACT}

DAVID, R.A. Study of prestressed cable nets by the continuous medium method. São Carlos, 1995. Dissertação (Mestrado) Escola de Engenharia de São Carlos, Universidade de São Paulo.

This work presents a continuous medium method analysis of cable nets and their applications as suspended roofs for large free spans. Initially the theory of the method is presented and later applied to get the system of differential equation that represents the problem. Finally this system is numerically solved with computational procedures. Some examples are presented and the results compared with those obtained with others methods and numerical procedures. Some analysis and design considerations and further developments in this subject are also included.

Keywords: Tensile structures; suspended roofs; cable nets structures; prestressing. 


\section{INTRODUÇÃO}

\section{1- Histórico}

A busca de maneiras que façam com que os espaços cobertos tenham uma melhor e mais eficiente utilização tem sido um dos mais importantes objetivos de arquitetos e engenheiros. A opção por coberturas que vençam grandes vãos e que proporcionem 0 uso de espaços desobstruídos pode levar à utilização de coberturas suspensas.

O uso deste tipo de cobertura se justifica por dois fatores: o primeiro fator é o estético, pois a variedade de modelos e formas possiveis com a utilização de sistemas suspensos apresenta uma opção adicional para a expressão arquitetônica; o segundo fator, e o mais importante, é o econômico, pois as coberturas suspensas têm realmente um menor custo que outros tipos de coberturas quando o objetivo é cobrir grandes áreas livres.

Os sistemas suspensos são utilizados desde a antiguidade, quando o homem, empregando elementos da própria natureza como cordas, folhas e pele de animais, construia tendas para abrigá-lo, protegendo-o das intempéries.

Algum tempo depois com o aparecimento das técnicas de tecer este sistema de cobertura, a tenda, obteve um avanço quanto a sua qualidade. Surgiram assim os mais versáteis tipos de tenda que, construídos com o emprego de cordas e tecidos, foram amplamente utilizados por todos os povos, principalmente pelos de cultura nômade.

As cordas e os tecidos também foram utilizados com bastante frequência na construção de coberturas pênseis. Segundo FRAGOSO (1965), os gregos empregaram este tipo de cobertura no Odeon de Atenas e no Teatro de Epidauro. 
Outros autores, KRISHNA (1978) e SALES (1988), relatam que no ano 70 D.C. os romanos construiram, empregando cordas de cânhamo e tecido de linho, uma cobertura suspensa para o Coliseu. O tecido costurado às cordas e estas fixadas às paredes do contorno formariam uma imensa cobertura pênsil que cobriria uma área de aproximadamente $23000 \mathrm{~m}^{2}$.

Infelizmente, a vida útil destas estruturas era relativamente curta devido aos materiais empregados que se deterioravam facilmente sob ação do sol e da chuva, exigindo uma renovação constante.

Alguns séculos mais tarde, com a revolução industrial, é que aparece um novo material para a construção civil, proporcionando o grande impulso para o desenvolvimento da engenharia, o aço, empregado como elemento estrutural, disponivel em larga escala no mercado.

Para assinalar ainda o século passado, uma das poucas coberturas pênseis construídas foram as dos pavilhöes da Exposição Industrial, realizada em 1896, em Nijny-Novgorod na Rússia.

A cobertura pênsil destes pavilhōes, projetada por V.G. Shookhov, era formada por tiras de aço entrelaçadas. Maiores detalhes em BARBATO (1991).

No início deste século, cabe mencionar a construção em 1932 de uma cobertura pênsil destinada a cobrir oito grandes silos na cidade de Albany nos Estados Unidos. Esta construção, segundo alguns autores, marca uma nova era da construção das coberturas suspensas.

$O$ ressurgimento deste tipo de construção vem acontecer realmente em 1937 com o projeto de Bernard Lafaille para o pavilhão da França na Exposição de Zagreb, Croácia.

Lafaille aperfeiçoou sua idéia inicial, o que Ihe permitiu, em 1951 , apresentar o projeto para o Centro de Indústria Mecânica de Paris, que consistia de uma superfice de dupla curvatura reversa suspensa de dois arcos perimetrais inclinados, cobrindo uma área total de $36.000 \mathrm{~m}^{2}$. Este projeto não chegou a ser executado, mas vale ser citado devido à coincidência que existe entre este projeto e a idéia apresentada por $M$. Nowicki para a cobertura do State Fair Arena, em Raleigh, na Carolina do Norte que é considerada o marco da utilização das coberturas pênseis na modernidade.

O projeto da Arena em Raleigh foi concluído em 1952 pelo arquiteto W.H. Deitrich e pelo engenheiro F.N. Severud e sua construção foi realizada no período entre 1952 e 1953. 
A cobertura pênsil da arena, em forma de superfície de dupla curvatura reversa, é suspensa por uma estrutura perimetral formada por dois arcos de concreto armado de eixos parabólicos e inclinados de $22^{\circ} \mathrm{em}$ relação à horizontal, por pilares de aço revestidos de concreto e que servem de apoio para os arcos, e por dois encontros de concreto armado onde são articulados os dois arcos. Maiores detalhes em BARBATO (1991).

Nos últimos anos construiram-se várias coberturas pênseis que têm demonstrado, pelo excelente desempenho, que a idéia de Nowicki foi muito fecunda.

No Brasil, as primeiras coberturas pênseis foram executadas na Exposição do IV Centenário de São Paulo, em 1954, no Parque do Ibirapuera, sendo uma delas a do Pavilhão do Rio Grande do Sul. Esta cobertura é do tipo de dupla curvatura reversa cobrindo uma área de $6120 \mathrm{~m}^{2}$, com projeto do arquiteto Jayme Luna dos Santos e dos engenheiros Alberto Borges e R.C. Alliana.

\section{2- Conceitos Básicos}

A cobertura pênsil, também conhecida como cobertura suspensa, é um sistema construtivo composto por um sistema estrutural formado por cabos e barras de aço, isolados ou adequadamente associados, e por um sistema vedante que se apóia no sistema estrutural.

O sistema vedante é formado pela vedação propriamente dita e por acessórios que têm como finalidade fixar a vedação no sistema estrutural. Como vedação podem ser empregados elementos dos mais diversos materiais tais como aço, concreto, madeira ou qualquer outro material que proporcione uma boa estanqueidade, isolamento térmico, acústico e translucidade se o projeto assim o exigir.

Por sua vez, os cabos que formam o sistema estrutural podem ser associados de modo a formar ou cestas não protendidas, ou cestas protendidas ou cabos-treliças.

Os conceitos acima colocados serão detalhados a seguir: 


\subsection{1- Sistemas Estruturais}

\subsubsection{1- Cestas Não Protendidas}

As cestas não protendidas são geradas pela adequada associação de um conjunto de cabos livremente suspensos. A posição relativa dos cabos e a sua configuração de equilíbrio definem a forma da superficie da cesta.

Dentre as cestas não protendidas a mais simples é a composta por cabos dispostos paralelamente entre sí, nivelados e com uma única curvatura, Figura 1.1.a.
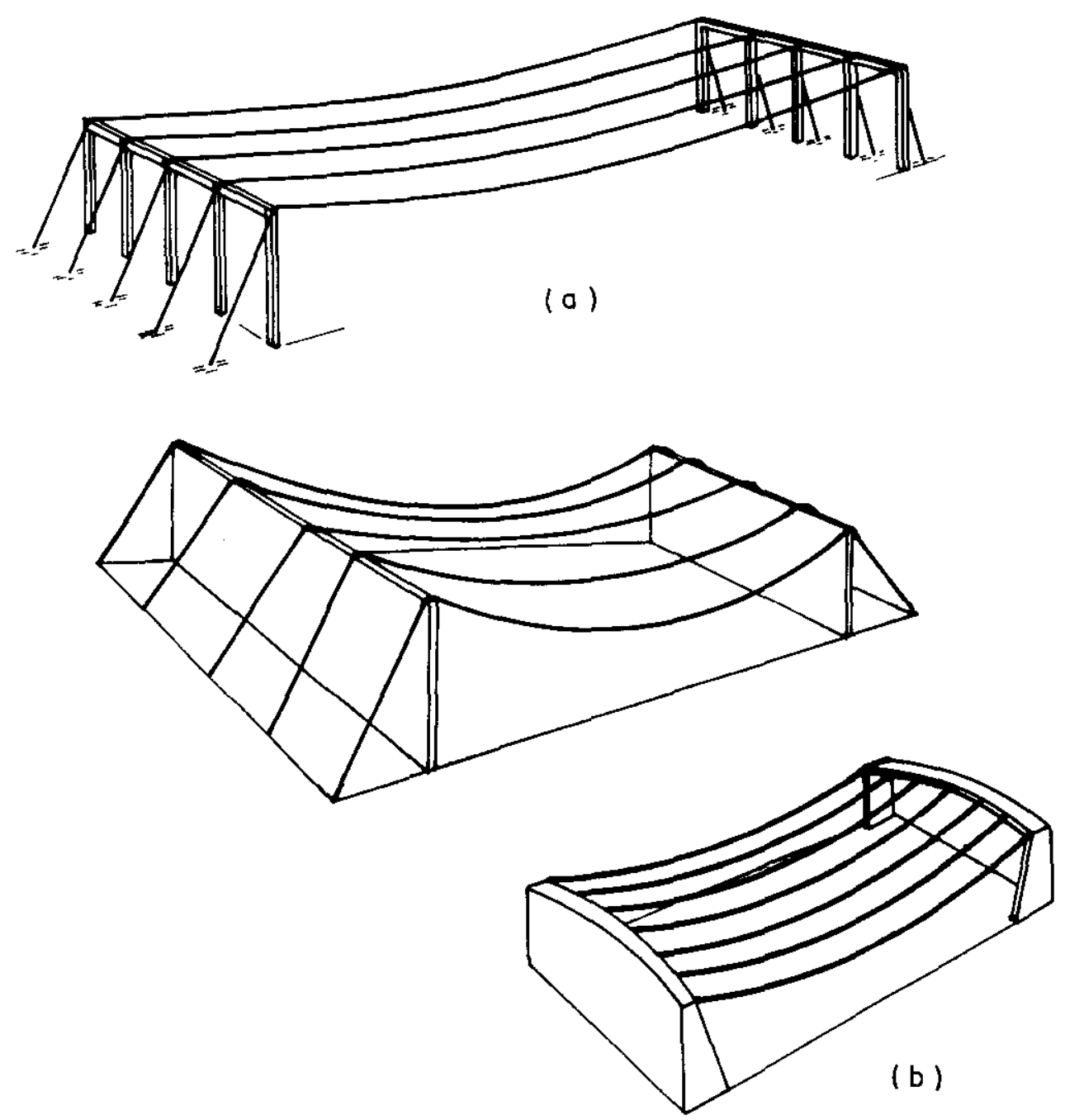

Figura 1.1- Esquemas de cestas não protendidas

Uma outra alternativa é a que se obtém mediante a variação progressiva da altura dos pilares ou da flecha dos cabos. Neste caso, a 
cesta possui dupla curvatura reversa ou de mesmo sentido, Figura 1.1.b.

Nestes casos, sob o ponto de vista econômico, recomenda-se a utilização de vãos entre 30 e 60 metros, espaçamento entre os cabos de 2 a 4 metros e a relação entre a flecha e o vão em torno de $1 / 10$, SALES (1988).

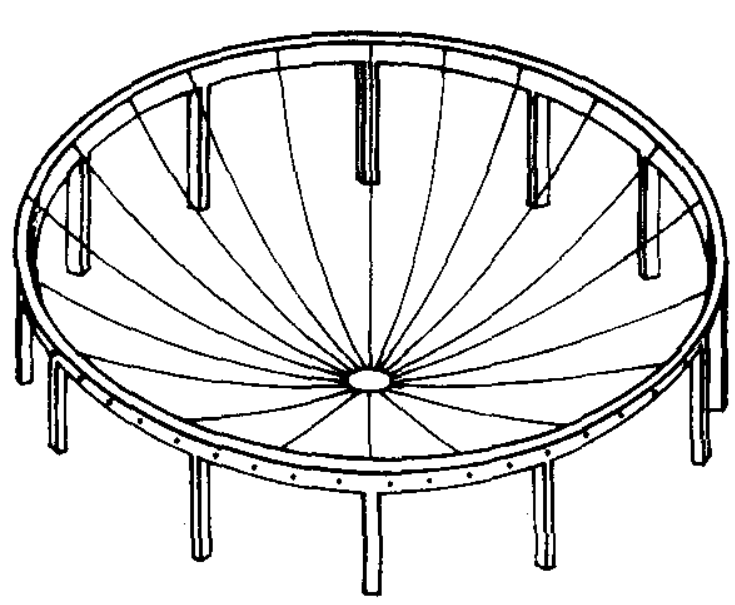

(a)
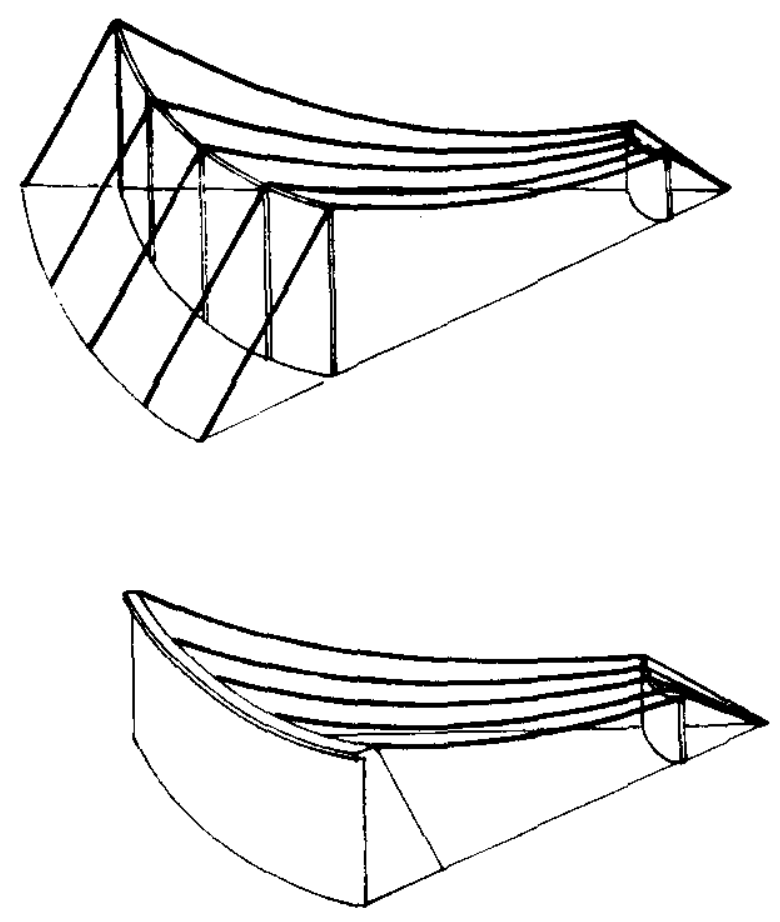

(c)

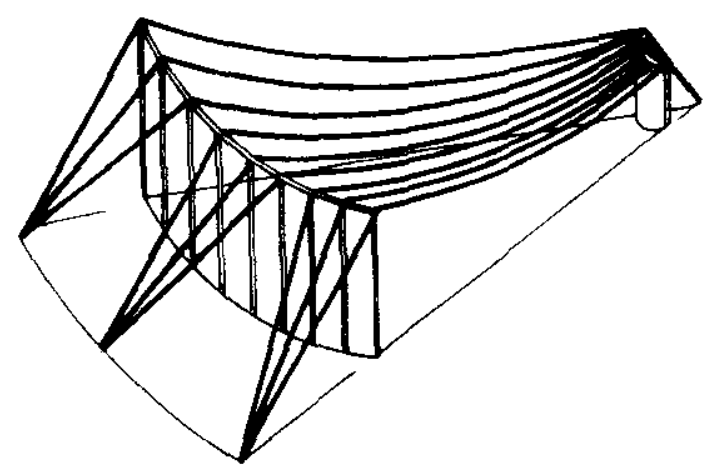

Figura 1.2- Esquemas de cestas não protendidas (continuação)

Outra forma muito difundida de cestas não protendidas é a de planta circular, composta por dois anéis cujos centros são extremidades de um 
segmento perpendicular aos planos que os contém, e por cabos radiais nestes ancorados. Neste caso, a cesta resultante tem a configuração de uma superfície de revolução de dupla curvatura de mesmo sentido, Figura 1.2.a.

Uma variante dessa cesta é a que se obtém com a utilização de uma torre central, os cabos radiais ancoram-se em um anel externo e na extremidade superior da torre. A superfície gerada tem a forma de uma superficie de revolução de dupla curvatura reversa, Figura 1.2.b.

Nestas formas de cestas, recomenda-se que os diâmetros dos anéis fiquem entre 45 e 90 metros e a relação entre flecha e o vão entre $1 / 9$ e 1/12, SALES (1988).

Logicamente, cestas de cabos radiais podem ser usadas em coberturas de plantas elípticas ou de planta com forma de setor circular, Figura 1.2.c.

\subsubsection{2- Cestas Protendidas}

São estruturas em cujos cabos, adequadamente dispostos, aplicamse esforços de protensão.

Aqui destaca-se o sistema estrutural constituido por dois conjuntos de cabos associados de maneira que formem malhas retangulares e determinem uma superfície de dupla curvatura reversa, Figura 1.3.a.

A um dos conjuntos pode-se dar o nome de cabos tensores, que são aqueles aos quais imprime-se a protensão, e ao outro conjunto dá-se o nome de cabos portantes. O valor da protensão deverá evidentemente ser aquele que mantiver o sistema sempre tracionado.

Adequadamente projetadas quanto a forma e protensão, as cestas protendidas resultam bastante rígidas. Assim sendo, os vãos a vencer pelas cestas protendidas podem ser bem maiores do que os vencidos por outras estruturas.

Do ponto de vista econômico, recomenda-se empregá-las para vãos acima de 100 metros e com valores máximos compatíveis com as propriedades do material a ser empregado.

As cestas protendidas são mais utilizadas em coberturas de planta circular ou elíptica. Algumas cestas são concebidas com contorno formado por um cabo de aço, dando origem assim a uma forma de cobertura 
totalmente livre onde os cabos associados transversalmente compõem malhas de diversas formas e dimensões, Figura 1.3.b. A protensão da estrutura é feita pelos cabos da própria cesta ou por meio de cabos isolados especialmente projetados.
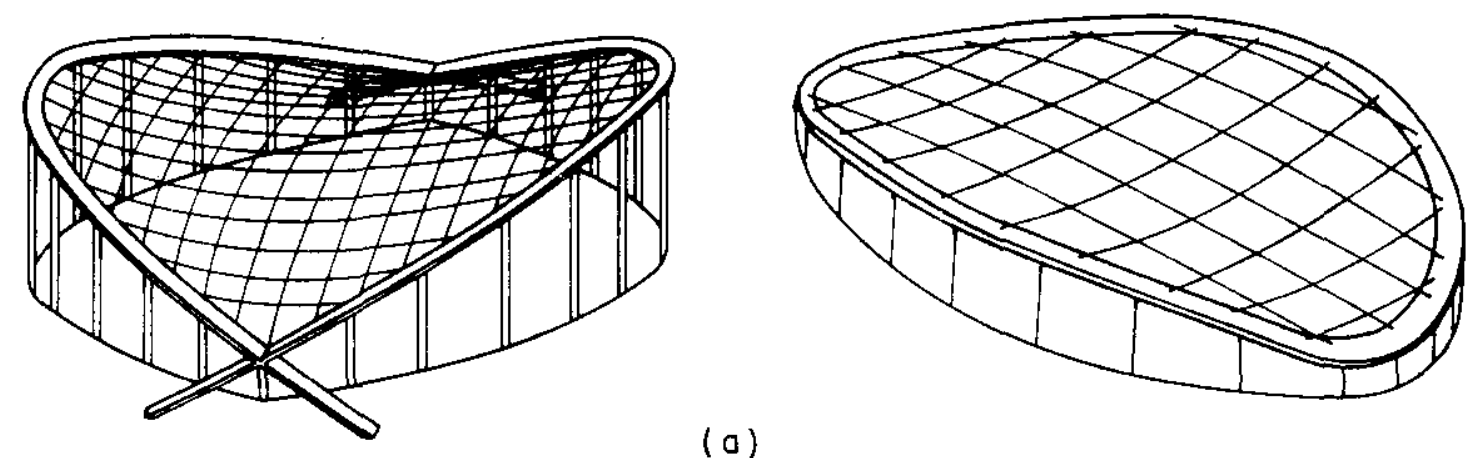

(a)
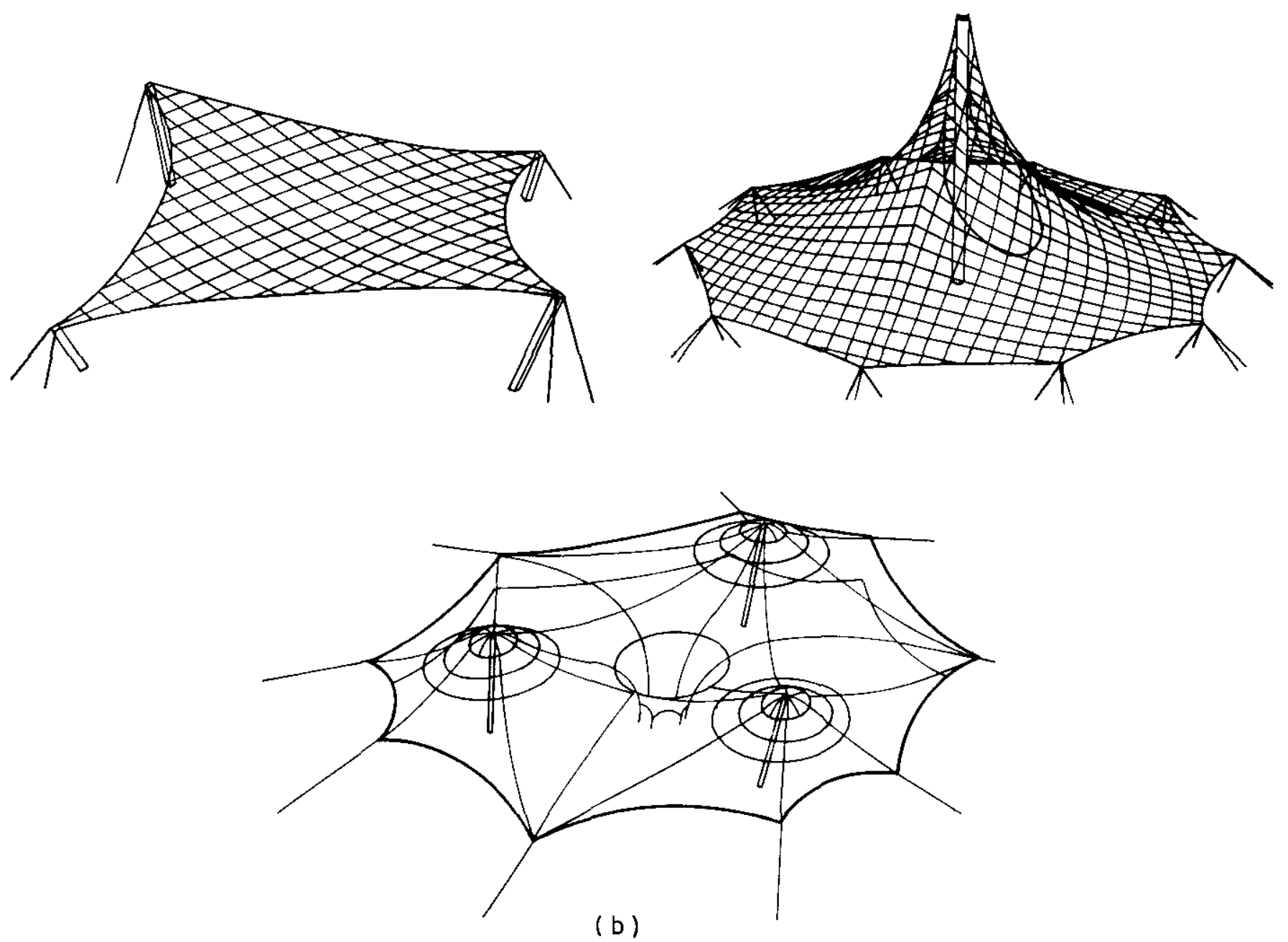

Figura 1.3- Esquemas de cestas protendidas 


\subsubsection{3- Cabos-Treliça}

Constituidos essencialmente por dois cabos e por um conjunto de barras, os cabos treliça são estruturas protendidas que têm a forma de uma treliça plana de banzos não paraielos, Figura 1.4.
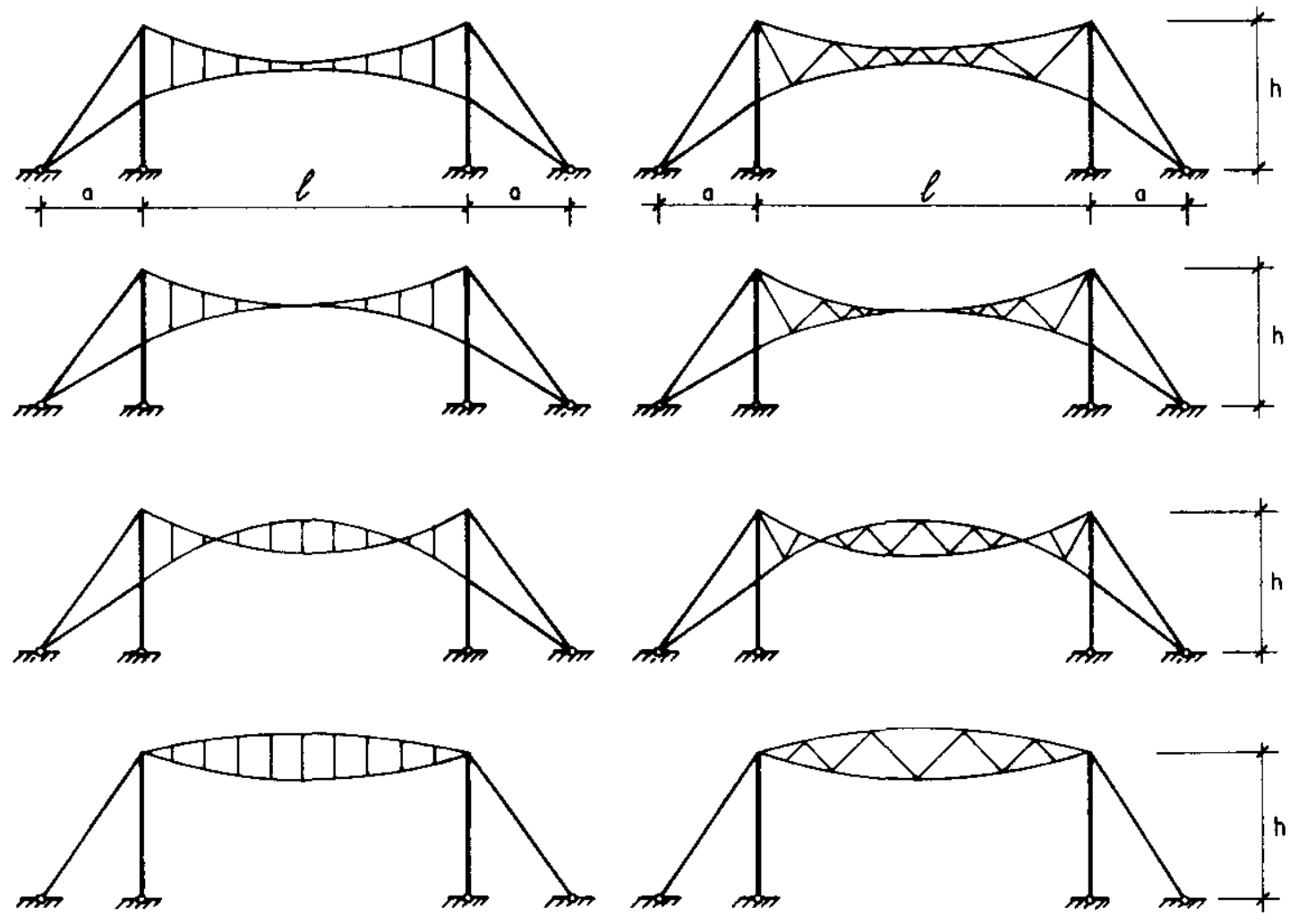

Figura 1.4- Esquemas de cabos-treliças

Dependendo da posição relativa entre os dois cabos, as barras, que podem ser verticais ou inclinadas, ficam sujeitas a esforços ou de tração ou compressão.

Quanto à protensão, esta pode ser aplicada aos cabos treliça ou por meio das hastes ou por meio dos cabos, devendo obviamente o conjunto permanecer sempre tracionado.

Para compor o sistema estrutural, os cabos treliça podem ser dispostos paralelamente, radialmente ou mesmo transversalmente. 
A disposição paralela entre cabos-treliça pode resultar em coberturas cilindricas de dupla curvatura ou de mesmo sentido, Figura 1.5.

Estas coberturas têm vãos recomendados entre 45 e 90 metros, espaçamento entre cabos de 2 a 5 metros e relação entre a flecha e o vão de $1 / 10$ a $1 / 12$. Podem ser construídas com apoios desnivelados, pilares engastados ou articulados e estaiados e em vãos simples ou duplos.
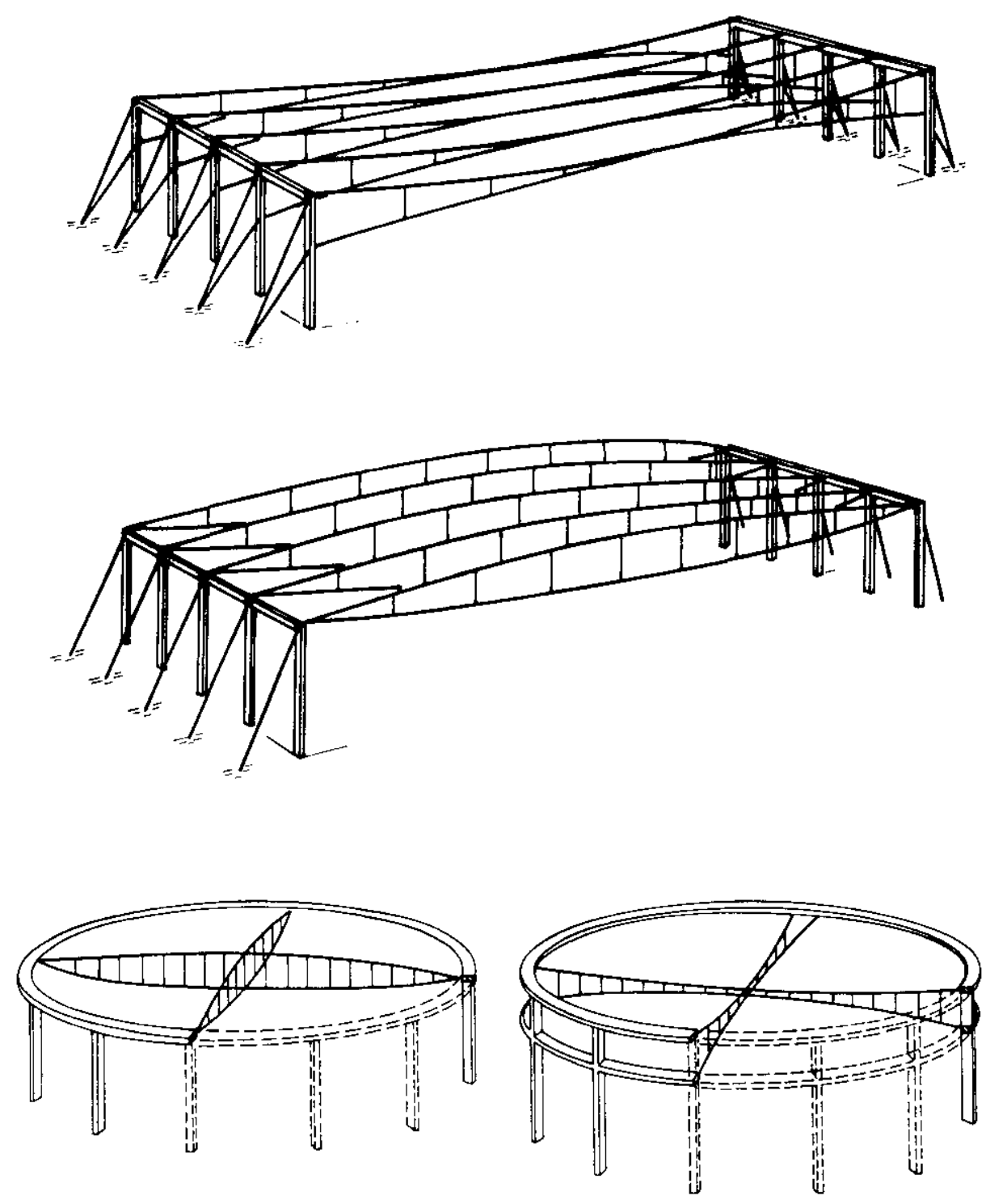

Figura 1.5- Esquemas de sistemas estruturais compostos por cabos-treliças

As coberturas de planta circular, elíptica ou em setor de coroa circular, formadas pela disposição radial dos cabos-treliça, Figura 1.6, têm 
seus vãos recomendados entre 60 e 120 metros e relação entre a flecha máxima e o vão de $1 / 12$ a 1/15, SALES (1988).
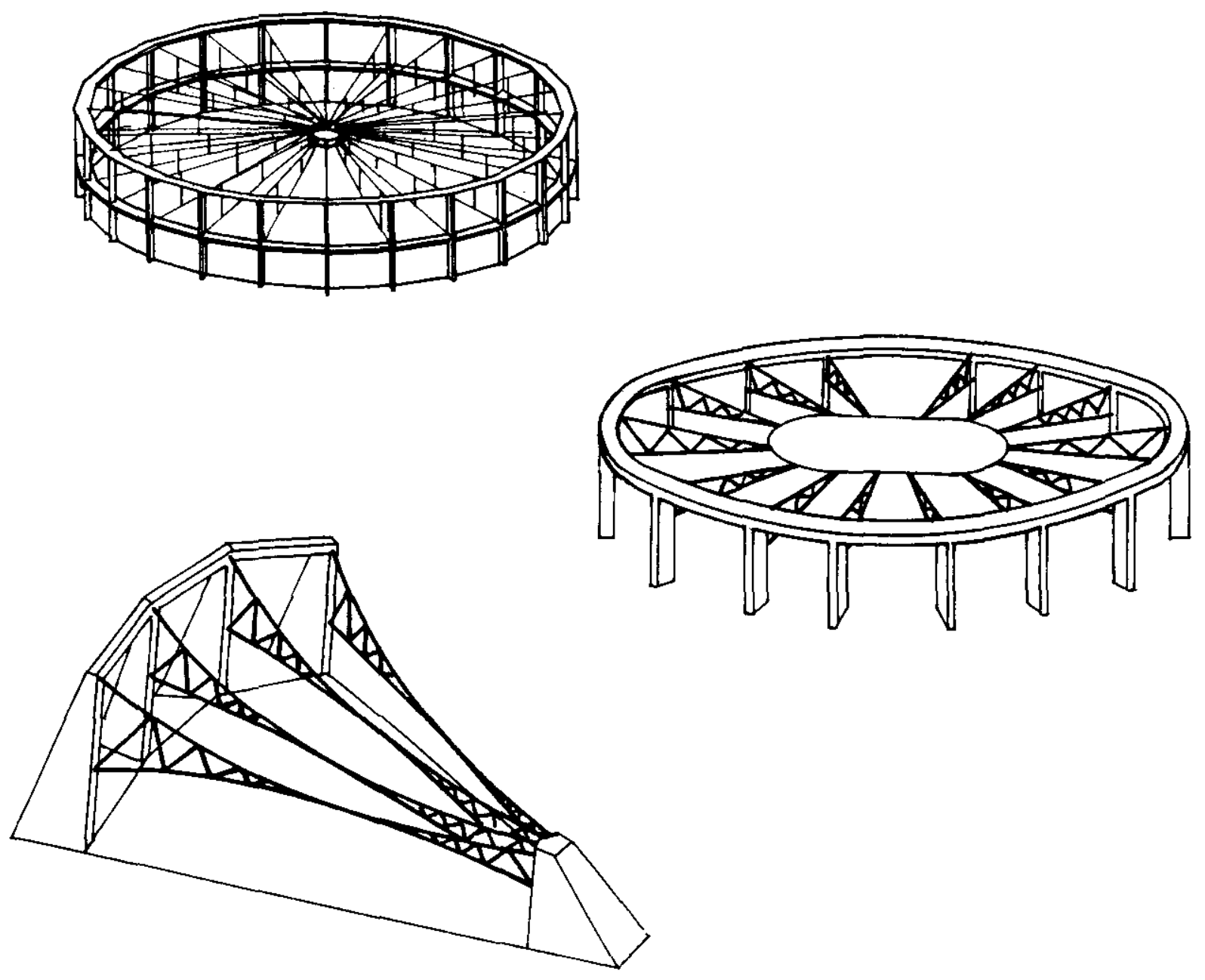

Figura 1.6- Esquemas de sistemas estruturais compostos por cabos-treliça

\subsubsection{4- Cabos de Aço e Seus Acessórios}

Os fabricantes nacionais de cabos de aço obedecem prescrições de normas da Associação Brasileira de Normas Técnicas (ABNT), da British Standard Specification (BSS), da American Petroleum Institute (API) e de outras normas estrangeiras, fornecendo cabos para múltiplas aplicações com diâmetros que variam desde $3,2 \mathrm{~mm}$ até $60,3 \mathrm{~mm}$ e em faixas de tensões de ruptura da ordem de $600 \mathrm{MPa}$ até $2300 \mathrm{MPa}$, SALES, (1988). 
Os cabos de aço são formados por um núcleo central, denominado de alma, e por um conjunto de pernas que são helicoidalmente torcidas em torno do núcleo.

As pernas, por sua vez, são formadas por um fio central e por um conjunto de fios que são torcidos helicoidalmente em torno do fio central, Figura 1.7.

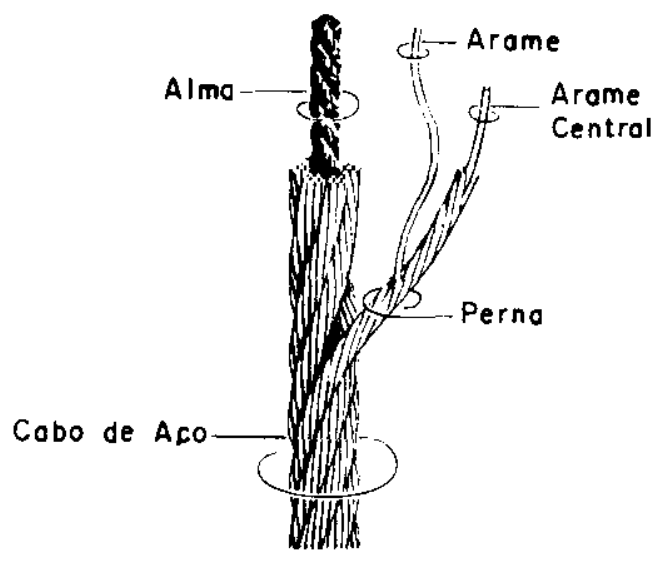

Figura 1.7- Formação de um cabo de aço

Os cabos de aço constituídos por uma só perna são denominados de cordoalhas. Os que possuem mais de uma perna recebem a denominação genérica de cabo.

As pernas de um cabo, quando formadas por mais de uma camada de fios, são executadas com o mesmo passo para os arames de camadas diferentes, assegurando assim um contato permanente entre os arames de camadas sucessivas. Este contato é que atribui uma maior resistência ao esmagamento das pernas ou das cordoalhas, distribui as tensões internas geradas pelo atrito entre os arames e torna os cabos mais estáveis diminuindo a tendência à torção quando não há solicitação.

O contato entre os fios que compöem o cabo pode ser melhorado empregando-se na sua construção fios de diâmetros diferentes. Esta técnica deu origem às construções mais conhecidas que são: Seale, Warrigton, Filler e Mista, descritas a seguir: 
A) A construção Seale emprega duas camadas de arames com o mesmo número de fios, sendo a camada interna de diâmetro menor. Esta construção proporciona uma alta resistência à abrasão devido ao maior diâmetro dos fios externos, Figura 1.8.a.

B) A construção Warrington emprega duas camadas de arames de diâmetros diferentes dispostos alternadamente na camada externa gerando uma superfície externa mais lisa e uma seção mais compacta. Esta construção proporciona uma alta resistência ao esmagamento e boa estabilidade ao cabo, Figura 1.8.b.

C) A construção Filler apresenta os espaços entre as camadas externas preenchidas com arames de diâmetro menor, gerando assim uma seção mais compacta se comparada com as já descritas e proporciona uma boa resistência à abrasão e ao esmagamento, Figura 1.8.c.

D) A construção mista é obtida combinando-se as construções anteriores duas a duas.

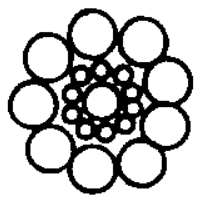

(a)

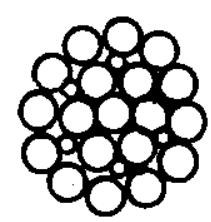

(c)

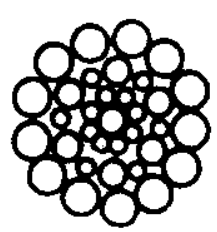

(d)

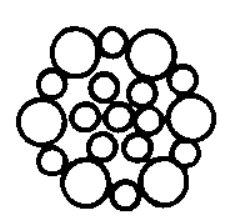

(b)

Figura 1.8- Construções mais usuais

A única que é fabricada pelos fornecedores nacionais é a Warrington-Seale, Figura 1.8.d, que apresenta uma camada de arames de diâmetro pequeno junto ao núcleo, uma segunda camada com arames de diâmetros diferentes dispostos alternadamente e uma última camada de 
arames de diâmetro maior. Esta construção gera um cabo resistente ao esmagamento, pouco flexivel, com pouco atrito interno e resistente à abrasão.

A flexibilidade de um cabo, que é medida pela sua maior ou menor resistência ao enrolamento, é função dos diâmetros dos fios que o compõe. Assim, evidentemente, cabos construídos com fios de diâmetros pequenos são mais flexiveis que cabos construídos com fios de diâmetros mais grossos.

O diâmetro dos fios também influencia na resistência do cabo; fios de diâmetro menor, devido ao processo de fabricação, apresentam um aumento de resistência.

Com relação ao sentido de torção dos fios, os cabos podem ser de torção Lang ou de torção regular, Figura 1.9.

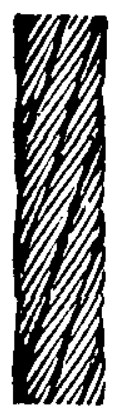

(a)

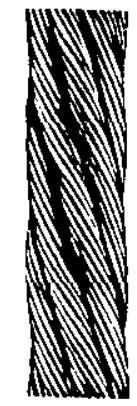

Figura 1.9- Torção dos cabos de aço

O cabo é de torção Lang, Figura 1.9.a, quando o sentido de enrolamento dos fios para a confecção das pernas é coincidente com o sentido de enrolamento das pernas em torno do núcleo do cabo; neste caso há um aumento na resistência à abrasão e na flexibilidade do cabo.

A torção regular, Figura 1.9.b, ocorre quando os sentidos de enrolamento são diferentes, e assim há um aumento na estabilidade do cabo. 
Os cabos podem ser pré-formados ou não. O cabo é dito pré-formado quando as pernas e os arames passam por um processo adicional na fabricação que os mantém curvados na forma helicoidal. Nestes cabos as tensões são melhor distribuídas e a tendência ao desenrolamento é sensivelmente diminuida.

Quanto a alma dos cabos estas podem ser de fibras naturais, artificiais ou de aço.

Como alma de fibras naturais utilizam-se o sisal ou o rami, como artificial o polipropileno, e a de aço utiliza-se ou uma perna ou um cabo de aço propriamente dito.

Os cabos que empregam alma de fibra são mais deformáveis que os que empregam alma de aço. Estas deformações, chamadas de estruturais, podem ser quase totalmente eliminadas com a aplicação de um préestiramento ao cabo na ocasião da fabricação.

O processo de pré-estiramento consiste em aplicar ao cabo uma força de tração durante um determinado período de tempo, com intensidade da ordem de $60 \%$ da sua capacidade última. Um cabo pré-estirado apresenta apenas deformações elásticas.

O módulo de elasticidade ou módulo de deformação de um cabo préestirado assume um valor praticamente constante para trações menores que a aplicada no pré-estiramento.

Vale ressaltar aqui que a carga de trabalho de um cabo pré-estirado, para que o mesmo trabalhe dentro do regime de proporcionalidade, deve ser inferior a $90 \%$ da força aplicada no pré-estiramento e que esta, por sua vez, deve ser inferior a $60 \%$ da carga mínima efetiva fornecida pelo fabricante, conforme Cable Roof Structures (1968).

A identificação dos cabos é feita por dois números: o primeiro representa a quantidade de pernas que 0 mesmo possui e o segundo número representa a quantidade de arames existentes em cada perna. Por exemplo, um cabo identificado como $6 \times 7$ possui seis pernas com sete arames em cada uma.

A área metálica de um cabo de aço pode ser calculada multiplicandose o quadrado do diâmetro nominal do cabo por um fator que depende da construção utilizada.

Quanto ao acabamento, os arames que compõem os cabos podem ser galvanizados ou polidos. A escolha do tipo de acabamento depende das condições do ambiente de trabalho dos cabos. 
Para melhorar as condições de durabilidade, o cabo pode ser fornecido já lubrificado pelo fabricante. Nos cabos que empregam alma de fibra, o óleo lubrificante é inicialmente absorvido pela alma e, posteriormente, transferido aos fios do cabo, mantendo uma lubrificação permanente.

Segundo SALES (1988), e também tendo-se em vista a exposição aqui feita, pode-se concluir que para as coberturas pênseis usuais, os cabos mais indicados são os de construção Filler ou Warrington - Seale de torção regular, por serem mais estáveis e menos deformáveis transversalmente; pré-estirados e pré-formados, com alma de aço, portanto menos deformáveis longitudinalmente; com acabamento polido e com lubrificação em nivel normal.

Quanto à fixação, os cabos podem ser fixos nas estruturas de apoio ou por meio de terminais chumbados, chamados soquetes, ou com o emprego de grampos e sapatilhas, Figura 1.10.
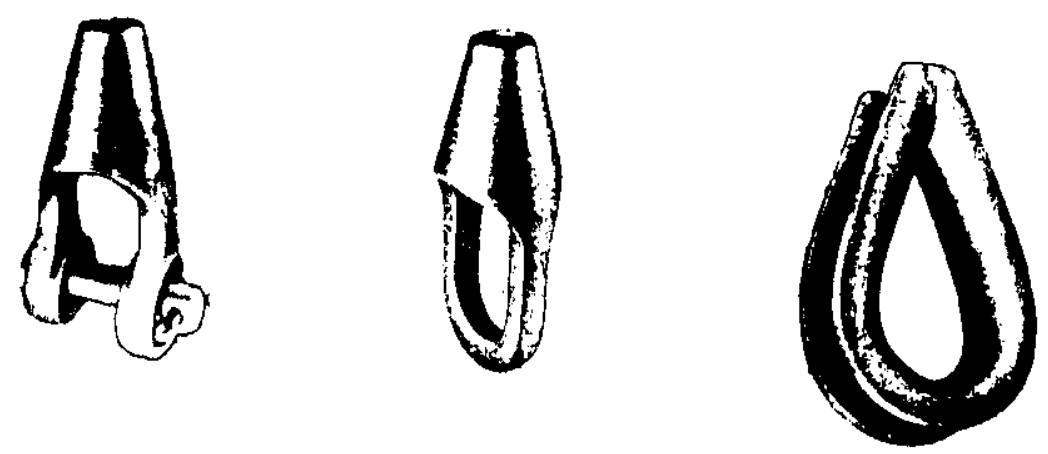

Figura 1.10- Soquetes e sapatilhas protetoras

A fixação do cabo no soquete é feita por caldeamento. Este caldeamento consiste na colocação de metal, zinco ou liga de chumbo e antimônio, em estado de fusão, no orifício do soquete onde previamente foi introduzida a extremidade do cabo devidamente desfiada.

A fixação das sapatilhas na extremidade do cabo é realizada com o emprego de grampos especiais, sempre em número de três ou mais. Para garantir a eficiência da ligação, é necessário observar a posição dos 
grampos, Figura 1.11.

O emprego de sapatilhas e grampos não permite que se considere a total capacidade do cabo e segundo alguns fabricantes esta perda de eficiência é da ordem de $20 \%$.

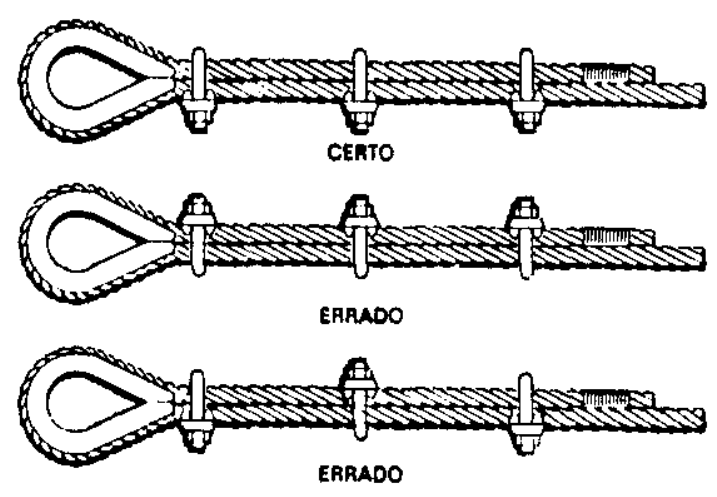

Figura 1.11-Sapatilhas protetoras; sentido de colocação dos grampos.

\subsection{2- Sistema Vedante}

O sistema vedante das coberturas é composto pela vedação propriamente dita, pelos acessórios de fixação desta vedação no sistema estrutural e, em alguns casos, de mantas e materiais isolantes e impermeáveis, que são colocados sobre a vedação para melhorar as condições de utilização da cobertura.

Como vedação, podem ser usadas placas de concreto ou de argamassa armada cuja armadura, se prolongada além das faces laterais e dobrada em forma de gancho, pode servir de apoio destas piacas no sistema estrutural.

Estas placas podem também ser utilizadas apoiadas em perfis metálicos ou em outras estruturas destinadas a este fim, Figura 1.12.

A vedação com elevado peso próprio, como as placas de concreto ou argamassa armada, são normalmente utilizadas nas cestas não protendidas para fornecer uma maior estabilidade à estrutura de cabos, limitando os desiocamentos a valores compativeis com o uso da cobertura. 

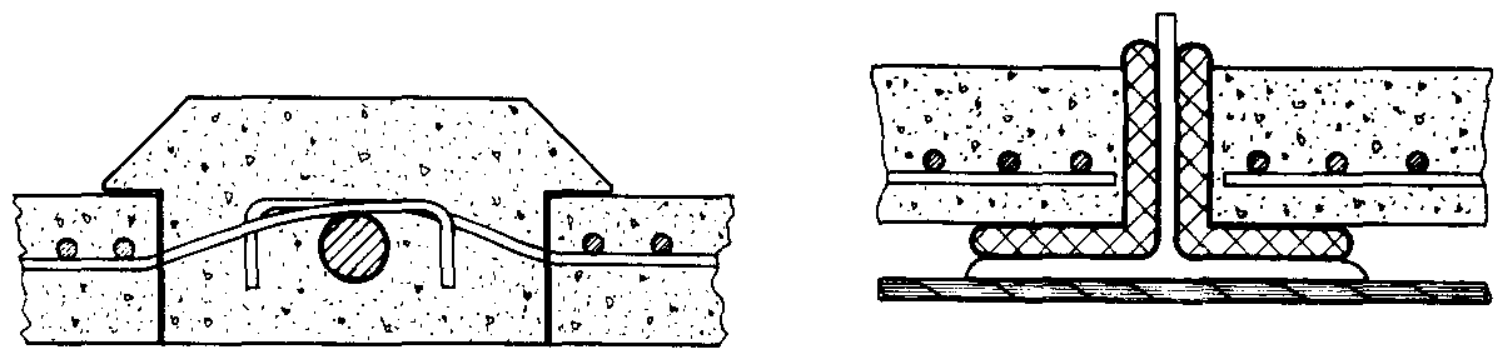

Figura 1.12- Fixação das placas de argamassa ou de concreto armado.

Já a vedação com baixo peso próprio é empregada em sistemas estruturais mais rígidos, como as cestas protendidas e cabos-treliças, e nestes casos tem apenas a função de vedar.

Neste caso, são empregadas as telhas metálicas ou de fibrocimento que podem ser fixadas diretamente aos cabos ou então apoiadas sobre perfís metálicos ou de madeira, Figura 1.13.

Estas telhas merecem atenção especial nas regiões de traspasse, principalmente as localizadas nos pontos onde os cabos possuem inclinação aproximadamente nula, como acontece nos pontos de flecha máxima.
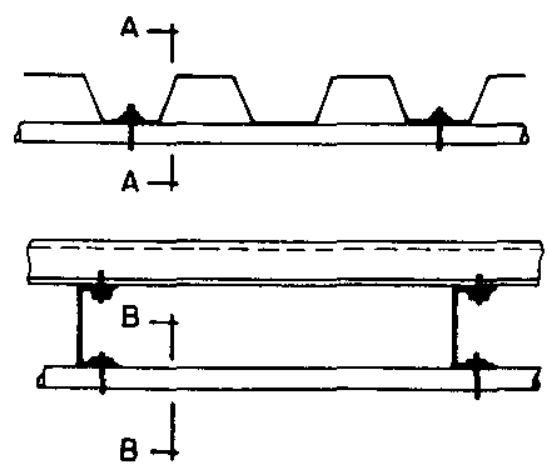

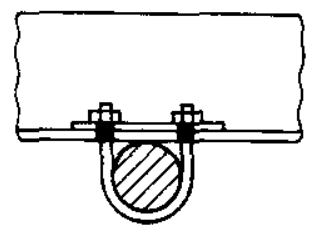

CORTE A-A

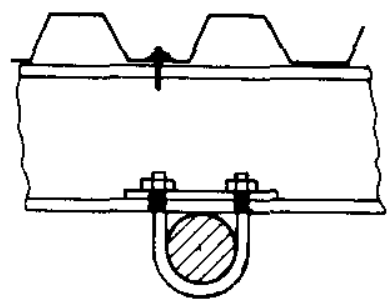

CORTE B-B

Figura 1.13- Fixação das telhas de aço ou de alumínio 
Quando é prevista a utilização de chapas lisas metálicas ou de acrílico, torna-se necessária a colocação de perfis de contorno e molduras de materiais flexíveis para garantir a vedação da cobertura, Figura 1.14.
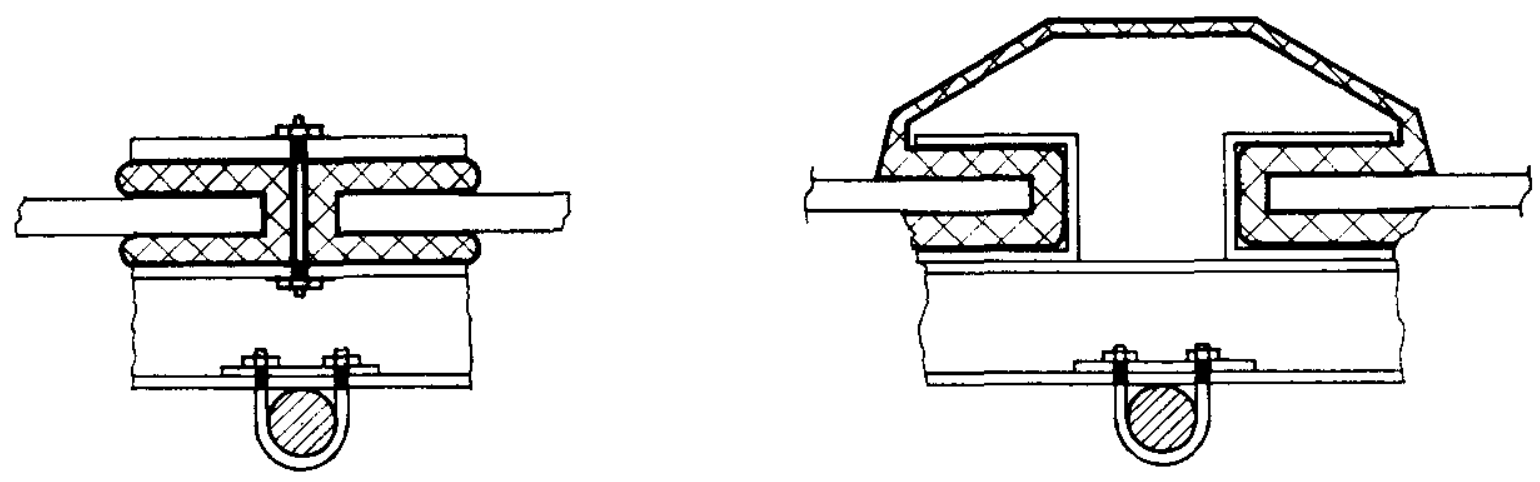

Figura 1.14- Fixação de chapas lisas

É também possivel utilizar como vedação lâminas de plástico ou de náilon. Neste caso, os cabos podem ser envolvidos pela membrana dispensando outros acessórios de fixação, Figura 1.15.

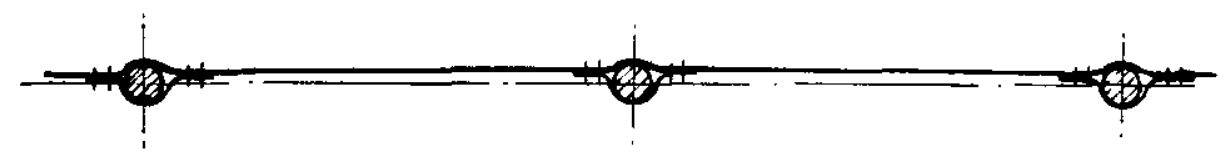

Figura 1.15- Fixação de lâminas de plástico ou de náilon

Cabe ainda ressaltar que, nas coberturas pênseis, o sistema vedante deve ser projetado de modo a absorver os deslocamentos relativos que certamente surgirão entre os sistemas de vedação e estrutural. $O$ impedimento destes deslocamentos pode ocasionar a ruptura da vedação, que por estar fixada aos cabos passa a absorver uma parcela significativa 
dos esforços de tração dos cabos.

Com relação à vedação lateral da cobertura, além dos cuidados naturais que devem ser tomados quando do fechamento de grandes áreas, deve-se evitar que os deslocamentos, dos cabos situados nas extremidades da cobertura, sejam impedidos pela estrutura suporte do fechamento lateral. Uma solução proposta por SALES (1988) é a de deixar um espaço que permita o deslocamento dos cabos, conforme mostrado na Figura 1.16.a e em outros casos, a possibilidade de substituir os cabos extremos por vigas rígidas conforme mostrado na Figura 1.16.b.
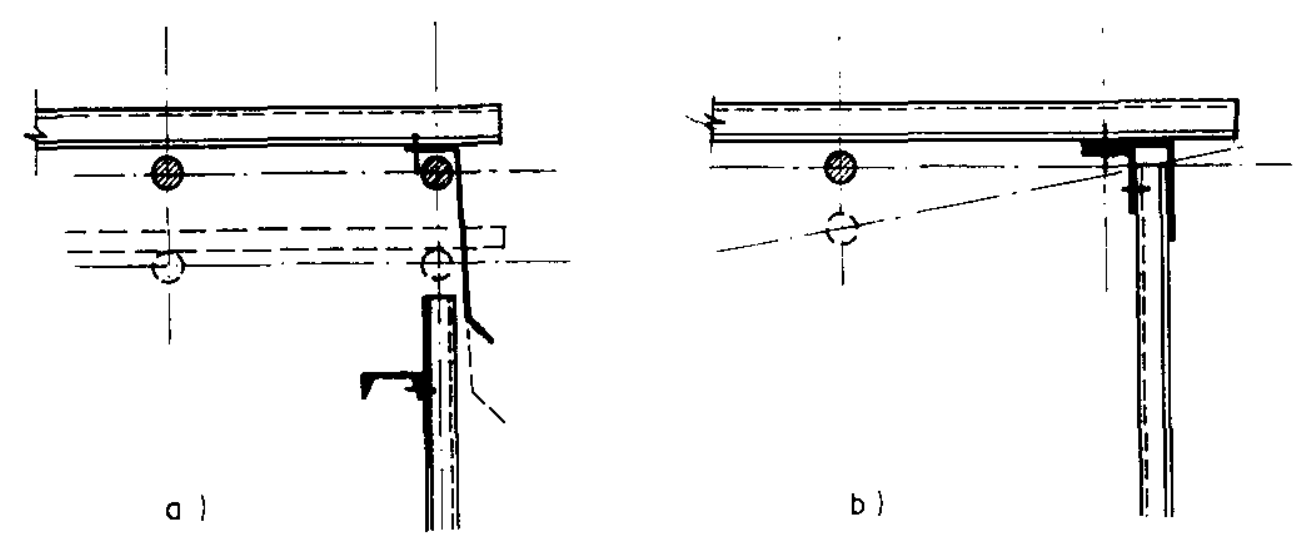

Figura 1.16- Detalhe do encontro da vedação com o fechamento lateral.

\section{3- Aplicações de Cestas Protendidas em Coberturas}

Visto que o trabalho aqui apresentado tratará do sistema estrutural denominado cesta protendida, a seguir serão descritas algumas obras construídas empregando-se este tipo de estrutura.

\subsection{1- Arena da Feira Estadual em Raleigh}

Construida em Raleigh, Carolina do Norte, nos Estados Unidos, em 1953, foi projetada pelos arquitetos Mathew Nowicki e William Henly Deitrick e pelos engenheiros Severud, Perone e Krueger. 
Esta obra tem sido considerada um marco no desenvolvimento das coberturas pênseis, pois foi somente depois de seu projeto e construção que este tipo de cobertura começou a ser efetivamente empregado.

A cobertura, em forma de superfície de dupla curvatura reversa, é suspensa de dois arcos de concreto armado de eixos parabólicos contidos em planos inclinados e que são suportados por pilares, Figura 1.17.

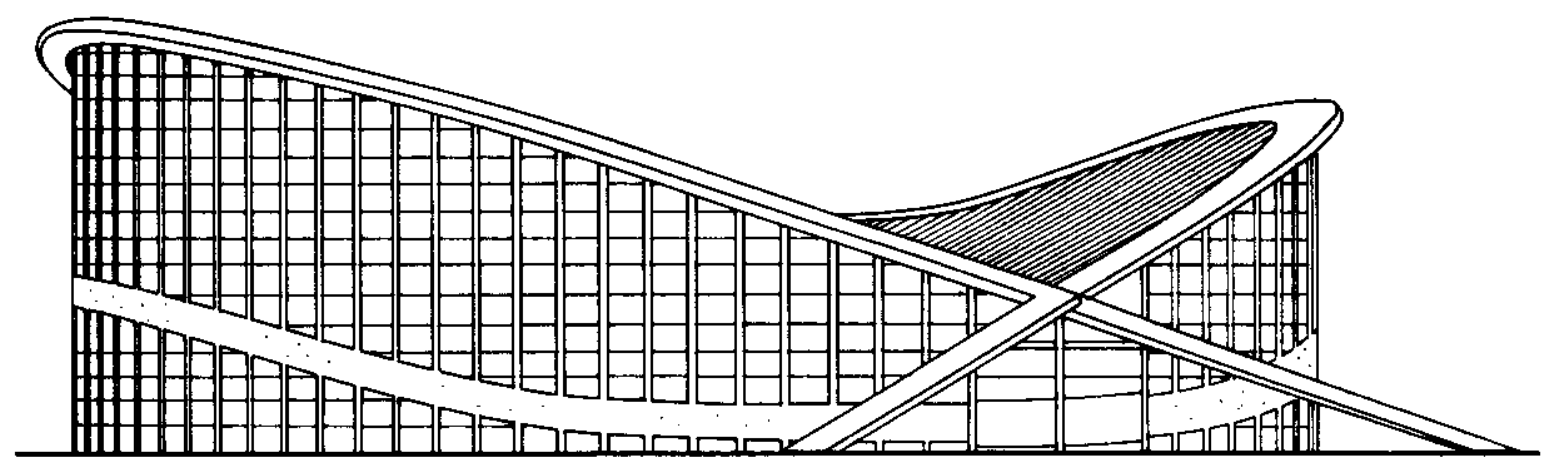

\section{VISTA}

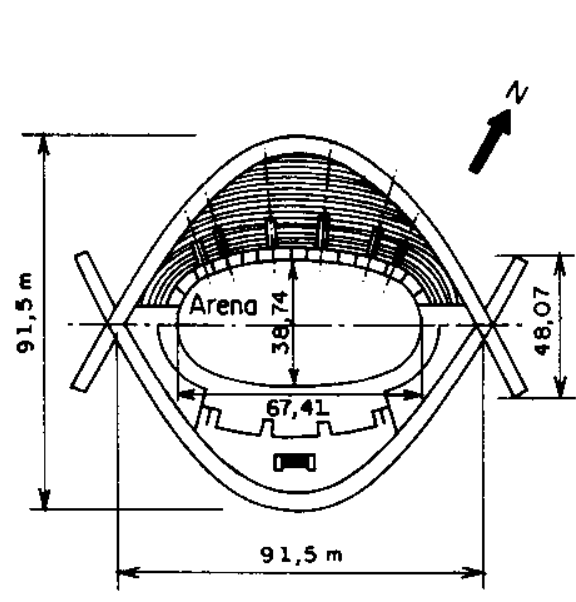

PLANTA

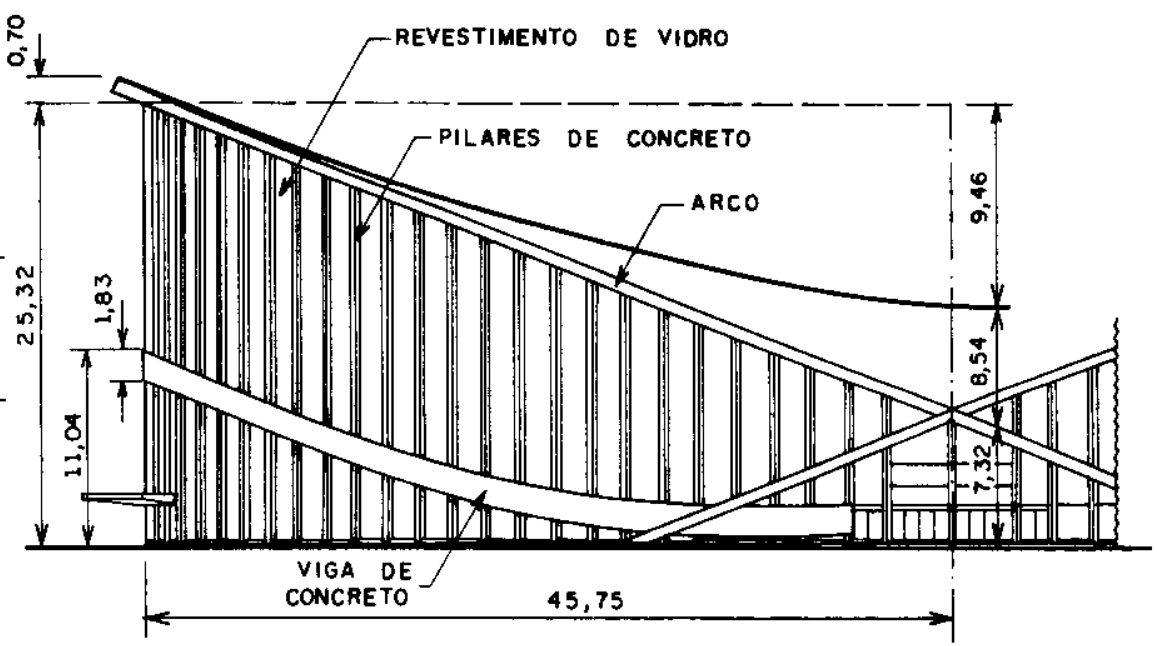

ELE VACĀOO

Figura 1.17- Vista externa e planta da Arena da Feira Estadual em Raleigh 
A rede, formada pelos cabos portantes ( 47 cabos com diâmetros variando de 19 a $32 \mathrm{~mm}$ ) e pelos cabos tensores (47 cabos com diâmetros variando de 13 a $19 \mathrm{~mm}$ ), foi calculada para receber uma carga permanente de $0,3 \mathrm{kN} / \mathrm{m}^{2}$ e duas cargas acidentais, uma positiva de $1,22 \mathrm{kN} / \mathrm{m}^{2}$ e outra negativa de $0,78 \mathrm{kN} / \mathrm{m}^{2}$.

Além dos cabos citados foram utilizados tirantes suplementares que conectavam a cesta com a estrutura de contorno, com a finalidade de combater as elevadas sucçōes nas regiōes próximas aos vértices dos arcos parabólicos. Essa solução foi adotada porque nessas regiões não foi possível dar aos cabos a protensão necessária devido à pequena curvatura da rede.

Como elemento de vedação foi usada tela de orlon pintada com neoprene, que posteriormente foi substituída por lâminas metálicas corrugadas.

\subsection{2- Pavilhão do Rio Grande do Sul}

A primeira cobertura pênsil construída no Brasil foi a do Pavilhão do Rio Grande do Sul, construído para a exposição do IV Centenário de São Paulo no Parque lbirapuera em 1954. O projeto é de autoria do arquiteto Jaime Luna dos Santos e dos engenheiros Alberto Borges e R.C. Alliana.

Cobrindo uma área de aproximadamente $6200 \mathrm{~m}^{2}$, o sistema estrutural era composto de dois arcos circulares de aço laminado, distanciados entre si de $102,80 \mathrm{~m}$, com $59,40 \mathrm{~m}$ de vão e $20 \mathrm{~m}$ de flecha, Figura 1.18.

Sobre os arcos circulares foram dispostos 46 cabos portantes, cujas extremidades foram reunidas em dez grupos e ancorados ao solo por meio de blocos de concreto ciclópico. Os cabos tensores, em número de 19 , foram posicionados em planos verticais paralelos aos planos dos arcos e foram ancorados individualmente ao solo também por meio de blocos de concreto.

Os cabos empregados eram de fabricação nacional e possuiam diâmetros variáveis de 15,9 a 23,8mm.

Para a vedação, foram utilizadas telhas onduladas de alumínio que se apoiavam em caibros de madeira dispostos paralelamente aos cabos tensores. 

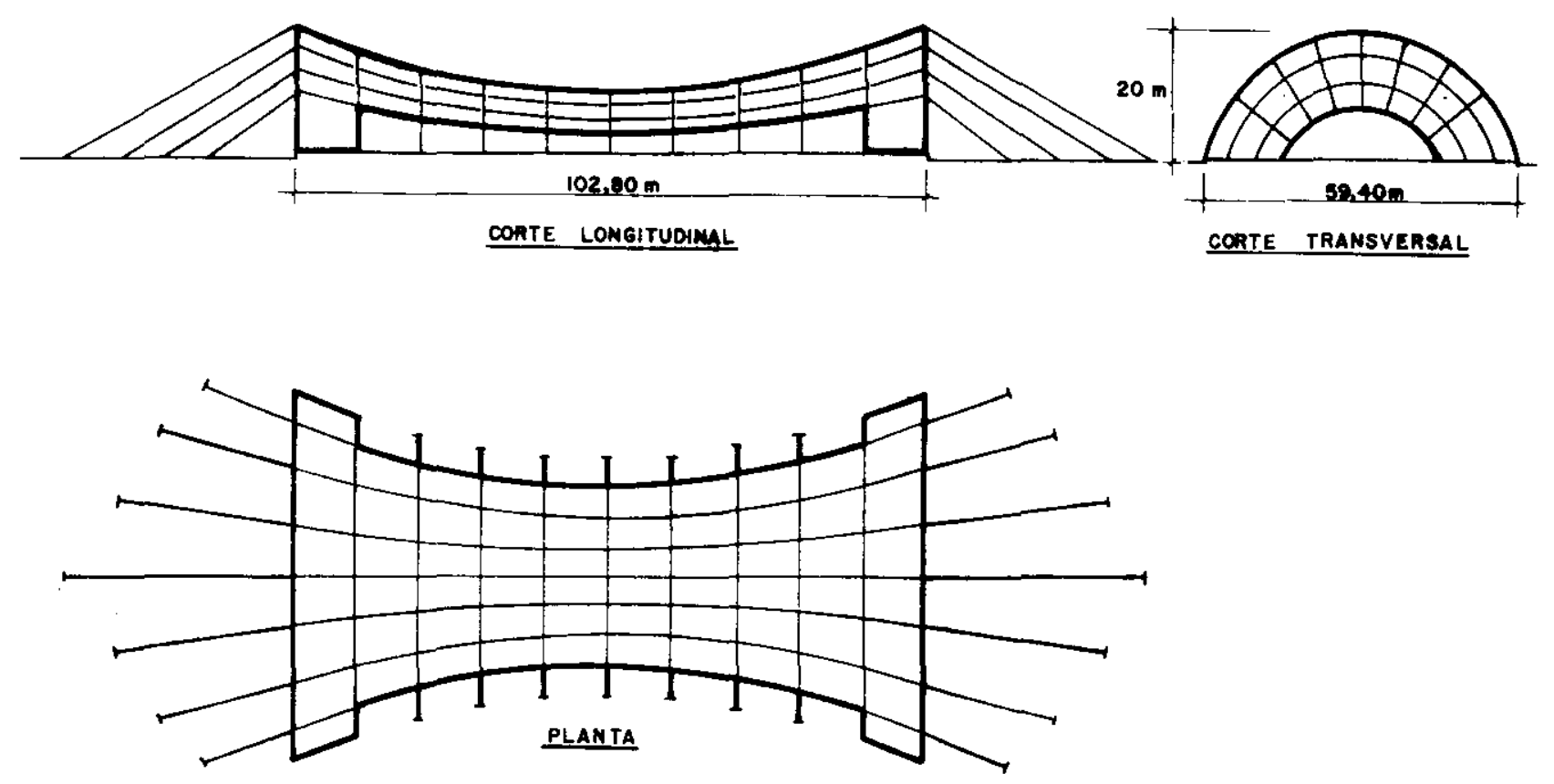

Figura 1.18- Pavilhão do Rio Grande do Sul

\subsection{3- Ginásio de Esportes de Milão}

Obra construída no início dos anos 70 na cidade de Milão, Itália, teve seu projeto elaborado pelos arquitetos T.Valle e G.Valle e cálculo estrutural executado pelos engenheiros G.Romaro, B.Schrefier e R.Rosi.

A cobertura do ginásio, em forma de parabolóide hiperbólico de planta circular com aproximadamente $11600 \mathrm{~m}^{2}$ de área, Figura 1.19.a, é suspensa de uma estrutura de contorno formada por trinta e oito balanços de concreto armado, por peças em forma de losango construídas com chapas de aço e por um anel em aço com seção transversal do tipo caixão, Figura 1.19.b.

0 anel metálico tem eixo definido pela intersecção de um cilíndro com um parabolóide hiperbólico e foi construído no local por meio de soldagem de cento e cinquenta e dois segmentos produzidos em usina, onde são ancorados os cabos da cesta. 
A cobertura foi construída instalando-se inicialmente 56 cabos portantes e 56 cabos tensores. Em seguida, protendeu-se a cesta estirandose os cabos tensores e terminando com a fixação da vedação onde foram empregadas telhas corrugadas de aço laminado.
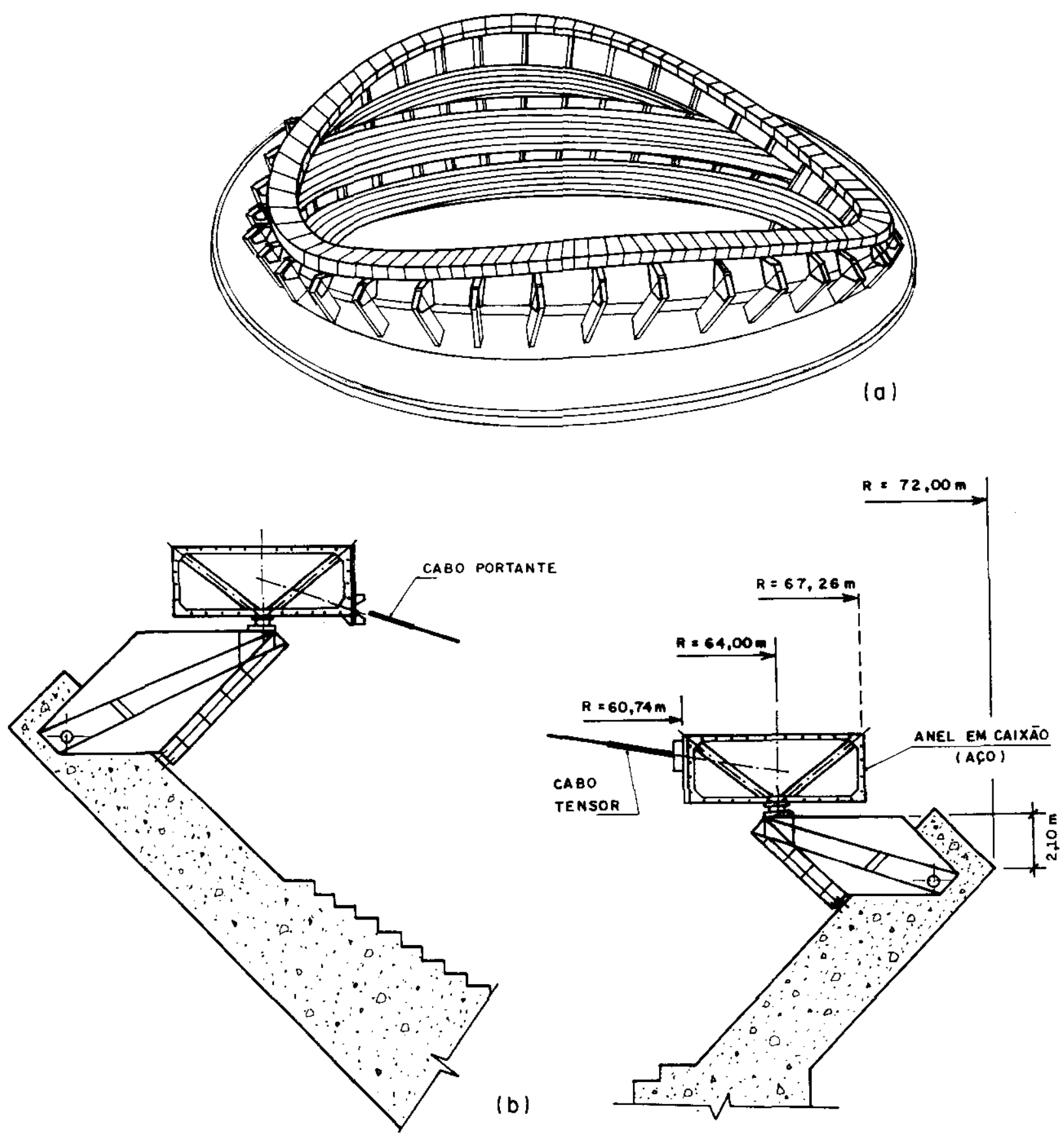

Figura 1.19- Ginásio de Esportes de Milão 


\subsection{4- Ringue de Patinação no Gelo em Munique}

Obra concluída no início de 1983 na cidade de Munique, Alemanha, teve seu projeto elaborado pelo arquiteto Kurt Ackermann e cálculo estrutural executado pelo engenheiro J. Schlaich.

Esta obra é um caso raro onde a própria cobertura constitue a edificação ou seja, a forma acompanhou a função, Figura 1.20.

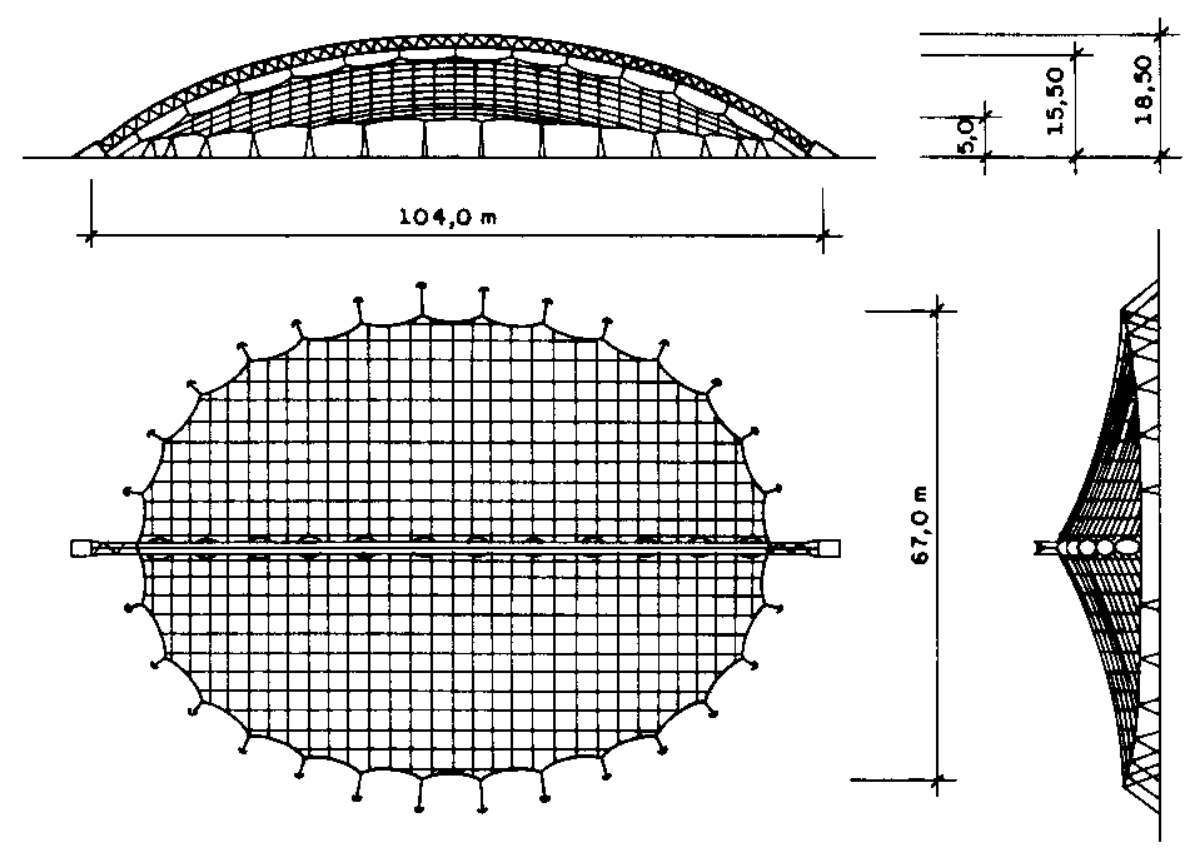

Figura 1.20- Ringue de Patinação no gelo em Munique

Resolveu-se uma área em planta, de $104,00 \times 67,00 \mathrm{~m}^{2}$, onde os cabos foram extendidos entre um arco posicionado longitudinalmente e o contorno que também é formado por cabos.

O arco longitudinal foi projetado como uma treliça espacial cujos elementos são tubos de aço com diâmetros de $245 \mathrm{~mm}$ para os banzos paralelos e $83 \mathrm{~mm}$ para as diagonais. 
A rede é formada por cabos galvanizados com diâmetro de $11,5 \mathrm{~mm}$ e os cabos que compõem o contorno da cesta têm diâmetro de $60 \mathrm{~mm}$.

No contorno, foram colocados tirantes devidamente ancorados no solo que serviram como guias para a fixação de painéis de vidro que compuseram a fachada do edifício.

Sobre os cabos da cobertura foram posicionados caibros de madeira que serviram de apoio para a vedação composta por uma membrana branca e translúcida de PVC revestida com poliester. Junto ao arco treliçado, na parte mais alta da cobertura, existem aberturas entre os dois grupos de cabos; essas aberturas foram fechadas adequadamente usando vidros transparentes permitindo assim que o arco treliçado seja visto do lado de dentro da edificação.

\section{4- Conteúdo do Trabalho}

Visando a um melhor conhecimento e ao mesmo tempo fornecendo uma visão geral sobre o assunto, foi desenvolvido o presente trabalho que procura mostrar a viabilidade técnica de um dos tipos de coberturas pênseis, as cestas protendidas.

Desta maneira, no primeiro capítulo procurou-se apresentar um breve histórico sobre as coberturas pênseis, os conceitos básicos, as formas e os tipos mais usuais, bem como os materiais mais empregados.

No segundo capítulo apresenta-se o estudo de cestas protendidas a partir da Técnica do Meio Contínuo, na qual a estrutura constituída por elementos discretos, cabos, é assimilada a uma membrana contínua equivalente, no que respeita à rigidez, e cujo comportamento pode ser investigado mediante o emprego de equações diferenciais.

No caso em estudo, a cesta protendida formada por cabos isolados é substituída por uma membrana metálica equivalente que resiste somente a esforços de tração.

Definiu-se como sendo superficie inicial a membrana solicitada apenas pela protensão. Quando um carregamento externo é aplicado ou há variação de temperatura ou as extremidades dos cabos sofrem um deslocamento, passa-se a ter uma membrana definida como superfície deslocada. 
Para que fossem obtidos os esforços e os deslocamentos da membrana isolou-se, da superfície deslocada, um elemento infinitesimal e para ele escreveram-se as equações de equilíbrio, as equações que relacionam deslocamentos e deformações $e$ as equações constitutivas. Estas equações adequadamente combinadas conduziram à equação integro-diferencial que, resolvida, permitiu a obtenção dos esforços e deslocamentos da membrana.

No final deste capítulo fez-se considerações sobre a resolução do sistema de equações encontrada, já visando à utilização de programa computacional como instrumento de cálculo.

No terceiro capitulo foi apresentada a estrutura básica do programa computacional elaborado em linguagem FORTRAN para microcomputadores e o seu fluxograma que permite uma visão global do processo de cálculo. A listagem do programa se encontra no apêndice ao final deste trabalho.

Ainda no final do capitulo apresentou-se um exemplo de aplicação numérica cuja finalidade é ilustrar a utilização do programa computacional. Apresentaram-se para uma cesta de cabos protendidos as entradas de dados e os resultados obtidos.

No quarto capítulo apresentam-se alguns exemplos de cestas protendidas calculadas pela Técnica do Meio Contínuo, e cujos resultados foram comparados com outros, obtidos através do emprego de outras técnicas de cálculo, encontrados na literatura.

Finalmente no quinto capítulo apresentam-se algumas considerações sobre o trabalho apresentado e também propõem-se questões a serem investigadas em pesquisas posteriores, para um estudo mais completo e detalhado das cestas protendidas. 


\section{ESTUDO DE CESTAS PROTENDIDAS}

\subsection{Equações Gerais}

\subsection{1- Fundamentos Geométricos}

Considerando-se a Figura 2.1 define-se o vetor posição da superfície inicial como sendo:

$$
r=x e_{x}+y e_{y}+z(x, y) e_{z}
$$

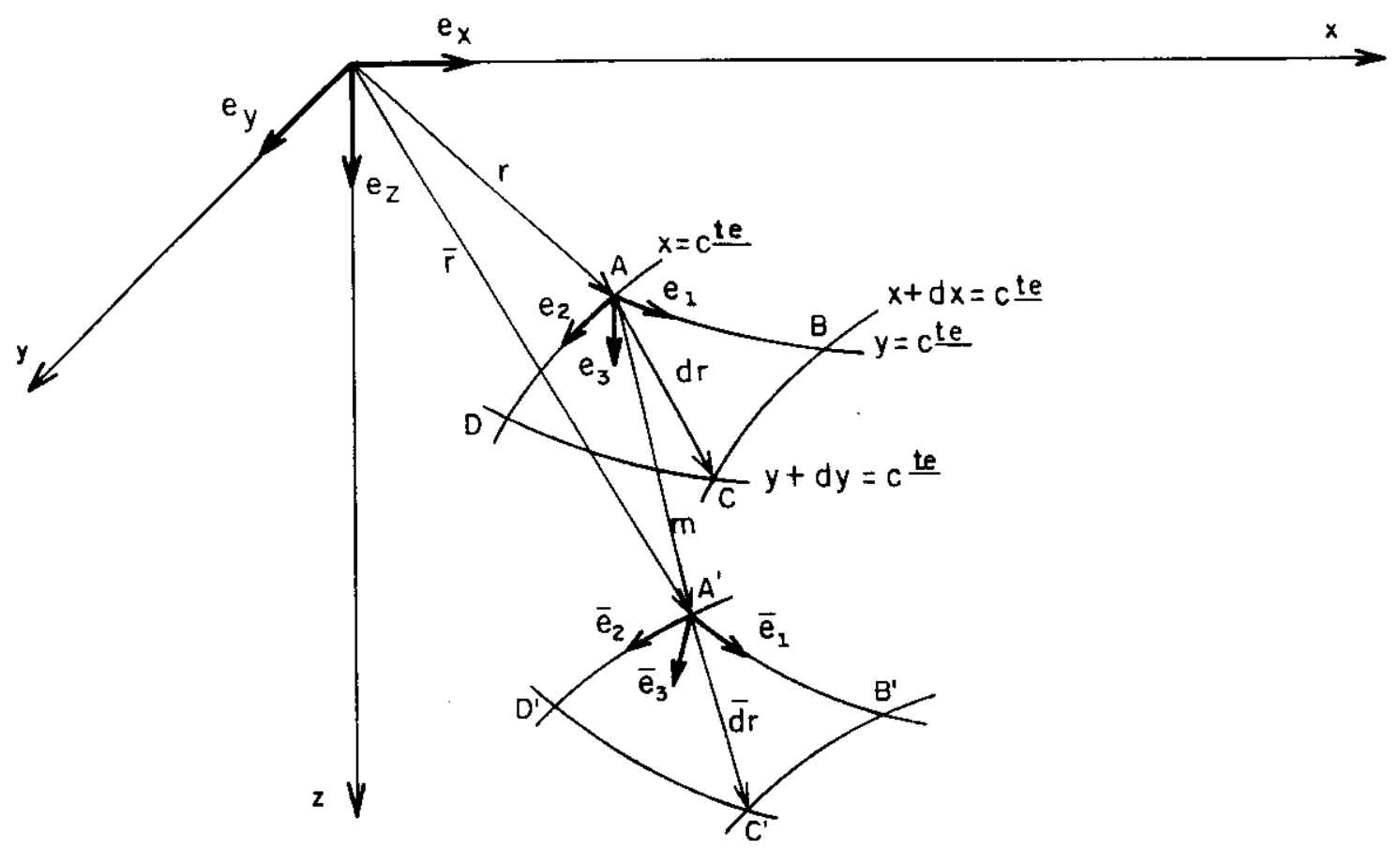

Figura 2.1- Notação geométrica das superfícies 
fazendo-se

$$
\frac{\partial r}{\partial x}=r^{\prime}
$$

e,

$$
\frac{\partial r}{\partial y}=r^{\bullet}
$$

definem-se os valores

$$
\begin{aligned}
& g_{11}=r^{\prime} \cdot r^{\prime}=1+z^{\prime 2} \\
& g_{12}=r^{\prime} \cdot r^{\bullet}=z^{\prime} z^{\bullet} \\
& g_{22}=r^{\bullet} \cdot r^{\bullet}=1+z^{\circ 2}
\end{aligned}
$$

Os versores tangentes, $e_{1}$ e $e_{2}$, e normal, $e_{3}$, à superfície, no ponto A, são dados por:

$$
\begin{aligned}
& e_{1}=\frac{r^{\prime}}{\left|r^{\prime}\right|}=\frac{e_{x}+z^{\prime} e_{z}}{\sqrt{g_{11}}} \\
& e_{2}=\frac{r^{\bullet}}{\left|r^{\bullet}\right|}=\frac{e_{y}+z^{\bullet} e_{z}}{\sqrt{g_{22}}} \\
& e_{3}=\left(e_{1}\right) \times\left(e_{2}\right)=\frac{-z^{\prime} e_{x}-z^{\bullet} e_{y}+e_{z}}{\sqrt{g_{11} g_{22}}}=\frac{-z^{\prime} e_{x}-z^{\bullet} e_{y}+e_{z}}{\sqrt{g}}
\end{aligned}
$$

Nota-se ainda que sendo a equação (2.1), $r=r(x, y, z(x, y))$, uma função de duas variáveis, tem-se: 


$$
d r=\frac{\partial r}{\partial x} d x+\frac{\partial r}{\partial y} d y
$$

ou,

$$
d r=d x e_{x}+d y e_{y}+\left(z^{\prime} d x+z^{*} d y\right) e_{z}
$$

Com a equação (2.8), pode-se calcular o comprimento do arco $\widehat{A C}$ como sendo:

$$
\widehat{A C}=d s=|d r|=\sqrt{d r \cdot d r}
$$

ou,

$$
d s=\sqrt{\left(1+z^{\prime 2}\right) d x^{2}+2 z^{\prime} z^{\bullet} d x d y+\left(1+z^{\bullet 2}\right) d y^{2}}
$$

Considerando-se as equações (2.2), (2.3) e (2.4), pode-se escrever a equação (2.9) como:

$$
d s=\sqrt{g_{11} d x^{2}+2 g_{12} d x d y+g_{22} d y^{2}}
$$

A equação (2.10) é denominada Primeira Forma Fundamental da teoria das superficies, CARMO (1976).

Usando a equação (2.9), podem-se calcular os comprimentos dos lados do elemento de superficie a saber:

$$
\begin{aligned}
& A B=(d s)_{y=\text { const }}=\sqrt{g_{11}} d x \\
& A D=(d s)_{x=\text { const }}=\sqrt{g_{22}} d y \\
& C D=(d s)_{y+d y=\text { const }}=\left[\sqrt{g_{11}}+\frac{\partial}{\partial y} \sqrt{g_{11}} d y\right] d x \\
& B C=(d s)_{x+d x=\text { const }}=\left[\sqrt{g_{22}}+\frac{\partial}{\partial x} \sqrt{g_{22}} d x\right] d y
\end{aligned}
$$


A área do elemento de superfície é dada por:

$\mathrm{dA}=\left|\mathrm{r}^{\prime} \times \mathrm{r}^{\bullet}\right|$

$d A=\sqrt{z^{\prime 2}+z^{-2}+1} d x d y$

Usando-se as equações (2.2) e (2.4), faz-se:

$g=g_{11} g_{22}$

$g=1+z^{\cdot 2}+z^{12}+z^{\cdot 2} z^{12}$

Desprezando-se os infinitésimos de ordem superior, tem-se:

$g=1+z^{\cdot 2}+z^{12}$

Daí, tem-se que:

$d A=\sqrt{g} d x d y$

Observando-se ainda a Figura 2.1 e sendo $u=u(x, y), v=v(x, y) e$ $w=w(x, y)$ os deslocamentos do ponto $A$ segundo as direções $x, y e z$ respectivamente, o vetor deslocamento do referido ponto é dado por:

$m=u e_{x}+v e_{y}+w e_{z}$

Assim, o vetor posição da superfície deslocada é dado como sendo:

$$
\begin{aligned}
& \bar{r}=r+m \\
& \bar{r}=(x+u) e_{x}+(y+v) e_{y}+(z+w) e_{z}
\end{aligned}
$$

Analogamente ao que foi feito para superfície inicial, têm-se 


$$
\begin{aligned}
& \bar{g}_{11}=\left(1+u^{\prime}\right)^{2}+v^{\prime 2}+\left(z^{\prime}+w^{\prime}\right)^{2} \\
& \bar{g}_{22}=u^{\bullet 2}+\left(1+v^{\bullet}\right)^{2}+\left(z^{\bullet}+w^{\bullet}\right)^{2}
\end{aligned}
$$

Os versores, tangentes e normal à superfície, são dados por

$$
\begin{aligned}
& \bar{e}_{1}=\frac{\left(1+u^{\prime}\right) e_{x}+v^{\prime} e_{y}+\left(z^{\prime}+w^{\prime}\right) e_{z}}{\sqrt{\bar{g}_{11}}} \\
& \bar{e}_{2}=\frac{u^{\bullet} e_{x}+\left(1+v^{\bullet}\right) e_{y}+\left(z^{\bullet}+w^{\bullet}\right) e_{z}}{\sqrt{\bar{g}_{22}}} \\
& \bar{e}_{3}=\frac{1}{\sqrt{\bar{g}_{11} \bar{g}_{22}}}\left\{\left[v^{\prime}\left(z^{\bullet}+w^{\bullet}\right)+\left(z^{\prime}+w^{\prime}\right)\left(1+v^{\bullet}\right)\right] e_{x}+\right. \\
& +\left[\left(z^{\prime}+w^{\prime}\right) u^{\bullet}-\left(1+u^{\prime}\right)\left(z^{\bullet}+w^{\bullet}\right)\right] e_{y}+\left[\left(1+u^{\prime}\right)\right. \\
& \left.\left.\left(1+v^{\bullet}\right)-v^{\prime} u^{\bullet}\right] e_{z}\right\}
\end{aligned}
$$

Reescrevendo a equação (2.10) para a superfície deslocada, obtémse:

$$
\overline{d s}=\sqrt{\bar{g}_{11} d x^{2}+2 \bar{g}_{12} d x d y+\bar{g}_{22} d y^{2}}
$$

Com a equação (2.23), calculam-se os comprimentos dos lados do elemento de superfície: 


$$
\begin{aligned}
& A^{\prime} B^{\prime}=(\bar{d} s)_{y=\text { const. }}=\sqrt{\bar{g}_{11}} d x \\
& A^{\prime} D^{\prime}=(\bar{d} s)_{x=\text { const. }}=\sqrt{\bar{g}_{22}} d y \\
& C^{\prime} D^{\prime}=(\bar{d} s)_{y+d y=\text { const. }}=\left(\sqrt{\bar{g}_{11}}+\frac{\partial}{\partial y} \sqrt{\bar{g}_{11}} d y\right) d x \\
& B^{\prime} C^{\prime}=(\bar{d} s)_{x+d x=\text { const. }}=\left(\sqrt{\bar{g}_{22}}+\frac{\partial}{\partial x} \sqrt{\bar{g}_{22}} d x\right) d y
\end{aligned}
$$

A área da superfície do elemento deslocado é dada por:

$$
\begin{aligned}
\overline{\mathrm{d}} A= & \left|\bar{r}^{\prime} \cdot \bar{r}^{\bullet}\right| \\
\overline{\mathrm{d}} A= & \left\{\left[v^{\prime}\left(z^{\bullet}+w^{\bullet}\right)-\left(1+v^{\bullet}\right)\left(z^{\prime}+w^{\prime}\right)\right]^{2}+\left[u^{\bullet}\left(z^{\prime}+w^{\bullet}\right)+\right.\right. \\
& \left.\left.-\left(1+u^{\prime}\right)\left(z^{\bullet}+w^{\bullet}\right)\right]^{2}+\left[\left(1+u^{\prime}\right)\left(1+v^{\bullet}\right)-v^{\prime} u^{\bullet}\right]^{2}\right\}^{1 / 2} d x d y
\end{aligned}
$$

ou,

$$
\overline{\mathrm{d}} \mathrm{A}=\sqrt{\bar{g}} \mathrm{dxdy}
$$

onde,

$$
\overline{\mathrm{g}}=\bar{g}_{11} \bar{g}_{22}
$$

\subsection{2- Condições de Equilíbrio}

Considerando-se o elemento deslocado e tendo-se em vista os esforços atuantes por unidade de largura, $T_{1} \in T_{2}$, e o vetor carregamento, $p(x, y)=p_{x} e_{x}+p_{y} e_{y}+p_{z} e_{z}$, Figura 2.2, obtém-se inicialmente a equação vetorial de equilíbrio na direção do eixo $x$. 
33

$$
\begin{aligned}
& \left\{\left[T_{1} \bar{e}_{1}+\frac{\partial\left(T_{1} \bar{e}_{1}\right)}{\partial x} d x\right]\left[\sqrt{\bar{g}_{22}}+\frac{\partial \sqrt{\bar{g}_{22}}}{\partial x} d x\right] d y\right\} \cdot e_{x}-\left[\left(T_{1} \bar{e}_{1}\right) \sqrt{\bar{g}_{22}} d y\right] \cdot e_{x}+ \\
& +\left\{\left[T_{2} \bar{e}_{2}+\frac{\partial\left(T_{2} \bar{e}_{2}\right)}{\partial y} d y\right]\left[\sqrt{\bar{g}_{11}}+\frac{\partial \sqrt{\bar{g}_{11}}}{\partial y} d y\right] d x\right\} \cdot e_{x}-\left[\left(T_{2} e_{2}\right) \sqrt{\bar{g}_{11}} d x\right] \cdot e_{x}+ \\
& +(p \bar{d} A) \cdot e_{x}=0
\end{aligned}
$$

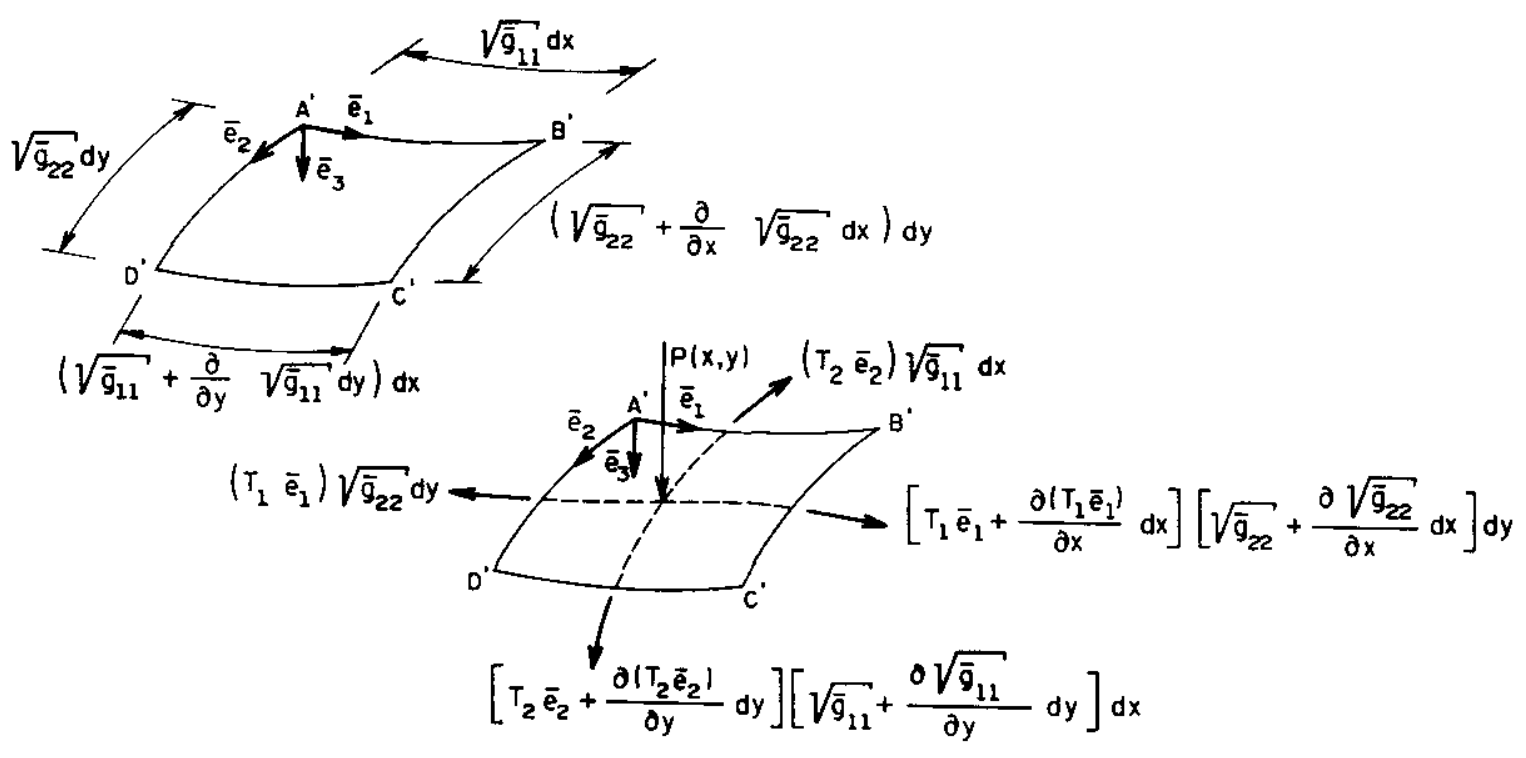

Figura 2.2- Elemento de membrana com dimensões e esforços atuantes

Desenvolvendo-se a equação (2.30), levando-se em consideração as equações (2.20), (2.21) e (2.29), desprezando-se os infinitésimos de ordem superior $e$, finalmente, dividindo-se a expressão obtida pelo produto $d x d y$, 
resulta:

$$
\frac{\partial}{\partial x}\left[T_{1} \frac{\sqrt{\bar{g}_{22}}}{\sqrt{\bar{g}_{11}}}\left(1+u^{\prime}\right)\right]+\frac{\partial}{\partial y}\left[T_{2} \frac{\sqrt{\bar{g}_{11}}}{\sqrt{\bar{g}_{22}}} u^{\bullet}\right]+p_{x} \sqrt{\bar{g}}=0
$$

Do mesmo modo, obtêm-se as equações vetoriais de equilíbrio nas direções y e z, respectivamente:

$$
\begin{aligned}
& \frac{\partial}{\partial x}\left[T_{1} \frac{\sqrt{\bar{g}_{22}}}{\sqrt{\bar{g}_{11}}} v^{\prime}\right]+\frac{\partial}{\partial y}\left[T_{2} \frac{\sqrt{\bar{g}_{11}}}{\sqrt{\bar{g}_{22}}}\left(1+v^{\bullet}\right)\right]+p_{y} \sqrt{\bar{g}}=0 \\
& \frac{\partial}{\partial x}\left[T_{1} \frac{\sqrt{\bar{g}_{22}}}{\sqrt{\bar{g}_{11}}}\left(z^{\prime}+w^{\prime}\right)\right]+\frac{\partial}{\partial y}\left[T_{2} \frac{\sqrt{\bar{g}_{11}}}{\sqrt{\bar{g}_{22}}}\left(z^{\bullet}+w^{\bullet}\right)\right]+p_{z} \sqrt{\bar{g}}=0
\end{aligned}
$$

As equações (2.31.a), (2.31.b) e (2.31.c) são as equações diferenciais que governam o equilíbrio da membrana tracionada.

Estas três equações contêm cinco incógnitas, os esforços $T_{1}$ e $T_{2}$ e os deslocamentos $u, v$ e $w$, portanto são necessárias mais duas equaçōes que relacionem esforços, deslocamentos e deformações.

\subsection{3- Condições de Elasticidade}

Considerando-se, no elemento de membrana, o lado $A B$ de comprimento inicial ds e $A^{\prime} B^{\prime}$ de comprimento final $\bar{d} s$, Figura 2.1 , obtém-se a deformação específica $\varepsilon$ a partir dos deslocamentos.

Escrevendo-se a deformação $\varepsilon$ da membrana em A na direção de $e_{1}$,

$$
\varepsilon_{1}=\frac{\overline{\mathrm{d} s}-\mathrm{ds}}{\mathrm{ds}}
$$


Levando-se as equações (2.11) e (2.24) e considerando-se as equações (2.2) e (2.18) na equação (2.32), tem-se:

$$
\varepsilon_{1}=\frac{\sqrt{\left(1+u^{\prime}\right)^{2}+v^{\prime 2}+\left(z^{\prime}+w^{\prime}\right)^{2}} d x-\sqrt{\left(1+z^{\prime 2}\right)} d x}{\sqrt{1+z^{\prime 2}} d x}
$$

ou,

$$
\varepsilon_{1}=\sqrt{1+2\left[\frac{u^{\prime}+z^{\prime} w^{\prime}}{\left(1+z^{\prime 2}\right)}+\frac{u^{\prime 2}+v^{\prime 2}+w^{\prime 2}}{2\left(1+z^{\prime 2}\right)}\right]}-1
$$

$\mathrm{Na}$ equação (2.33), expandindo-se a raiz em série de Taylor e tomando-se apenas os dois primeiros termos desta série, tem-se:

$$
\varepsilon_{1}=\frac{u^{\prime}+z^{\prime} w^{\prime}}{\left(1+z^{\prime 2}\right)}+\frac{u^{\prime 2}+v^{\prime 2}+w^{\prime 2}}{2\left(1+z^{\prime 2}\right)}
$$

Do mesmo modo, escreve-se a deformação específica da membrana na direção e $e_{2}$; com considerações análogas as feitas anteriormente, tem-se:

$$
\varepsilon_{2}=\frac{v^{\bullet}+z^{\bullet} w^{\bullet}}{\left(1+z^{\bullet 2}\right)}+\frac{u^{\bullet 2}+v^{\bullet 2}+w^{\bullet 2}}{2\left(1+z^{\bullet 2}\right)}
$$

Sabe-se ainda que o elemento de membrana está submetido aos esforços de tração $T$, seja na direção de $e_{1}, T_{1}$ ou na direção de $e_{2}, T_{2}$. Estes esforços são divididos em duas parcelas $T_{0}$ e $T_{p}$ definidos como esforço devido à protensão e esforço devido às ações externas respectivamente.

Assim, têm-se:

$$
T_{1}=T_{01}+T_{p 1}
$$

e,

$$
T_{2}=T_{02}+T_{p 2}
$$


Considere-se novamente o elemento de membrana de lado com comprimento inicial ds e comprimento final $\bar{d} s$ submetidos a esforços de tração, Figura 2.3.
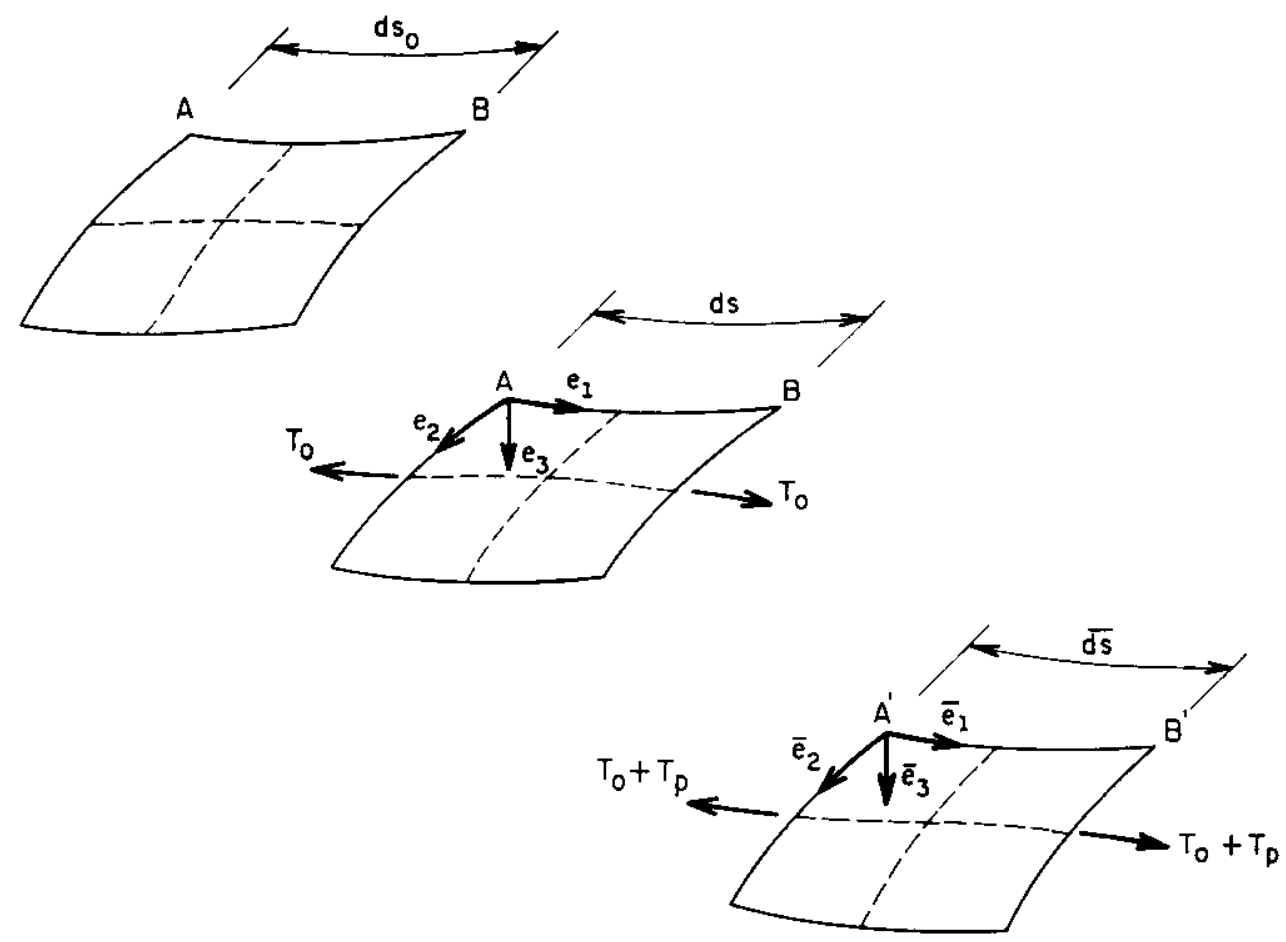

Figura 2.3- Elemento de membrana submetido a esforços de tração.

Cabe ressaltar que o elemento inicial de lado, ds, está submetido apenas ao esforço de protensão $T_{0}$ e o elemento final de lado, $\bar{d} s$, obviamente está submetido simultaneamente ao esforço de protensão e ao esforço devido às ações externas, $T_{0}$ e $T_{p}$.

Tomou-se ainda, para desenvolvimento do equacionamento, um elemento de referência de lado com comprimento $\mathrm{ds}_{0}$ e sem estar submetido a algum esforço.

Considerando-se a Figura 2.3, sabe-se que a lei de Hooke aplicada ao elemento fornece relações entre esforços e deformações. 
Assim, na direção de $e_{1}$, tem-se:

$$
\frac{d s-d s o}{d s o}=\frac{T_{01}}{E A}
$$

e,

$$
\frac{\bar{d} s-d s o}{d s o}=\frac{\left(T_{01}+T_{p 1}\right)}{E A}
$$

Com estas duas equações chega-se a

$$
\frac{\overline{d s}-d s}{d s}=\frac{T_{p 1}}{\left(E A+T_{01}\right)}
$$

Da equação (2.32) escreve-se,

$$
\varepsilon_{1}=\frac{T_{p 1}}{\left(E A+T_{01}\right)}
$$

Considerando-se que no estudo aqui apresentado utilizou-se a Técnica do Meio Contínuo, a área A é obtida, em cada direção, como sendo a relação entre a área da seção do cabo e o espaçamento entre os cabos que formam a cesta.

Assim, tem-se:

$$
A=\frac{A_{s}}{\ell}
$$

onde:

A : área equivalente da seção transversal do cabo.

$A_{s}$ : área da seção transversal do cabo.

$\ell$ : distância em planta entre cabos.

E : módulo de elasticidade longitudinal do cabo. 
Pode-se escrever a equação (2.37) nas direções x e y como sendo,

$$
A_{x}=\frac{A_{s}}{\ell_{x}}
$$

e,

$$
A_{y}=\frac{A_{s}}{\ell_{y}}
$$

Assim com a equação (2.38) reescreve-se a equação (2.36) como sendo:

$$
\varepsilon_{1}=\frac{T_{p 1}}{\left(E A_{x}+T_{01}\right)}
$$

Do mesmo modo, tem-se a deformação específica na direção de $e_{2}$ como sendo:

$$
\varepsilon_{2}=\frac{T_{p 2}}{\left(E A_{y}+T_{02}\right)}
$$

Existindo também uma variação de temperatura, pode-se superpor linearmente a deformação específica causada por esta variação às já calculadas nas equações (2.40) e (2.41). Assim, têm-se:

$$
\begin{aligned}
& \varepsilon_{1}=\frac{T_{p 1}}{\left(E A_{x}+T_{01}\right)}+\alpha \Delta t \\
& \varepsilon_{2}=\frac{T_{p 2}}{\left(E A_{y}+T_{02}\right)}+\alpha \Delta t
\end{aligned}
$$

onde,

$\alpha$ : coeficiente de dilatação térmica linear do material do cabo.

$\Delta \mathrm{t}$ : variação de temperatura. 
Ressalta-se que pelo fato da cesta ser formada por um conjunto de cabos em cada direção, pode-se ter para a cesta valores variáveis do módulo de elasticidade longitudinal E em cada direção. Neste caso, cada conjunto seria formado por cabos de diferentes materiais.

Assim, reescrevendo-se as equações (2.42) e (2.43), têm-se:

$$
\varepsilon_{1}=\frac{T_{p 1}}{\left(E_{x} A_{x}+T_{01}\right)}+\alpha \Delta t_{x}
$$

e,

$$
\varepsilon_{2}=\frac{T_{p 2}}{\left(E_{y} A_{y}+T_{02}\right)}+\alpha \Delta t_{y}
$$

Combinando-se as equações (2.34) com (2.44), tem-se:

$$
\frac{u^{\prime}+z^{\prime} w^{\prime}}{\left(1+z^{\prime 2}\right)}+\frac{u^{\prime 2}+v^{\prime 2}+w^{\prime 2}}{2\left(1+z^{\prime 2}\right)}=\frac{T_{p 1}}{\left(E_{x} A_{x}+T_{01}\right)}+\alpha \Delta t_{x}
$$

Desprezando-se, nesta equação, os infinitésimos de ordem superior e também a parcela $T_{01}$ devido à protensão, na presença do termo $E_{x} A_{x}$, rigidez equivalente do cabo, e após considerar a equação (2.2), obtém-se:

$$
T_{p 1}=\left[\frac{u^{\prime}+z^{\prime} w^{\prime}}{g_{11}}-\alpha \Delta t_{x}\right] E_{x} A_{x}
$$

De modo análogo, a partir da combinação das equaçōes (2.35) com (2.45), tem-se o esforço devido às cargas externas na direção de $e_{2}$ dado como,

$$
T_{p 2}=\left[\frac{v^{\bullet}+z^{\bullet} w^{\bullet}}{g_{22}}-\alpha \Delta t_{y}\right] E_{y} A_{y}
$$




\subsection{4- Componentes Horizontais dos Esforços}

Conforme Figura 2.2, podem-se obter as componentes horizontais dos esforços $T_{1}$ e $T_{2}$ como sendo:

$$
\begin{aligned}
& H_{x}=\left(T_{1} \bar{e}_{1}\right) \cdot e_{x}=\frac{T_{1}\left(1+u^{\prime}\right)}{\sqrt{\bar{g}_{11}}} \\
& H_{y}=\left(T_{2} \bar{e}_{2}\right) \cdot e_{y}=\frac{T_{2}\left(1+v^{*}\right)}{\sqrt{\bar{g}_{22}}}
\end{aligned}
$$

Assim como escreveu-se anteriormente para os esforços $T_{1}$ e $T_{2}$, as componentes horizontais podem ser decompostas em duas parcelas, uma devido somente à protensão e outra devido às cargas externas. Então têmse:

$$
H_{x}=H_{o x}+H_{p x}
$$

e,

$$
H_{y}=H_{o y}+H_{p y}
$$

Deste modo, das equações (2.48) e (2.49) resultam

$$
\begin{aligned}
& H_{o x}=\frac{T_{01}}{\sqrt{g_{11}}}\left(1+u^{\prime}\right) \\
& H_{p x}=\frac{T_{p 1}}{\sqrt{g_{11}}}\left(1+u^{\prime}\right) \\
& H_{o y}=\frac{T_{02}}{\sqrt{g_{22}}}\left(1+v^{*}\right) \\
& H_{p y}=\frac{T_{p 2}}{\sqrt{g_{22}}}\left(1+v^{*}\right)
\end{aligned}
$$


Levando-se as equações (2.53) na (2.46) e (2.55) na (2.47), reescrevem-se as equações como sendo:

$$
H_{p x}=\frac{E_{x} A_{x}}{\sqrt{g_{11}} g_{11}}\left(1+u^{\prime}\right)\left(u^{\prime}+z^{\prime} w^{\prime}-g_{11} \alpha \Delta t_{x}\right)
$$

e,

$$
H_{p y}=\frac{E_{y} A_{y}}{\sqrt{\bar{g}_{22}} g_{22}}\left(1+v^{\bullet}\right)\left(v^{\bullet}+z^{\bullet} w^{\bullet}-g_{22} \alpha \Delta t_{y}\right)
$$

A fim de obter certas simplificações, descartam-se a variação das deformações em relação à unidade, as mesmas variações de ordem superior e, observando-se as equações (2.2), (2.4), (2.15), (2.18), (2.19) e (2.29), pode-se escrever que:

$$
\begin{aligned}
& g_{11}=\bar{g}_{11}, \\
& g_{22}=\bar{g}_{22}
\end{aligned}
$$

e,

$$
\mathrm{g}=\overline{\mathrm{g}}
$$

Assim, as equações das componentes horizontais dos esforços são obtidas por:

$$
\begin{aligned}
& H_{p x}=\frac{E_{x} A_{x}}{\left(g_{11}\right)^{3 / 2}}\left(u^{\prime}+z^{\prime} w^{\prime}-g_{11} \alpha \Delta t_{x}\right) \\
& H_{p y}=\frac{E_{y} A_{y}}{\left(g_{22}\right)^{3 / 2}}\left(v^{\bullet}+z^{\bullet} w^{\bullet}-g_{22} \alpha \Delta t_{y}\right)
\end{aligned}
$$

e chamando de 


$$
D_{x}=\frac{E_{x} A_{x}}{\left(g_{11}\right)^{3 / 2}}
$$

e

$$
D_{y}=\frac{E_{y} A_{y}}{\left(g_{22}\right)^{3 / 2}}
$$

onde,

$D_{x}, D_{y}$ : são funções de rigidez que dependem somente da geometria e das propriedades mecânicas da cesta.

Reescrevem-se as equações dos esforços como:

$$
\begin{aligned}
& H_{p x}=D_{x}\left(u^{\prime}+z^{\prime} w^{\prime}-g_{11} \alpha \Delta t_{x}\right) \\
& H_{p y}=D_{y}\left(v^{\bullet}+z^{\bullet} w^{\bullet}-g_{22} \alpha \Delta t_{y}\right)
\end{aligned}
$$

Voltando às funções de rigidez $D_{x}$ e $D_{y}$, considerando-se que $E_{x} A_{x}$ e $E_{y} A_{y}$ sejam constantes em cada direção e tendo-se em vista as equações (2.2) e (2.4), pode-se obter a variação da rigidez em cada direção da cesta protendida.

Assim, têm-se:

$$
\begin{aligned}
& D_{x}^{\prime}=-\frac{3}{g_{11}} D_{x} z^{\prime} z^{\prime \prime} \\
& D_{y}^{\bullet}=-\frac{3}{g_{22}} D_{y} z^{\bullet} z^{\bullet \bullet}
\end{aligned}
$$




\subsection{5- Equações Diferenciais}

As equações (2.31.a), (2.31.b) e (2.31.c) que governam o equilibrio da membrana podem ser simplificadas usando-se as mesmas considerações anteriores e, tendo-se em vista as equações (2.48) e (2.49), são reescritas como sendo:

$$
\begin{aligned}
& H_{x}^{\prime}+\left(H_{y} u^{\bullet}\right)^{\bullet}+p_{x}=0 \\
& \left(H_{x} v^{\prime}\right)^{\prime}+H_{y}^{\bullet}+p_{y}=0 \\
& {\left[H_{x}\left(z^{\prime}+w^{\prime}\right)\right]^{\prime}+\left[H_{y}\left(z^{\bullet}+w^{\bullet}\right)\right]^{\bullet}+p_{z}=0}
\end{aligned}
$$

com as equações (2.50) e (2.51) têm-se que:

$$
\begin{aligned}
& \left(H_{o x}+H_{p x}\right)^{\prime}+\left[\left(H_{o y}+H_{p y}\right) u^{\bullet}\right]^{\bullet}+p_{x}=0 \\
& {\left[\left(H_{o x}+H_{p x}\right) v^{\prime}\right]^{\prime}+\left(H_{o y}+H_{p y}\right)^{\bullet}+p_{y}=0} \\
& {\left[\left(H_{o x}+H_{p x}\right)\left(z^{\prime}+w^{\prime}\right)\right]^{\prime}+\left[\left(H_{o y}+H_{p y}\right)\left(z^{\bullet}+w^{\bullet}\right)\right]^{\bullet}+p_{z}=0}
\end{aligned}
$$

$\mathrm{Na}$ configuração inicial do elemento de membrana, tem-se que as componentes horizontais dos esforços são somente devido à protensão; não há ainda carregamento externo.

$$
p_{x}=p_{y}=p_{z}=0
$$

e,

$$
\Delta t_{x}=\Delta t_{y}=0
$$


44

e assume-se que não há deslocamentos, isto é:

$$
\mathrm{u}=\mathrm{v}=\mathrm{w}=0
$$

Portanto, levando estas considerações nas equações de equilibrio (2.60.a), (2.60.b) e (2.60.c), têm-se:

$$
\begin{aligned}
& \left(H_{o x}\right)^{\prime}=0 \\
& \left(H_{o y}\right)^{\bullet}=0 \\
& H_{o x} z^{\prime \prime}+H_{o y} z^{* \bullet}=0
\end{aligned}
$$

As equações (2.61.a) e (2.61.b) mostram que as componentes horizontais no estado inicial são constantes ao longo de cada cabo. $\mathrm{Na}$ equação (2.61.c), desde que ambas componentes horizontais sejam positivas, tem-se que:

$$
\frac{z^{\prime \prime}}{z^{0}}<0
$$

A superfície da cesta tem uma curvatura gaussiana negativa, CARMO (1976). Esta é a condição necessária para que a aplicação da protensão seja possível.

Levando-se as equações (2.61.a), (2.61.b) e (2.61.c) nas equações (2.60.a), (2.60.b) e (2.60.c), têm-se:

$$
\begin{aligned}
& H_{p x}^{\prime}+\left(H_{p y} u^{\bullet}\right)^{\bullet}+p_{x}=0 \\
& \left(H_{p x} v^{\prime}\right)^{\prime}+H_{p y}^{\bullet}+p_{y}=0 \\
& {\left[H_{p x}\left(z^{\prime}+w^{\prime}\right)\right]^{\prime}+\left[H_{p y}\left(z^{\bullet}+w^{\bullet}\right)\right]^{\bullet}+p_{z}=0}
\end{aligned}
$$


Levando-se as equações (2.56) e (2.57) nas equações (2.60.a), (2.60.b) e (2.60.c) e considerando-se as equações (2.58), (2.59), (2.61.a), (2.61.b) e (2.61.c), têm-se:

$$
\begin{aligned}
& D_{x}\left[u^{\prime \prime}+z^{\prime \prime} w^{\prime}+z^{\prime} w^{\prime \prime}-\frac{3}{g_{11}} z^{\prime} z^{\prime \prime}\left(u^{\prime}+z^{\prime} w^{\prime}\right)+z^{\prime} z^{\prime \prime} \alpha \Delta t_{x}+\right. \\
& \left.-g_{11} \alpha \Delta t_{x}^{\prime}\right]+D_{y}\left[\left(v^{\bullet}+z^{\bullet} w^{\bullet}-g_{22} \alpha \Delta t_{y}\right) u^{\bullet \bullet}+\left(v^{\bullet \bullet}+z^{\bullet \bullet} w^{\bullet}+\right.\right. \\
& \left.+z^{\bullet} w^{\bullet \bullet}\right) u^{\bullet}-\frac{3}{g_{22}} z^{\bullet} z^{\bullet \bullet}\left(v^{\bullet}+z^{\bullet} w^{\bullet}\right) u^{\bullet}+\left(z^{\bullet} z^{\bullet \bullet} \alpha \Delta t_{y}+\right. \\
& \left.\left.-g_{22} \alpha \Delta t_{y}^{\bullet}\right) u^{\bullet}\right]+H_{o y} u^{\bullet}+p_{x}=0
\end{aligned}
$$

$D_{y}\left[v^{\bullet \bullet}+z^{\bullet \bullet} w^{\bullet}+z^{\bullet} w^{\bullet \bullet}-\frac{3}{g_{22}} z^{\bullet} z^{\bullet \bullet}\left(v^{\bullet}+z^{\bullet} w^{\bullet}\right)+z^{\bullet} z^{\bullet \bullet} \alpha \Delta t_{y}+\right.$

$\left.-g_{22} \alpha \Delta t_{y}^{*}\right]+D_{x}\left[\left(u^{\prime}+z^{\prime} w^{\prime}-g_{11} \alpha \Delta t_{x}\right) v^{\prime \prime}+\left(u^{\prime \prime}+z^{\prime \prime} w^{\prime}+z^{\prime} w^{\prime \prime}\right) v^{\prime}+\right.$

$\left.-\frac{3}{g_{11}} z^{\prime} z^{\prime \prime}\left(u^{\prime}+z^{\prime} w^{\prime}\right) v^{\prime}+\left(z^{\prime} z^{\prime \prime} \alpha \Delta t_{x}-g_{11} \alpha \Delta t_{x}^{\prime}\right) v^{\prime}\right]+$

$+\mathrm{H}_{\mathrm{ox}} \mathrm{V}^{\prime \prime}+\mathrm{p}_{\mathrm{y}}=0$ 


$$
\begin{aligned}
& D_{x}\left\{\left(u^{\prime}+z^{\prime} w^{\prime}-g_{11} \alpha \Delta t_{x}\right)\left(z^{\prime \prime}+w^{\prime \prime}\right)+\left[u^{\prime \prime}+z^{\prime \prime} w^{\prime}+z^{\prime} w^{\prime \prime}+\right.\right. \\
& \left.\left.-\frac{3}{g_{11}} z^{\prime} z^{\prime \prime}\left(u^{\prime}+z^{\prime} w^{\prime}\right)+z^{\prime} z^{\prime \prime} \alpha \Delta t_{x}-g_{11} \alpha \Delta t_{x^{\prime}}\right]\left(z^{\prime}+w^{\prime}\right)\right\}+ \\
& +D_{y}\left\{\left(v^{\bullet}+z^{\bullet} w^{\bullet}-g_{22} \alpha \Delta t_{y}\right)\left(z^{\bullet \bullet}+w^{\bullet \bullet}\right)+\left[v^{\bullet \bullet}+z^{\bullet \bullet} w^{\bullet}+\right.\right. \\
& \left.+z^{\bullet} w^{\bullet \bullet}-\frac{3}{g_{22}} z^{\bullet} z^{\bullet \bullet}\left(v^{\bullet}+z^{\bullet} w^{\bullet}\right)+z^{\bullet} z^{\bullet \bullet} \alpha \Delta t_{y}-g_{22} \alpha \Delta t_{y}^{\bullet}\right] \\
& \left.\left(z^{\bullet}+w^{\bullet}\right)\right\}+H_{o x} w^{\prime \prime}+H_{o y} w^{\bullet \bullet}+p_{z}=0
\end{aligned}
$$

As equações (2.63.a), (2.63.b) e (2.63.c) são equações diferenciais não lineares de segunda ordem em $u, v e w$.

As simplificações assumidas não introduzem erros significantes, segundo Otto (1972), portanto, descrevem exatamente o problema de uma cesta de cabos ortogonais em planta.

Admitindo-se que $H_{x}$ e $H_{y}$, nos casos usuais, são da mesma ordem de grandeza, pode-se ainda fazer mais algumas simplificações que levarão à linearização das equações (2.63.a), (2.63.b) e (2.63.c).

Observando-se as equações (2.60.a), (2.60.b) e (2.60.c) e tendo-se,

$$
\mathrm{H}_{\mathrm{py}} \mathrm{u}^{\bullet}<\mathrm{H}_{\mathrm{px}}
$$

vem que:

$$
\mathrm{H}_{\mathrm{py}}^{\bullet} \mathrm{u}^{\bullet}+\mathrm{H}_{\mathrm{py}} \mathrm{u}^{\bullet \bullet}=\left(\mathrm{H}_{\mathrm{py}} \mathrm{u}^{\bullet}\right)^{\bullet}<\mathrm{H}_{\mathrm{px}}^{\prime}
$$

e ainda:

$$
\mathrm{H}_{\mathrm{oy}} \mathrm{u}^{\bullet \bullet}<\mathrm{H}_{\mathrm{px}}^{\prime}
$$


Assim, são desprezadas as componentes $H_{y}$ da equação (2.60.a) e, do mesmo modo, são desprezadas as componentes $\mathrm{H}_{x}$ da equação (2.60.b). Admite-se ainda, na equação (2.60.c) que as variações de w são despreziveis se comparadas às variações de $z$.

Consideram-se ainda as equações (2.61.a), (2.61.b) e (2.61.c) e podem-se, então, reescrever as equações (2.60.a), (2.60.b) e (2.60.c) como sendo:

$$
\begin{aligned}
& H_{p x}^{\prime}+p_{x}=0 \\
& H_{p y}^{\prime}+p_{y}=0 \\
& H_{p x} z^{\prime \prime}+H_{o x} w^{\prime \prime}+H_{p y} z^{\bullet \bullet}+H_{o y} w^{\bullet \bullet}-p_{x} z^{\prime}-p_{y} z^{\bullet}+p_{z}=0
\end{aligned}
$$

Levando-se as equações (2.56) e (2.57) nestas equações, têm-se:

$$
\begin{aligned}
& {\left[D_{x}\left(u^{\prime}+z^{\prime} w^{\prime}-g_{11} \alpha \Delta t_{x}\right)\right]^{\prime}+p_{x}=0} \\
& {\left[D_{y}\left(v^{\bullet}+z^{\bullet} w^{\bullet}-g_{22} \alpha \Delta t_{y}\right)\right]^{\bullet}+p_{y}=0} \\
& D_{x}\left(u^{\prime}+z^{\prime} w^{\prime}-g_{11} \alpha \Delta t_{x}\right) z^{\prime \prime}+D_{y}\left(v^{\bullet}+z^{\bullet} w^{\bullet}-g_{22} \alpha \Delta t_{y}\right) z^{\bullet \cdot}+ \\
& +H_{\text {oy }} w^{\prime \prime}+H_{\text {oy }} w^{\bullet \bullet}-p_{x} z^{\prime}-p_{y} z^{\bullet}+p_{z}=0
\end{aligned}
$$

Desenvolvendo-se estas equações e tendo-se em vista as equações (2.58) e (2.59), chega-se às equações

$$
\begin{aligned}
& D_{x}\left[u^{\prime \prime}+z^{\prime \prime} w^{\prime}+z^{\prime} w^{\prime \prime}-\frac{3}{g_{11}} z^{\prime} z^{\prime \prime}\left(u^{\prime}+z^{\prime} w^{\prime}\right)+z^{\prime} z^{\prime \prime} \alpha \Delta t_{x}+\right. \\
& \left.-g_{11} \alpha \Delta t_{x}^{\prime}\right]+p_{x}=0
\end{aligned}
$$




$$
\begin{aligned}
& D_{y}\left[v^{\bullet \bullet}+z^{\bullet \bullet} w^{\bullet}+z^{\bullet} w^{\bullet \bullet}-\frac{3}{g_{22}} z^{\bullet} z^{\bullet \bullet}\left(v^{\bullet}+z^{\bullet} w^{\bullet}\right)+z^{\bullet} z^{\bullet \bullet} \alpha \Delta t_{y}+\right. \\
& \left.-g_{22} \alpha \Delta t_{y}^{\bullet}\right]+p_{y}=0 \\
& D_{x}\left(u^{\prime}+z^{\prime} w^{\prime}-g_{11} \alpha \Delta t_{x}\right) z^{\prime \prime}+D_{y}\left(v^{\bullet}+z^{\bullet} w^{\bullet}-g_{22} \alpha \Delta t_{y}\right) z^{\bullet \bullet}+ \\
& +H_{o x} w^{\prime \prime}+H_{o y} w^{\bullet \bullet}-p_{x} z^{\prime}-p_{y} z^{\bullet}+p z=0
\end{aligned}
$$

Assim as equaçōes (2.64.a), (2.64.b) e (2.64.c), básicas para o estudo das cestas protendidas, em comparação com as (2.63.a), (2.63.b) e (2.63.c), são lineares nas cargas e nos deslocamentos.

\section{2- Resolução do Sistema Final de Equações}

\subsection{1- Condições de contorno}

Para integrar as equações (2.64.a) e (2.64.b) é necessário estabelecer inicialmente as condições de contorno.

Supondo-se, inicialmente que a projeção em planta da superfície $z(x, y)$, seja uma função de $y$, Figura 2.4 .

Adota-se sempre que $x_{d} \geq x_{e}$, assim tem-se que:

$$
\ell_{x}(y)=x_{d}(y)-x_{e}(y) \geq 0
$$

Os deslocamentos do contorno causados pelo carregamento dado são funções de y, isto é:

$$
\begin{array}{ll}
\text { na borda esquerda } & u_{x e}(y), w_{x e}(y) \\
\text { na borda direita } & u_{x d}(y), w_{x d}(y)
\end{array}
$$




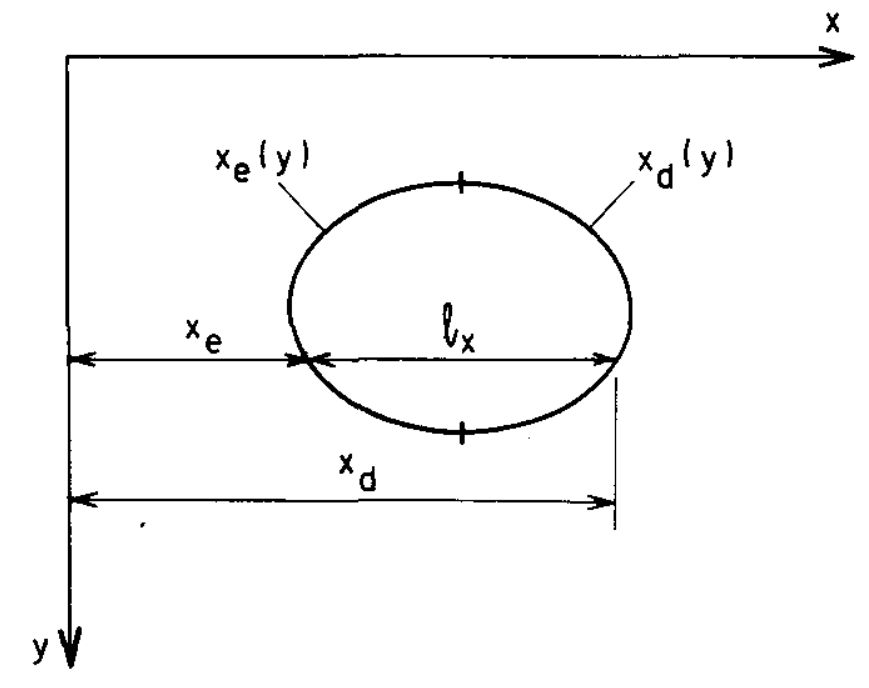

Figura 2.4- Curva do contorno como função de y.

Integrando-se, em $x$, a equação (2.64.a), tem-se:

$$
H_{p x}=D_{x}\left(u^{\prime}+z^{\prime} w^{\prime}-g_{11} \alpha \Delta t_{x}\right)=C_{1}(y)-\int_{0}^{x} p_{x} d x
$$

Integrando-se a equação (2.66) entre os limites $x_{e}$ e $x_{d}$ e isolando-se a constante de integração $C_{1}$, tem-se:

$$
\begin{aligned}
C_{1}(y) & =\phi_{x}(y)\left\{\int_{x_{e}}^{x_{d}}\left[\frac{1}{D_{x}} \int_{0}^{x} p_{x} d x\right] d x+W_{x}(y)+\right. \\
& \left.-\int_{x_{e}}^{x_{d}} g_{11} \alpha \Delta t_{x} d x-\int_{x_{e}}^{x_{d}} z^{\prime \prime} w d x\right\}
\end{aligned}
$$

onde,

$$
\frac{1}{\phi_{x}(y)}=\int_{x_{e}}^{x_{d}} \frac{d x}{D_{x}(x, y)}=\int_{x_{e}}^{x_{d}} \frac{\left(g_{11}\right)^{3 / 2}}{E_{x} A_{x}} d x
$$


e,

$$
W_{x}(y)=\left[u_{x d}(y)-u_{x e}(y)\right]+\left[z_{d}^{\prime} w_{x d}(y)-z_{e}^{\prime} w_{x e}(y)\right]
$$

Agora, supõe-se que a projeção em planta da superfície $z(x, y)$ resulte em uma função de x, Figura 2.5.

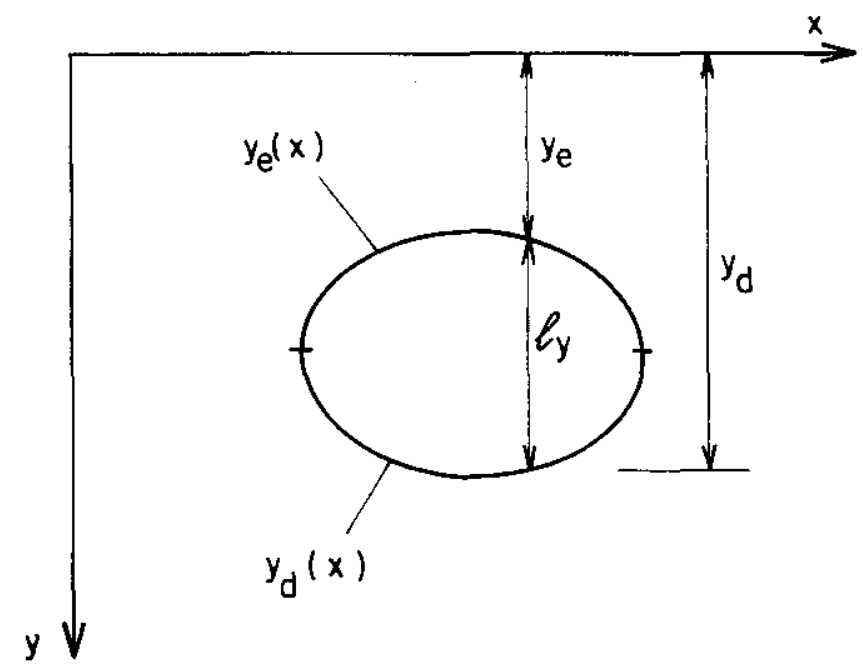

Figura 2.5- Curva do contorno como função de $\mathrm{x}$

Analogamente à função de $y$, tem-se que:

$\ell_{y}(x)=y_{d}(x)-y_{e}(x) \geq 0$

Os deslocamentos do contorno são dados por:

na borda esquerda

$$
v_{y e}(x), w_{y e}(x)
$$

na borda direita

$$
v_{y d}(x), w_{y d}(x)
$$


Assim, integrando-se, em y, a equação (2.64.b), tem-se:

$$
H_{p y}=D_{y}\left(v^{\bullet}+z^{*} w^{\bullet}-g_{22} \alpha \Delta t_{y}\right)=C_{2}(x)-\int_{0}^{y} p_{y} d y
$$

Integrando-se a equação (2.71) entre os limites $y_{e}$ e $y_{d}$ e isolando-se a constante de integração $\mathrm{C}_{2}$, tem-se:

$$
\begin{aligned}
C_{2}(x)= & \phi_{y}(x)\left\{\int_{y_{e}}^{y_{d}}\left[\frac{1}{D_{y}} \int_{0}^{y} p_{y} d x\right] d y+W_{y}(x)+\right. \\
& \left.-\int_{y_{e}}^{y_{d}} g_{22} \alpha \Delta t_{y} d y-\int_{y}^{y_{d}} z^{\bullet \bullet ~ w d y ~}\right\}
\end{aligned}
$$

onde,

$$
\frac{1}{\phi_{y}(x)}=\int_{y}^{y} d \frac{d y}{D_{y}(x, y)}=\int_{y_{e}}^{y_{d}} \frac{\left(g_{22}\right)^{3 / 2}}{E_{y} A_{e y}} d y
$$

e

$$
W_{y}(x)=\left[v_{y d}(x)-v_{y e}(x)\right]+\left[z_{d}^{\bullet} w_{y d}(x)-z_{d}^{\bullet} W_{y e}(x)\right]
$$

Levando-se as equações $(2.66),(2.67),(2.71)$ e (2.72) na equação (2.64.c), tem-se:

$$
\begin{aligned}
& z^{\prime \prime} \phi_{x}(y) \int_{x_{e}}^{x_{d}} z^{\prime \prime} w d x+z^{\bullet \bullet} \phi_{y}(x) \int_{x_{e}}^{x} z^{\bullet \bullet} w d y-H_{o x} w^{\prime \prime}+ \\
& -H_{o y} w^{\bullet \bullet}=\beta(x, y)
\end{aligned}
$$


onde,

$$
\begin{aligned}
\beta(x, y)= & -z^{\prime} p_{x}-z^{\prime \prime} \int_{0}^{x} p_{x} d x+z^{\prime \prime} \phi_{x}(y) \int_{x}^{x} d\left[\frac{1}{D_{x}} \int_{0}^{x} p_{x} d x\right] d x+ \\
& -z^{\bullet} p_{y}-z^{\bullet \bullet} \int_{0}^{y} p_{y} d y+z^{\bullet \bullet} \phi_{y}(x) \int_{y}^{y} d\left[\frac{1}{D_{y}} \int_{0}^{y} p_{y} d y\right] d y+ \\
& +p_{z}+z^{\prime \prime} \phi_{x}(y) W_{x}+z^{\bullet \bullet} \phi_{y}(x) W_{y}+ \\
& -z^{\prime \prime} \phi_{x}(y) \int_{x}^{x} g_{11} \alpha \Delta t_{x} d x-z^{\bullet \bullet} \phi_{y}(x) \int_{y}^{y} g_{e} g_{22} \alpha \Delta t_{y} d y
\end{aligned}
$$

A equação integro-diferencial (2.75) permite determinar os deslocamentos em pontos da superfície desde que se conheçam a função de carregamento $\beta(x, y)$, a configuração inicial de equilibrio da superfíce $z(x, y)$ e as funções de rigidez $E_{x} A_{x} \in E_{y} A_{y}$.

Obtido o valor $w$ e empregando-se adequadamente as equações (2.56), (2.57), (2.64.a) e (2.64.b), determinam-se os esforços $\mathrm{H}_{p x}$ e $\mathrm{H}_{p y}$ e os deslocamentos $u$ e $v$, respectivamente.

O primeiro membro da equação (2.75) contém termos que dependem apenas das características geométricas da superfície e deslocamentos incógnitos $\mathrm{w}$. O segundo membro da mesma equação contém termos que dependem exclusivamente do carregamento.

\subsection{2- Estudo dos Termos Geométricos}

Para a resolução da equação (2.75), admite-se inicialmente a projeção da superfície $z=z(x, y)$ em planta. Esta planta é dividida em intervalos uniformes $\Delta_{x}$ e $\Delta_{y}$ formando uma malha.

Tomando-se estes intervalos como sendo iguais às distâncias entre cabos, obtém-se a solução exata para o sistema de equações gerado pela 
equação (2.75).

Deve-se ainda supor o contorno da superfície como sendo formado por linhas poligonais conforme mostrado na Figura 2.6

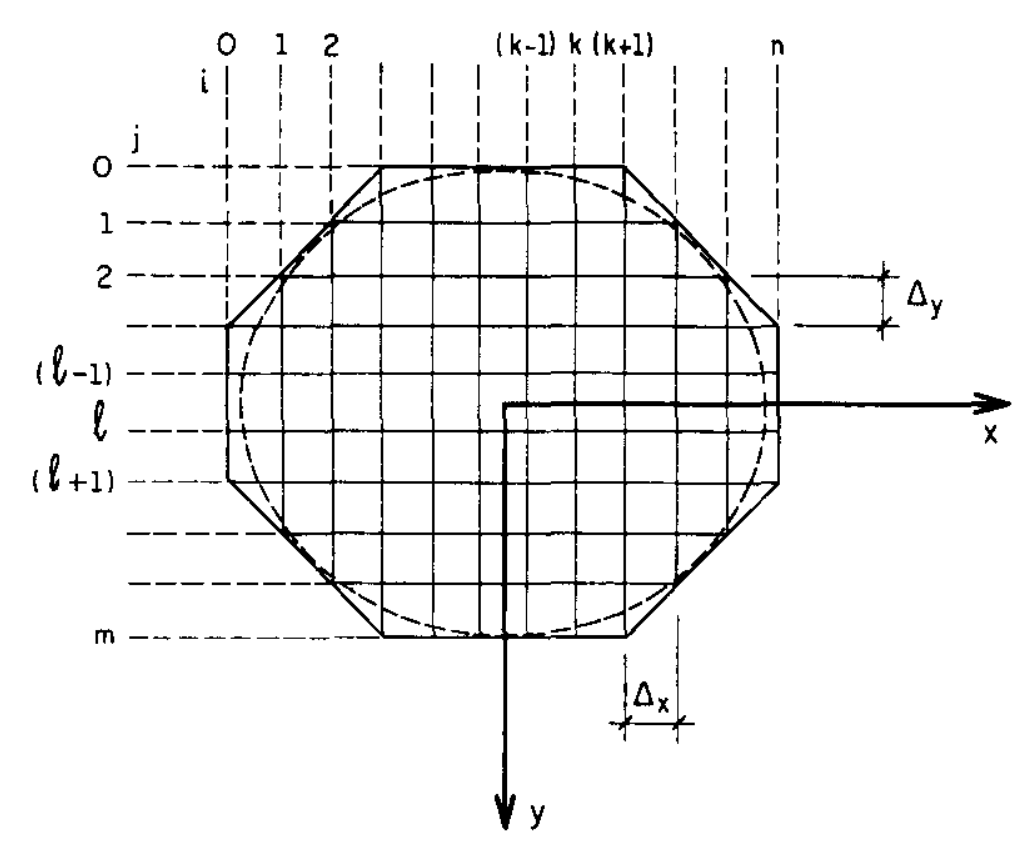

Figura 2.6- Contorno da superfície em planta e reticulado adotado.

Cada ponto da malha tem coordenadas (i, j) que se referem às direções $x$ e y respectivamente.

Para a montagem do sistema de equações cuja solução fornece os deslocamentos verticais em cada ponto $(i, j)$ da malha, na equação $(2.75)$ substitui-se as integrais por somatórias. No entanto, para os diferenciais, optou-se por utilizar o Método das Diferenças Finitas, aplicando-se para todos os pontos da malha diferenças finitas centrais utilizando-se um polinômio interpolador do segundo grau.

Assim, para o ponto de coordenadas $(k, l)$ da malha a equação (2.75), torna-se: 


$$
\begin{aligned}
& z_{k, 1}^{\prime \prime} \phi_{x \mid} \Delta_{x} \sum_{i=1}^{n} z_{k, 1}^{\prime \prime} w_{i, 1}+z_{k, 1}^{\bullet \bullet} \phi_{y k} \Delta_{y} \sum_{j=1}^{m} z_{k, i}^{\operatorname{co}} w_{k, j}+ \\
& -\frac{H_{o x, l}}{\left(\Delta_{x}\right)^{2}}\left(w_{k-1,1}-2 w_{k, 1}+w_{k+1,1}\right)-\frac{H_{o y, k}}{\left(\Delta_{y}\right)^{2}}\left(w_{k, 1-1}+\right. \\
& \left.-2 w_{k, l}+w_{k, 1+1}\right)=\beta_{k, l}
\end{aligned}
$$

ou simplesmente:

$$
\begin{aligned}
& A_{1}\left[\sum_{i=1}^{n} w_{i, 1}\right]+B_{k}\left[\sum_{j=1}^{m} w_{k, j}\right]-C\left(w_{k-1, l}-2 w_{k, l}+\right. \\
& \left.+w_{k+1,1}\right)-D\left(w_{k, 1-1}-2 w_{k, l}+w_{k, 1+1}\right)=\beta_{k, l}
\end{aligned}
$$

\subsection{3- Estudo dos Termos de Carregamento}

Considerando-se a equação (2.76), passa-se a estudar uma função de carregamento dada por $\beta(x, y)$.

Inicialmente, visto que as superfícies estudadas são muito abatidas, a grandeza $D$, conforme equações (2.56) e (2.57), varia pouco desde que a seção transversal do cabo seja constante ao longo de seu comprimento. Assim, nas integrais do primeiro termo da equaçăo (2.67), assumindo-se $D_{x}$ como sendo constante ao longo de $x$, tem-se:

$$
\int_{x_{e}}^{x_{d}}\left(\frac{1}{D_{x}} \int_{0}^{x} p_{x} d x\right) d x=\frac{1}{D_{x}} \int_{x_{e}}^{x_{d}} \int_{0}^{x} p_{x} d x d x
$$

Expressando-se o valor $1 / D_{X}$ em função de $\phi_{X}(y)$, equação (2.68), tem-se:

$$
\frac{1}{D_{x}}=\frac{1}{\ell_{x}(y)} \int_{x_{e}}^{x} \frac{d x}{D_{x}(x, y)}=\frac{1}{\ell_{x}(y) \phi_{x}(y)}
$$


Com as considerações feitas acima, expressam-se os segundo e terceiro termos da equação (2.76) como sendo:

$$
\begin{aligned}
& -z^{\prime \prime} \int_{0}^{x} p_{x} d x+z^{\prime \prime} \phi_{x}(y) \int_{x}^{x} d\left(\frac{1}{D_{x}} \int_{0}^{x} p_{x} d x\right) d x= \\
& =z^{\prime \prime}\left(-\int_{0}^{x} p_{x} d x+\frac{1}{\ell_{x}} \int_{x}^{x} d \int_{0}^{x} p_{x} d x d x\right)
\end{aligned}
$$

Usando-se analogia de viga, pode-se dizer que a expressão entre colchetes do lado direito da igualdade representa a força cortante de uma viga simplesmente apoiada, de comprimento $\ell_{x}$ e sujeita a um carregamento distribuido $p_{x}$, Figura 2.7
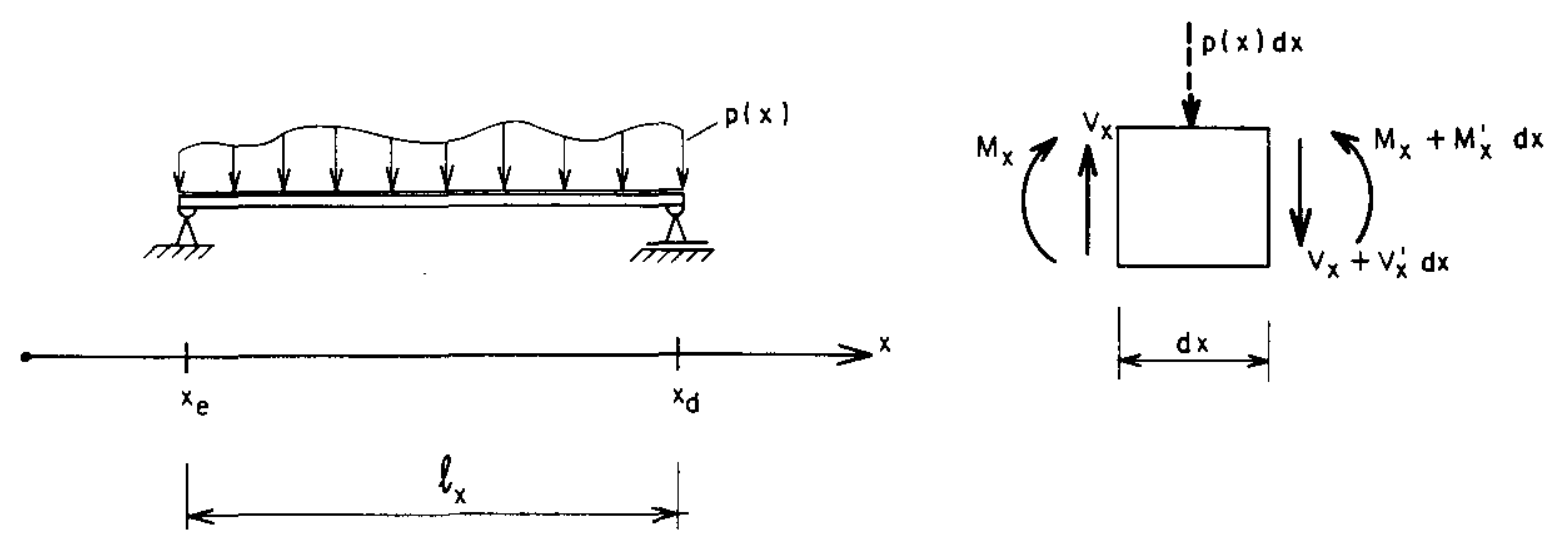

Figura 2.7- Analogia de viga para estudo dos termos de carregamento.

Assim sendo, diz-se que:

$$
V_{x}=-\int_{0}^{x} p_{x} d x+\frac{1}{\ell_{x}} \int_{x}^{x} d \int_{0}^{x} p_{x} d x d x
$$


Analogamente para a direção y, tem-se:

$$
V_{y}=-\int_{0}^{y} p_{y} d y+\frac{1}{\ell_{y}} \int_{y_{e}}^{y_{d}} \int_{0}^{y} p_{y} d y d y
$$

Analisando-se ainda, na equação (2.76) os termos que contêm variação de temperatura e considerando-se a equação (2.68), tem-se que:

$$
-\phi_{x}(y) \int_{x_{e}}^{x_{d}} g_{11} \alpha \Delta t_{x} d x=-\frac{1}{\int_{x_{e}}^{x_{d}} \frac{\left(g_{11}\right)^{3 / 2}}{E_{x} A_{x}} d x} \int_{x_{e}}^{x_{x}} g_{\uparrow \uparrow} \alpha \Delta t_{x} d x
$$

Sabendo-se que o produto $E_{x} f_{x x}$ é constante e considerando-se a equação (2.2) onde o infinitésimo de ordem superior é desprezivel em relação a unidade, tem-se que:

$$
-\phi_{x}(y) \int_{x_{e}}^{x_{d}} g_{11} \alpha \Delta t_{x} d x=-\frac{E_{x} A_{x}}{\ell_{x}} \int_{x_{e}}^{x_{d}} \alpha \Delta t_{x} d x
$$

Pode-se ainda dizer que:

$$
N_{x}(y)=-\frac{E_{x} A_{x}}{\ell_{x}} \int_{x_{e}}^{x_{d}} \alpha \Delta t_{x} d x
$$

analogamente para direção y, tem-se:

$$
N_{y}(y)=-\frac{E_{y} A_{y}}{\ell_{y}} \int_{y_{e}}^{y_{d}} \alpha \Delta t_{y} d y
$$

onde:

$N_{x}$ e $N_{y}$ : esforços normais devido à variação de temperatura.

Considerando-se a Figura 2.7, pode-se dizer que o momento fletor é dado por: 


$$
M_{x}(y)=\int_{x_{e}}^{x} d V_{x}(x, y) d x
$$

analogamente para a direção y, tem-se:

$$
M_{y}(x)=\int_{y}^{y} d V_{y}(x, y) d y
$$

Levando-se as equações (2.79), (2.80), (2.81) e (2.82) na equação (2.76), pode-se reescrevê-la como sendo:

$$
\begin{aligned}
\beta(x, y)= & -z^{\prime} p_{x}+z^{\prime \prime} V_{x}-z^{\bullet} p_{y}+z^{\bullet \bullet} V_{y}+p_{z}+ \\
& +z^{\prime \prime} \phi_{x} W_{x}+z^{\bullet \bullet} \phi_{y} W_{y}+z^{\prime \prime} N_{x}+z^{\bullet \bullet} N_{y}
\end{aligned}
$$

\section{3- Determinação dos Deslocamentos e dos Esforços nos Cabos}

Escreve-se a equação (2.78) para cada ponto interno do reticulado que corresponde a cada deslocamento $w_{i, j}$ incógnito. Assim, obtém-se um sistema linear de equações cuja solução fornece os deslocamentos verticais da malha considerada.

Com $w(x, y)$ conhecidos a partir das equações (2.66) e (2.67), (2.71) e (2.72) obtêm-se as componentes horizontais das forças nos cabos $\mathrm{H}_{\mathrm{px}}$ e $\mathrm{H}_{\mathrm{py}}$ causadas pelo carregamento externo. Com as equações (2.50) e (2.51), pode-se calcular as componentes das forças nos cabos nas direções dos eixos $x$ e $y$.

$O$ deslocamento horizontal na direção $x, u(x, y)$, é determinado a partir da equação (2.66). Isolando-se a incógnita $u$, integrando-se a equação $e$ considerando-se as equações (2.79), (2.81) e (2.83), tem-se: 


$$
\begin{aligned}
u= & \frac{x_{d}-x}{\ell_{x}}\left(u_{e x}+z_{e}^{\prime} w_{e x}\right)+\frac{x-x_{e}}{\ell_{x}}\left(u_{d x}+z_{d}^{\prime} w_{d x}\right)+ \\
& -z^{\prime} w-\frac{x-x_{e}}{\ell_{x}} \int_{x}^{x} z^{\prime \prime} w d x+\int_{x}^{x} z^{\prime \prime} w d x+ \\
& +\frac{1}{\ell_{x} \phi_{x}} M_{x}+\frac{x-x_{e}}{\ell_{x} \phi_{x}} N_{x}+\int_{x}^{x} g_{11} \alpha \Delta t_{x} d x
\end{aligned}
$$

Do mesmo modo, o deslocamento horizontal na direção de y é determinado usando-se a equação (2.71), isolando-se a incógnita $v$, integrando-se a equação e considerando-se as equações (2.80), (2.82) e (2.84). Tem-se, então:

$$
\begin{aligned}
v & =\frac{y_{d}-y}{\ell_{y}}\left(v_{e y}+z^{\bullet} w_{e y}\right)+\frac{y-y_{e}}{\ell_{y}}\left(v_{d y}+z_{d}^{\bullet} w_{d y}\right)+ \\
& -z^{\bullet} w-\frac{y-y_{e}}{\ell_{y}} \int_{y_{e}}^{y_{d}} z^{\bullet \bullet} w d y+\int_{y}^{y} z^{\bullet \bullet} w d y+\frac{1}{\ell_{y} \phi_{y}} M_{y}+ \\
& +\frac{y-y_{e}}{\ell_{y} \phi_{y}} N_{y}+\int_{y}^{y} g_{22} \alpha \Delta t_{y} d y
\end{aligned}
$$

Quando, na cesta de cabos com anel de contorno rígido, atua somente uma carga uniformemente distribuída, $p_{z}$, considerando-se as equações (2.86) e (2.87), segundo OTTO (1972) pode-se dizer que os deslocamentos u e v são obtidos por:

$$
u=-z^{\prime} w
$$

e,

$$
v=-z^{\bullet} w
$$




\section{ESTRUTURA DO PROGRAMA COMPUTACIONAL}

Utilizando-se o método descrito preparou-se um programa de cálculo, em linguagem FORTRAN, para microcomputadores.

O programa foi dividido em outros menores, estruturados de maneira que as operações fossem interrelacionadas, visando assim maior agilidade no cálculo computacional e melhor visualização dos passos seguidos.

\section{1- Programa CARACT.FOR}

Realiza a leitura e impressão dos dados da cesta protendida e da malha arbitrada, características geométricas e mecânicas dos cabos da cesta, e carregamentos atuantes. Calcula as curvaturas da superfície da cesta em cada direção, as coordenadas $x, y$ e $z$, dos nós da malha arbitrada, a rigidez dos cabos em cada direção e as componentes horizontais dos esforços preliminares nos cabos.

\section{2- Programa MATRIZ.FOR}

Sabe-se pelo equacionamento que o problema, de cestas protendidas analisadas pela Técnica do Meio Contínuo, é regido por um sistema de equações do tipo $\mathrm{MC} . \mathrm{W}=\mathrm{BE}$.

Assim, neste programa faz-se o cálculo dos termos e montagem da matriz MC, e também o cálculo do vetor independente de cargas, BE. 


\section{3- Programa RESULT.FOR}

Realiza o cálculo e impressão dos deslocamentos incógnitos dos nós da malha arbitrada, utilizando-se o Método de Gauss. Calcula e imprime as componentes horizontais dos esforços finais nos cabos em cada direção.

\section{4- Fluxogramas}

Fornece-se a seguir um fluxograma dos programas, Figuras 3.1, $3.2 \mathrm{e}$ 3.3, cuja listagem é dada integralmente no Apêndice, ao final do trabalho.

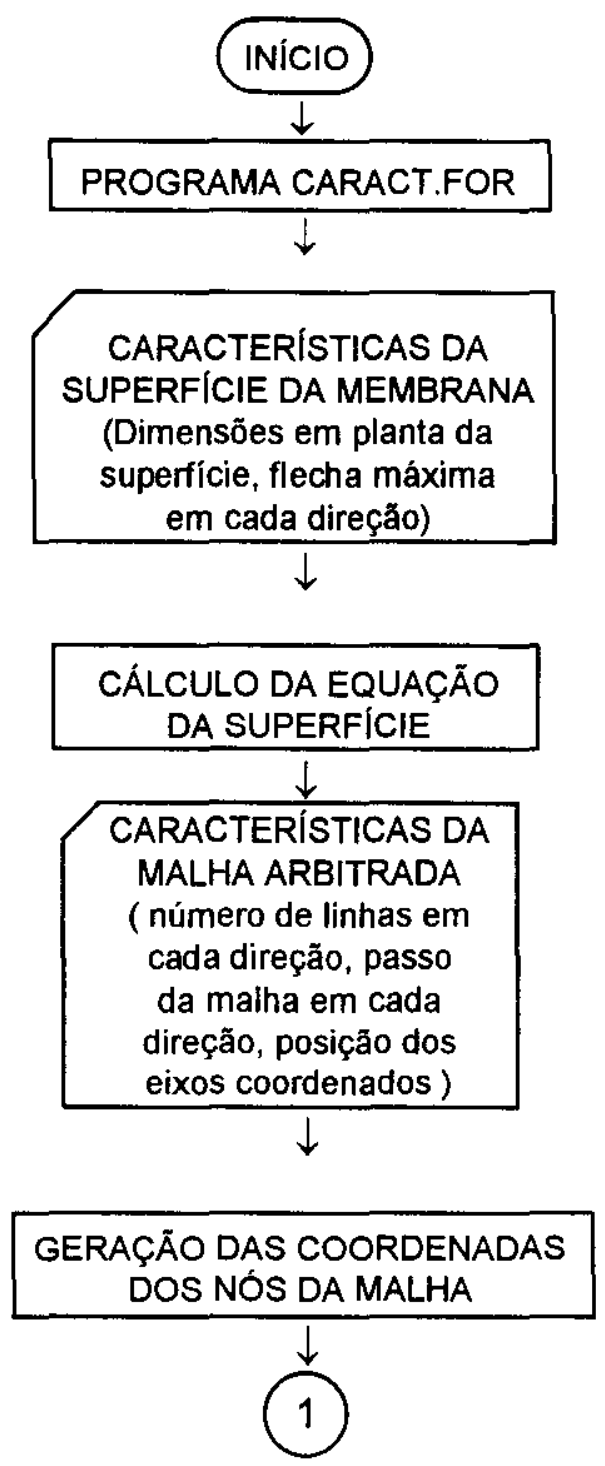




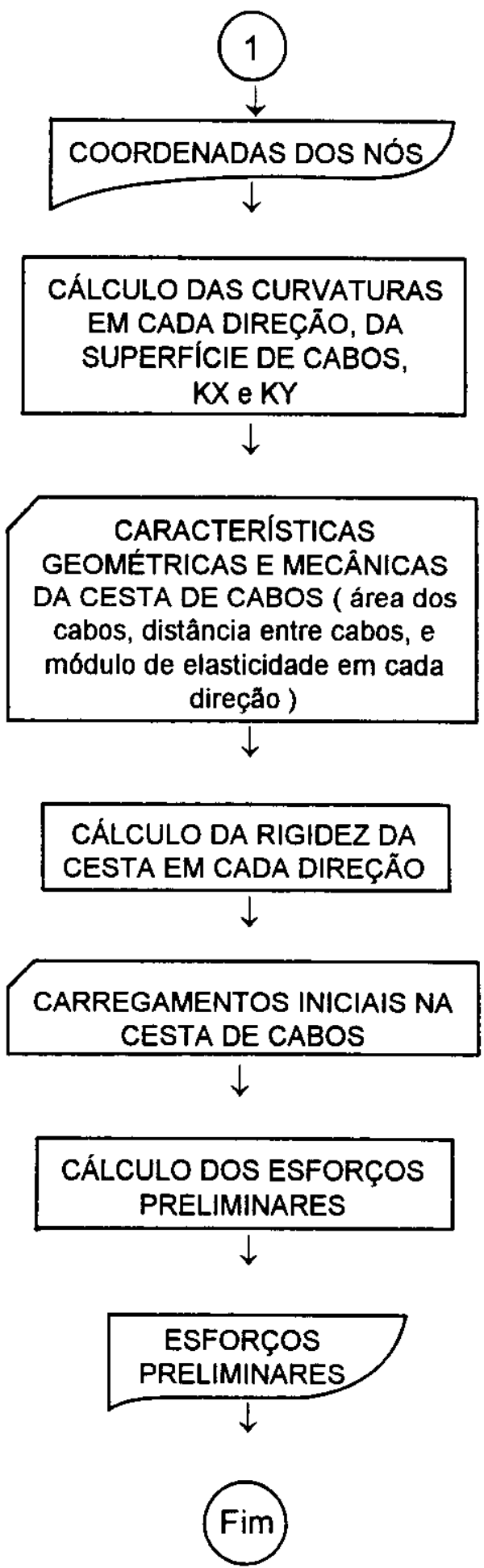

Figura 3.1- Fluxograma do programa CARACT.FOR 
INÍClO

$\downarrow$

PROGRAMA

MATRIZ.FOR

NÚMERO DE LINHAS NAS

DIREÇÕES $X$ e $Y, N X$ e NY

.CARGA PERMANENTE, G

.PASSOS DA MALHA EM CADA DIREÇÃO, PX e PY

.RIGIDEZ DA MALHA EM CADA DIREÇÃO, EFX e EFY

.COORDENADAS DOS NÓS DA MALHA, $X$ e $Y$

.COMPONENTES HORIZONTAIS DA PROTENSÃO, HXO E HYO

.CURVATURAS DA SUPERFÍCIE, KXe KY

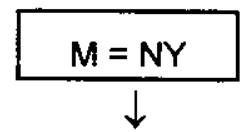

$J=2, M-1$

NÓ INICIAL E NÓ FINAL DE

CADA LINHA DA MALHA NA

DIREÇÃO i (DO EIXO X) NOIJ (J),

NOFJ (J) 

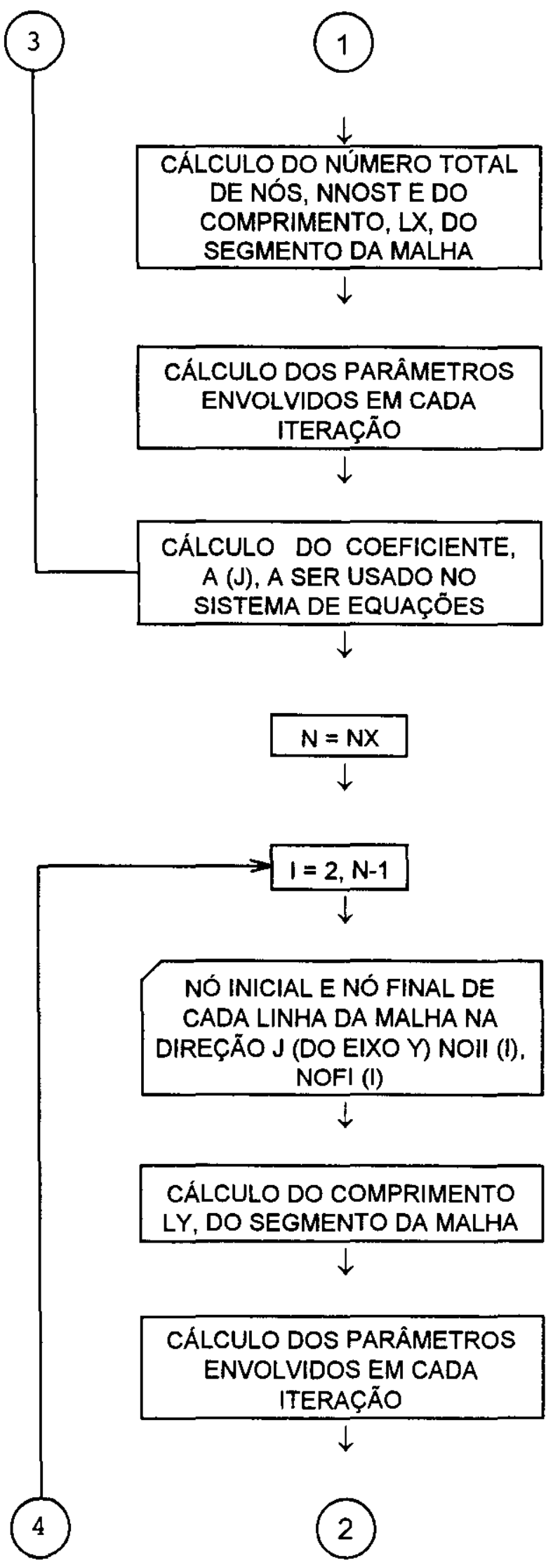


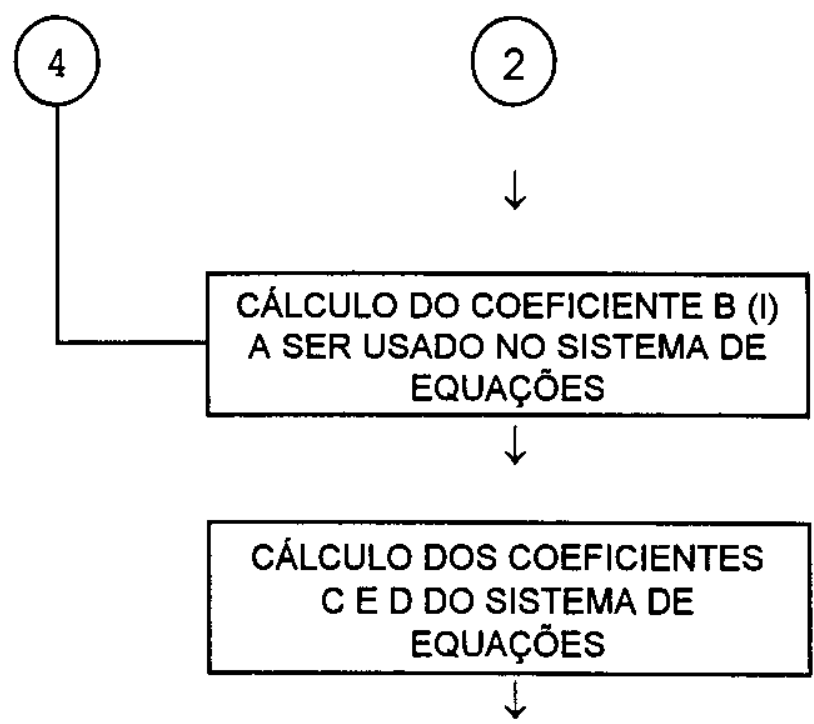

MONTAGEM DA MATRIZ MC

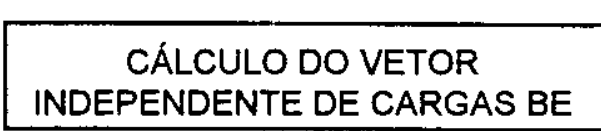

INDEPENDENTE DE CARGAS BE

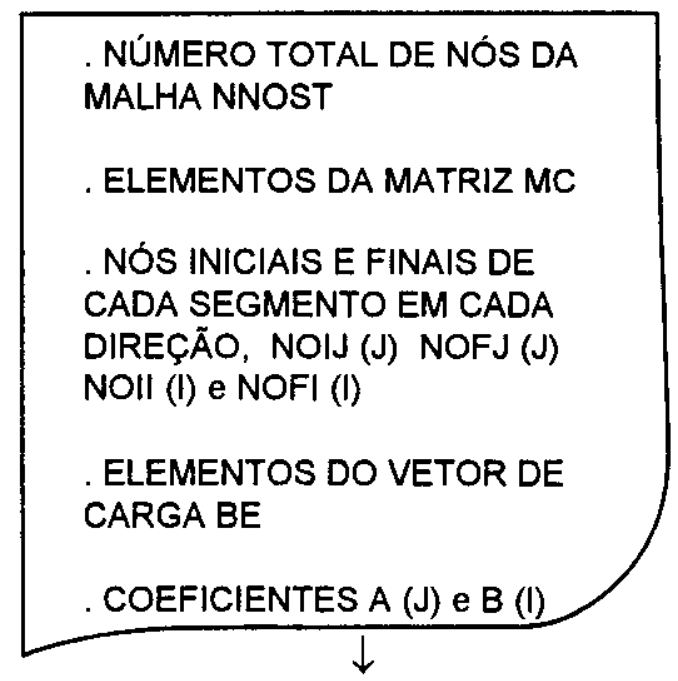

(Fim)

Figura 3.2- Fluxograma do programa MATRIZ.FOR 
$\frac{\text { INICIO }}{\downarrow}$

PROGRAMA RESULT.FOR

.NÚMERO TOTAL DE NÓS DA MALHA, NNOST

.ELEMENTOS DA MATRIZ MC

.NÓS INICIAIS E FINAIS DE CADA SEGMENTO EM CADA DIREÇÄO NOIJ (J), NOFJ (J), NOII (I) e NOFI (I)

.ELEMENTOS DO VETOR DE CARGA BE

.COEFICIENTES A (J) e B (I)

RESOLUÇÃO DO SISTEMA DE EQUAÇŌES

MONTAGEM DO VETOR SOLUÇÃO, DESL $(I, J)$

DESLOCAMENTOS DOS NÓS DA MALITA, DESL.

$\downarrow$

.CÁLCULO DAS COMPONENTES HORIZONTAIS DOS ESFORÇOS

EM CADA DIREÇÃO HXP e HYP $\downarrow$ 


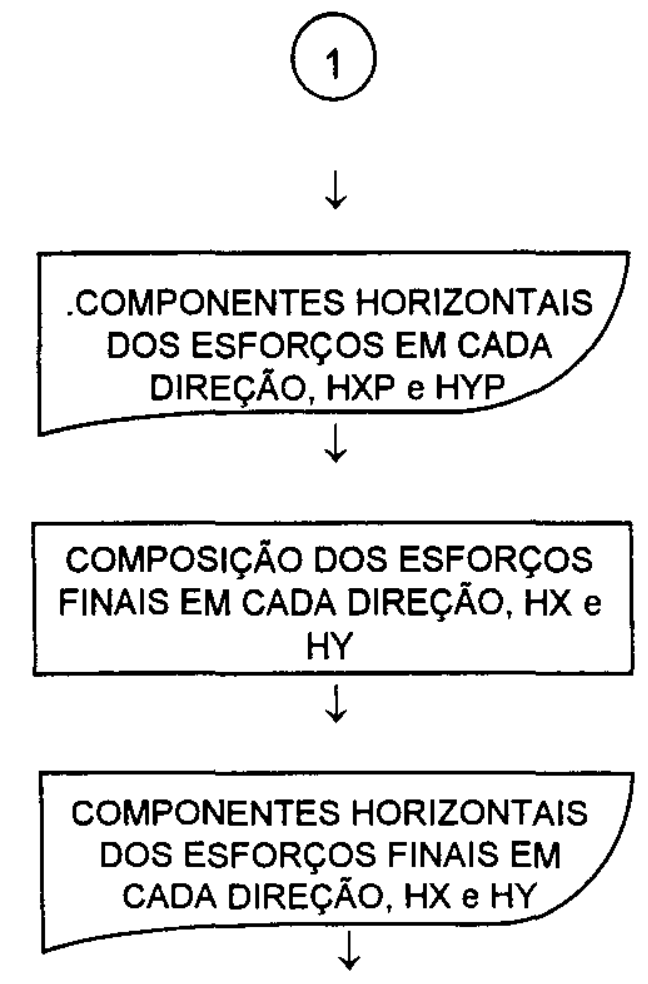

(FIM)

Figura 3.3- Fluxograma do programa RESULT.FOR

\section{5- Entrada de Dados}

Os dados de entrada para os programas são fornecidos em arquivos formatados e cujos nomes são ARQ1.DAT e ARQ2.DAT e estão descritos nas Tabelas 3.1 e 3.2 respectivamente. 
Tabela 3.1- Identificação do arquivo de dados ARQ1.DAT

\begin{tabular}{|c|c|c|c|}
\hline DADOS & IDENTIFICAÇÃO & UNIDADE & FORMATO \\
\hline a & $\begin{array}{l}\text { metade da maior dimensão, em } \\
x \text {, em planta: } a=\ell_{X} / 2 ; \text { sem } \\
\text { poligonizar o contorno. }\end{array}$ & $\mathrm{m}$ & F6.2 \\
\hline$b$ & $\begin{array}{l}\text { metade da maior dimensão em } \\
\text { y, em planta: } b=\ell y / 2 ; \text { sem } \\
\text { poligonizar o contorno }\end{array}$ & $\mathrm{m}$ & F6.2 \\
\hline c & flecha máxima para $y=0$ e $x=a$ & $\mathrm{~m}$ & F6.2 \\
\hline d & flecha máxima para $x=0$ e $y=b$ & $\mathrm{~m}$ & F6.2 \\
\hline$N X$ & $\begin{array}{l}\text { número de linhas no sentido do } \\
\text { eixo } x\end{array}$ & & 13 \\
\hline NY & $\begin{array}{l}\text { número de linhas no sentido do } \\
\text { eixo y }\end{array}$ & & 13 \\
\hline PX & passo da malha na direção $x$ & $\mathrm{~m}$ & F6.2 \\
\hline PY & passo da malha na direção $y$ & $\mathrm{~m}$ & F6.2 \\
\hline$T X$ & $\begin{array}{l}\text { posição dos eixos coorde- } \\
\text { nados: números de passos na } \\
\text { direção } x\end{array}$ & & F6.2 \\
\hline TY & $\begin{array}{l}\text { posição dos eixos coorde- } \\
\text { nados: número de passos na } \\
\text { direção y }\end{array}$ & & F6.2 \\
\hline$s x$ & $\begin{array}{l}\text { área da seção transversal do } \\
\text { cabo na direção do eixo } x \text {. }\end{array}$ & $\mathrm{cm}^{2}$ & F6.2 \\
\hline SY & $\begin{array}{l}\text { área da seção transversal do } \\
\text { cabo na direção do eixo y }\end{array}$ & $\mathrm{cm}^{2}$ & F6.2 \\
\hline
\end{tabular}


Tabela 3.1- Identificação do arquivo de dados ARQ1.DAT (continuação)

\begin{tabular}{|c|c|c|c|}
\hline DADOS & IDENTIFICAÇÃO & UNIDADE & FORMATO \\
\hline DELTAX & $\begin{array}{l}\text { distância entre cabos na } \\
\text { direção } x\end{array}$ & $\mathrm{~m}$ & F6.2 \\
\hline DELTAY & $\begin{array}{l}\text { distância entre cabos na } \\
\text { direção y }\end{array}$ & $\mathrm{m}$ & F6.2 \\
\hline EX & $\begin{array}{l}\text { módulo de elasticidade lon- } \\
\text { gitudinal dos cabos na direção } \\
\text { do eixo } x ; E X=\text { constante. }\end{array}$ & $\mathrm{kN} / \mathrm{cm}^{2}$ & F8.2 \\
\hline EY & $\begin{array}{l}\text { módulo de elasticidade dos } \\
\text { cabos na direção do eixo y, } \\
E Y=\text { constante }\end{array}$ & $\mathrm{kN} / \mathrm{cm}^{2}$ & F8.2 \\
\hline $\mathrm{HXO}$ & $\begin{array}{l}\text { força de protensão inicial na } \\
\text { direção do eixo } x\end{array}$ & $\mathrm{kN} / \mathrm{m}$ & F6.2 \\
\hline HYO & $\begin{array}{l}\text { força de protensão inicial na } \\
\text { direção do eixo y }\end{array}$ & $\mathrm{kN} / \mathrm{m}$ & F6.2 \\
\hline G & carregamento permanente & $\mathrm{kN} / \mathrm{m}^{2}$ & F6.4 \\
\hline SN & carregamento acidental & $\mathrm{kN} / \mathrm{m}^{2}$ & F6.4 \\
\hline DELTAT & Variação de temperatura & ${ }^{\circ} \mathrm{C}$ & 13 \\
\hline ALFAT & $\begin{array}{l}\text { coeficiente de dilatação térmica } \\
\text { do material do cabo. }\end{array}$ & $\mathrm{m} \cdot{ }^{\circ} \mathrm{C}^{-1}$ & F8.6 \\
\hline$Q$ & carga devido ao vento & $\mathrm{kN} / \mathrm{m}^{2}$ & F6.4 \\
\hline
\end{tabular}


Tabela 3.2- Identificação do arquivo de dados ARQ2.DAT

\begin{tabular}{lll}
\hline DADOS & \multicolumn{1}{c}{ IDENTIFICAÇÃo } & FORMATO \\
\hline NOIJ (J) & $\begin{array}{l}\text { nó inicial em x, para cada linha } \\
\text { da malha na direção do eixo y. }\end{array}$ & 13 \\
NOFJ (J) & $\begin{array}{l}\text { nó final em x, para cada linha } \\
\text { da malha na direção do eixo y. }\end{array}$ & 13 \\
NOII (I) & $\begin{array}{l}\text { nó inicial em y, para cada linha } \\
\text { da malha na direção do eixo } x .\end{array}$ & 13 \\
NOFI (I) & $\begin{array}{l}\text { nó final em y, para cada linha } \\
\text { da malha na direção do eixo } x .\end{array}$ & 13 \\
\hline
\end{tabular}

\section{6- Saída de Resultados}

Os resultados são obtidos em arquivos que são:

ARQ1.SAI, coordenadas dos nós da malha arbitrada e componentes horizontais dos esforços preliminares.

ARQ2.SAI, deslocamentos dos nós

ARQ3.SAI, componentes horizontais dos esforços finais nos cabos. 


\section{7- Exemplo de Aplicação Numérica}

Considera-se como exemplo de aplicação numérica uma cesta de cabos protendidos cobrindo uma área irregular conforme Figura 3.1, OTTO (1972).
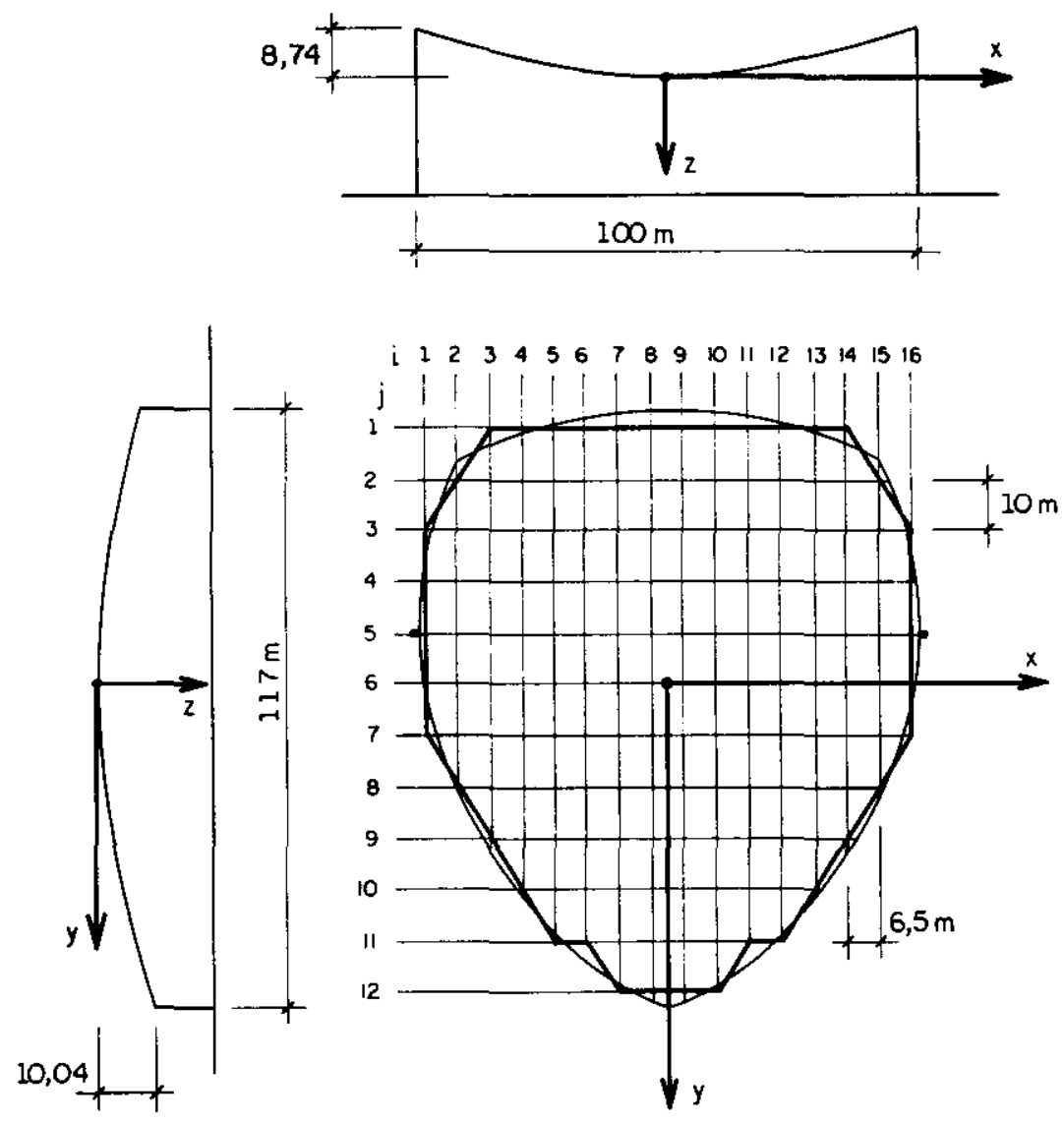

Figura 3.4- Planta da cesta protendida com dimensões principais, poligonal do contorno e malha adotadas. Exemplo 1.

Os cabos, em ambas direções, são de fios de aço em espiral, com diâmetros de $23 \mathrm{~mm}$ e tendo a seção transversal igual a $3,15 \mathrm{~cm}^{2}$ e módulo de elasticidade longitudinal igual a $15000,00 \mathrm{kN} / \mathrm{cm}^{2}$. A distância entre os cabos portantes, na direção do eixo $x$, é igual a $1,50 \mathrm{~m}$ e entre os cabos tensores é igual a $1,67 \mathrm{~m}$. 
A carga permanente é dada pelo peso da vedação propriamente dita igual a $34.10^{-2} \mathrm{kN} / \mathrm{m}^{2}$ e o peso próprio dos cabos e grampos igual a $4.10^{-2}$ $\mathrm{kN} / \mathrm{m}^{2}$.

Como carga acidental considera-se um valor de $75.10^{-2} \mathrm{kN} / \mathrm{m}^{2}$; uma variação de temperatura igual $a \pm 15^{\circ} \mathrm{C}$ e o coeficiente de dilatação térmica dos cabos igual a $1210^{-6} \mathrm{~m} .{ }^{\circ} \mathrm{C}^{-1}$; a protensão foi aplicada nos cabos na direção do eixo y com um valor igual a $75 \mathrm{kN} / \mathrm{m}$.

A seguir na Tabelas 3.3 e 3.4 , tem-se a entrada de dados do exemplo aqui exposto.

Tabela 3.3-ARQ1.DAT; Exemplo 1

\begin{tabular}{|c|c|c|}
\hline $48,7558,50-8,7410,04$ & $a, b, c, d$ & (4F6.2) \\
\hline $16126,5010,00$ & NX,NY,PX,PY & $(2 \mid 3,2 F 6.2)$ \\
\hline $7,50 \quad 5,00$ & TX, TY & $(2 F 6.2)$ \\
\hline $\begin{array}{llll}3,15 & 3,15 & 1,50 & 1,67\end{array}$ & SX,SY,DELTAX,DELTAY & (4F6.2) \\
\hline $15000,0015000,00$ & EX,EY & $(2 F 8.2)$ \\
\hline $0,0075,00$ & HXO,HYO & $(2 F 6.2)$ \\
\hline 0,3800 & G & (F6.4) \\
\hline 0,7500 & SN & (F6.4) \\
\hline $15 \quad 0,000012$ & DELTAT,ALFAT & $(13, F 8.6)$ \\
\hline 1,530 & $Q$ & (F6.4) \\
\hline
\end{tabular}


Tabela 3.4- ARQ2.DAT; Exemplo 1

\begin{tabular}{|c|c|c|c|}
\hline 2 & 15 & $\operatorname{NOIJ}(2) . \operatorname{NOFJ}(2)$ & $(2 \mid 3)$ \\
\hline 1 & 16 & $\operatorname{NOIJ(3).~NOFJ(3)~}$ & $(2 \mid 3)$ \\
\hline 1 & 16 & $\operatorname{NOIJ}(4)$. NOFJ(4) & $(2 \mid 3)$ \\
\hline 1 & 16 & $\operatorname{NOIJ(5).~NOFJ(5)~}$ & $(2 \mid 3)$ \\
\hline 1 & 16 & $\operatorname{NOIJ}(6) . \operatorname{NOFJ}(6)$ & $(2 \mid 3)$ \\
\hline 1 & 16 & $\operatorname{NOIJ}(7) . \operatorname{NOFJ}(7)$ & $(2 \mid 3)$ \\
\hline 2 & 15 & NOIJ(8). NOFJ(8) & $(2 \mid 3)$ \\
\hline 3 & 14 & $\operatorname{NOIJ}(9) . \operatorname{NOFJ}(9)$ & $(2 \mid 3)$ \\
\hline 4 & 13 & NOIJ(10).NOFJ(10) & $(2 \mid 3)$ \\
\hline 6 & 11 & NOIJ(11). NOFJ(11) & $(2 \mid 3)$ \\
\hline 2 & 8 & NOII (2), NOFI (2) & $(2 \mid 3)$ \\
\hline 1 & 9 & NOII (3), NOFI (3) & $(2 \mid 3)$ \\
\hline 1 & 10 & NOII (4), NOFI (4) & $(2 \mid 3)$ \\
\hline 1 & 11 & NOII (5), NOFI (5) & $(2 \mid 3)$ \\
\hline 1 & 11 & NOII (6), NOFI (6) & $(2 \mid 3)$ \\
\hline 1 & 12 & NOII (7), NOFI (7) & $(2 \mid 3)$ \\
\hline 1 & 12 & NOII (8), NOFI (8) & $(213)$ \\
\hline 1 & 12 & NOll (9), NOFI (9) & $(2 \mid 3)$ \\
\hline 1 & 12 & NOII (10), NOFI (10) & $(213)$ \\
\hline 1 & 11 & NOII (11), NOFI (11) & $(2 \mid 3)$ \\
\hline 1 & 11 & NOII (12), NOFI (12) & $(213)$ \\
\hline 1 & 10 & NOII (13), NOFI (13) & $(2 \mid 3)$ \\
\hline 1 & 9 & NOII (14), NOFI (14) & $(2 \mid 3)$ \\
\hline 2 & 8 & NOll (15), NOFI (15) & $(2 \mid 3)$ \\
\hline
\end{tabular}

$\mathrm{Na}$ tabela 3.5 apresentam-se os resultados obtidos nos arquivos de saída para a carga permanente. 
Tabela 3.5- Deslocamentos e esforços devido ao carregamento permanente.

\begin{tabular}{|c|c|c|c|c|c|c|c|c|}
\hline \multicolumn{9}{|c|}{$w(\mathrm{~cm})$} \\
\hline & 2 & 3 & 4 & 5 & 6 & 7 & 8 & $H_{p x}$ \\
\hline 2 & & 8,69 & 11,89 & 12,94 & 13,03 & 12,98 & 12,81 & 24,58 \\
\hline 3 & 8,22 & 13,42 & 15,99 & 17,01 & 17,11 & 17,04 & 16,84 & 30,63 \\
\hline 4 & 9,68 & 14,70 & 17,09 & 18,06 & 18,17 & 18,12 & 17,94 & 32,99 \\
\hline 5 & 9,80 & 14,83 & 17,25 & 18,30 & 18,52 & 18,56 & 18,42 & 33,54 \\
\hline 6 & 9,37 & 14,31 & 16,90 & 18,21 & 18,70 & 18,96 & 18,94 & 33,46 \\
\hline 7 & 9,61 & 12,59 & 15,75 & 17,72 & 18,77 & 19,43 & 19,61 & 32,32 \\
\hline 8 & & 7,58 & 12,56 & 15,87 & 17,89 & 19,22 & 19,75 & 31,55 \\
\hline 9 & & & 7,46 & 12,63 & 15,88 & 18,18 & 19,23 & 19,87 \\
\hline 10 & & & & 7,55 & 11,61 & 15,52 & 17,42 & 26,22 \\
\hline 11 & & & & & & 9,12 & 17,42 & 26,22 \\
\hline$H_{p y}$ & $-12,11$ & $-17,30$ & $-20,45$ & $-21,99$ & $-23,81$ & $-23,93$ & $-24,80$ & $\mathrm{kN} / \mathrm{m}$ \\
\hline
\end{tabular}

Nas Tabelas 3.6 e 3.7 apresentam-se os esforços calculados e os esforços máximos e mínimos obtidos com a combinação dos carregamentos. 
Tabela 3.6- Esforços Finais nos Cabos, direção do eixo $x$

\begin{tabular}{|c|c|c|c|c|c|c|c|c|c|c|}
\hline \multirow[b]{2}{*}{ CARREGAMENTO } & \multicolumn{10}{|c|}{$\mathrm{Hx}(\mathrm{kN} / \mathrm{m})$} \\
\hline & 2 & 3 & 4 & 5 & 6 & 7 & 8 & 9 & 10 & 11 \\
\hline PROTENSÃO & 60,00 & 60,00 & 60,00 & 60,00 & 60,00 & 60,00 & 60,00 & 60,00 & 60,00 & 60,00 \\
\hline PERMANENTE & 23,95 & 29,84 & 32,14 & 32,68 & 32,60 & 31,49 & 30,74 & 20,11 & 25,54 & 19,21 \\
\hline SOBRECARGA & 47,27 & 58,90 & 63,44 & 64,50 & 64,33 & 62,15 & 60,68 & 57,45 & 50,41 & 37,91 \\
\hline $\begin{array}{l}\text { VARIAÇÄO DE } \\
\text { TEMPERATURA }\end{array}$ & $\pm 4,92$ & $\pm 4,74$ & $\pm 4,74$ & $\pm 4,74$ & $\pm 4,66$ & $\pm 4,69$ & $\pm 4,71$ & $\pm 4,88$ & $\pm 4,88$ & $\pm 5,07$ \\
\hline VENTO (sucção) & $-96,44$ & $-120,15$ & $-129,41$ & $-131,58$ & $-131,25$ & $-126,80$ & $-123,79$ & $-117,19$ & $-102,85$ & $-77,35$ \\
\hline PROT.+PERM. & 83,95 & 89,84 & 92,14 & 92,68 & 92,60 & 91,49 & 90,74 & 89,11 & 85,54 & 79,21 \\
\hline $\mathrm{H} \times \mathrm{MAX}$ & 136,14 & 153,48 & 160,25 & 161,59 & 161,59 & 158,33 & 156,13 & 151,32 & 140,83 & 122,19 \\
\hline $\mathrm{H} \times \mathrm{MIN}$. & $-17,41$ & $-35,05$ & $-41,94$ & $-43,31$ & $-43,31$ & $-40,00$ & $-37,76$ & $-32,84$ & $-22,19$ & $-3,21$ \\
\hline
\end{tabular}


Tabela 3.7- Esforços finais nos cabos, direção do eixo y

\begin{tabular}{lccccccc}
\hline \multicolumn{7}{c}{ Hy $(\mathrm{kN} / \mathrm{m})$} \\
\hline CARREGAMENTO & 2 & 3 & 4 & 5 & 6 & 7 & 8 \\
\hline PROTENSÃO & 75,20 & 75,20 & 75,20 & 75,20 & 75,20 & 75,20 & 75,20 \\
PERMANENTE & $-11,80$ & $-16,86$ & $-19,92$ & $-21,44$ & $-23,20$ & $-23,31$ & $-24,17$ \\
SOBRECARGA & $-23,29$ & $-33,27$ & $-39,32$ & $-42,31$ & $-45,79$ & $-46,01$ & $-47,70$ \\
VARIAÇÃO DE & $\pm 5,46$ & $\pm 5,62$ & $\pm 5,71$ & $\pm 5,76$ & $\pm 5,81$ & $\pm 5,82$ & $\pm 5,84$ \\
TEMPERATURA & & & & & & & \\
VENTO (sUCção) & 47,52 & 67,87 & 80,21 & 86,30 & 93,42 & 93,87 & 97,31 \\
PROT.+PERM. & 63,40 & 58,34 & 55,28 & 53,76 & 52,00 & 51,89 & 51,03 \\
\hline Hy MAX. & 93,09 & 98,56 & 101,88 & 103,51 & 105,44 & 105,57 & 106,48 \\
Hy MIN. & 57,94 & 52,72 & 49,57 & 48,00 & 46,19 & 46,07 & 45,19 \\
\hline
\end{tabular}




\section{EXEMPLOS NUMÉRICOS}

Neste capítulo são apresentados exemplos numéricos utilizando-se as formulaçōes propostas neste trabalho e os resultados são comparados com resultados obtidos por outros processos de cálculo.

\section{1- Exemplo 2}

Considere-se um modelo de cesta de planta retangular, esquematizada conforme Figura 4.1, cujos dados foram obtidos em MØLLMANN \& MORTENSEN (1966). O modelo equivale a uma estrutura real em uma escala de 1:60.

Assume-se que os cabos se encontram na posição inicial, já protendida, conforme indica-se na Figura 4.1, sendo 28 cabos portantes e 9 cabos tensores dispostos de modo a formar uma superfície com a forma de um parabolóide hiperbólico.

Os cabos portantes, na direção do eixo x, estão espaçados de 5,29 $\mathrm{cm}$ e os cabos tensores, na direção do eixo y, de $10,53 \mathrm{~cm}$.

Em ambas direções os cabos têm seção transversal igual a 6,79.10-5 $\mathrm{cm}^{2}$ e módulo de elasticidade de $21537,20 \mathrm{kN} / \mathrm{cm}^{2}$.

O esforço de protensão previamente aplicado nos cabos tensores tem valor igual a $2,31.10^{-2} \mathrm{kN} / \mathrm{m}$. Admite-se um carregamento permanente de $1,058.10^{-6} \quad \mathrm{kN} / \mathrm{cm}^{2} \quad\left(0,1058 \mathrm{~g} / \mathrm{cm}^{2}\right)$ e uma sobrecarga de $1,753 \quad 10^{-6}$ $\mathrm{kN} / \mathrm{cm}^{2}\left(0,1753 \mathrm{~g} / \mathrm{cm}^{2}\right)$.

Para a resolução a malha arbitrada é coincidente com a posição dos cabos, portanto os resultados obtidos são os que realmente ocorrem na estrutura de cabos. 


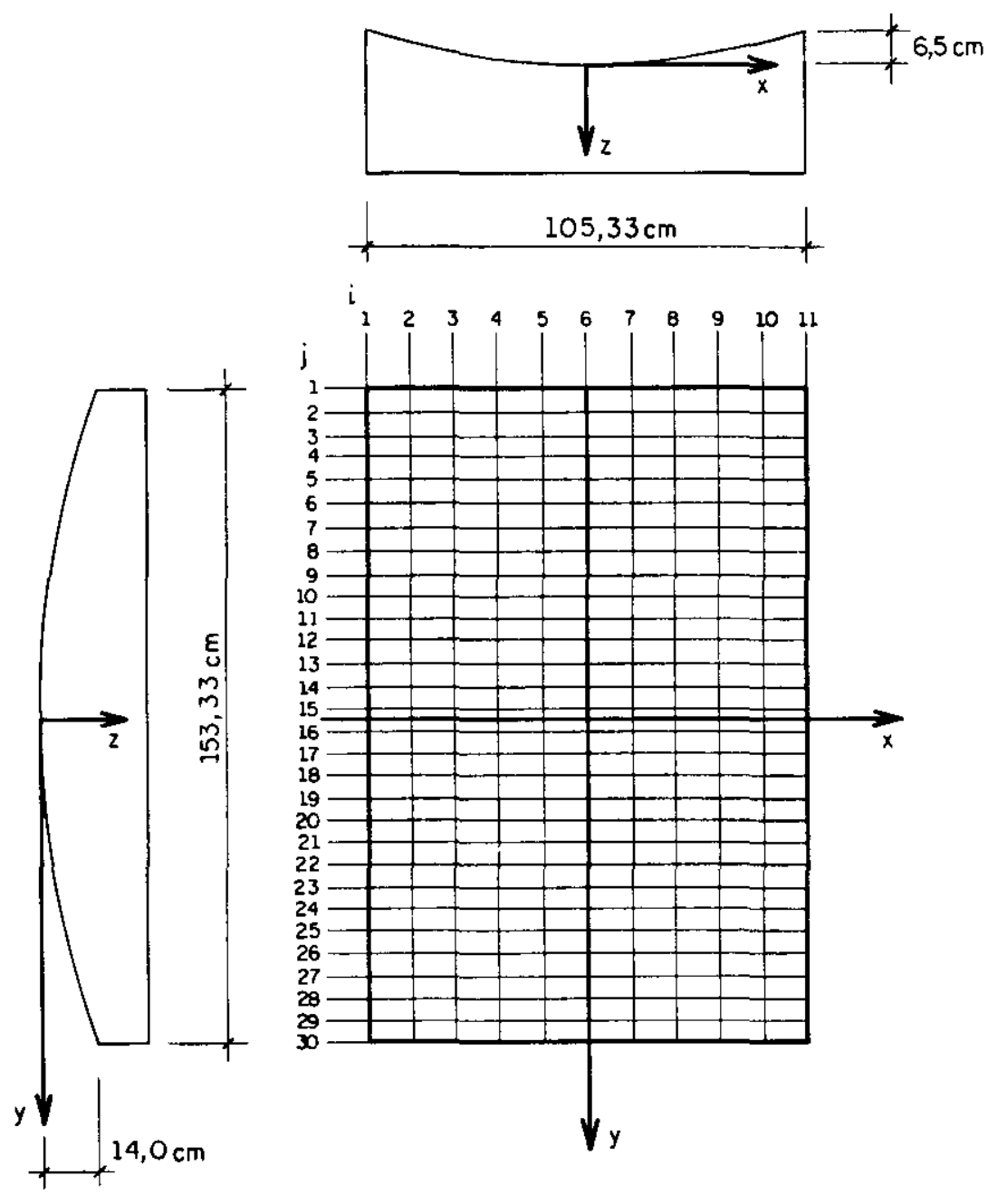

Figura 4.1- Características geométricas e malha arbitrada. Exemplo 2.

A Tabela 4.1 mostra os resultados obtidos, os deslocamentos e as componentes horizontais dos esforços nos cabos, para o caso de carregamento que corresponde a carga permanente mais carga acidental distribuídas sobre toda a superfície. Na Tabela são os valores mostrados em negrito.

Ainda na Tabela 4.1 têm-se os valores obtidos por MØLLMANN \& MORTENSEN (1966) segundo o estudo das cestas protendidas como um sistema estrutural discreto, maiores detalhes sobre o método de cálculo utilizado podem ser encontrados neste mesmo artigo supracitado. 
Tabela 4.1- Deslocamentos e Esforços obtidos através da Análise do Meio Contínuo, e Deslocamentos obtidos por MØLLMANN \& MORTENSEN (1966).

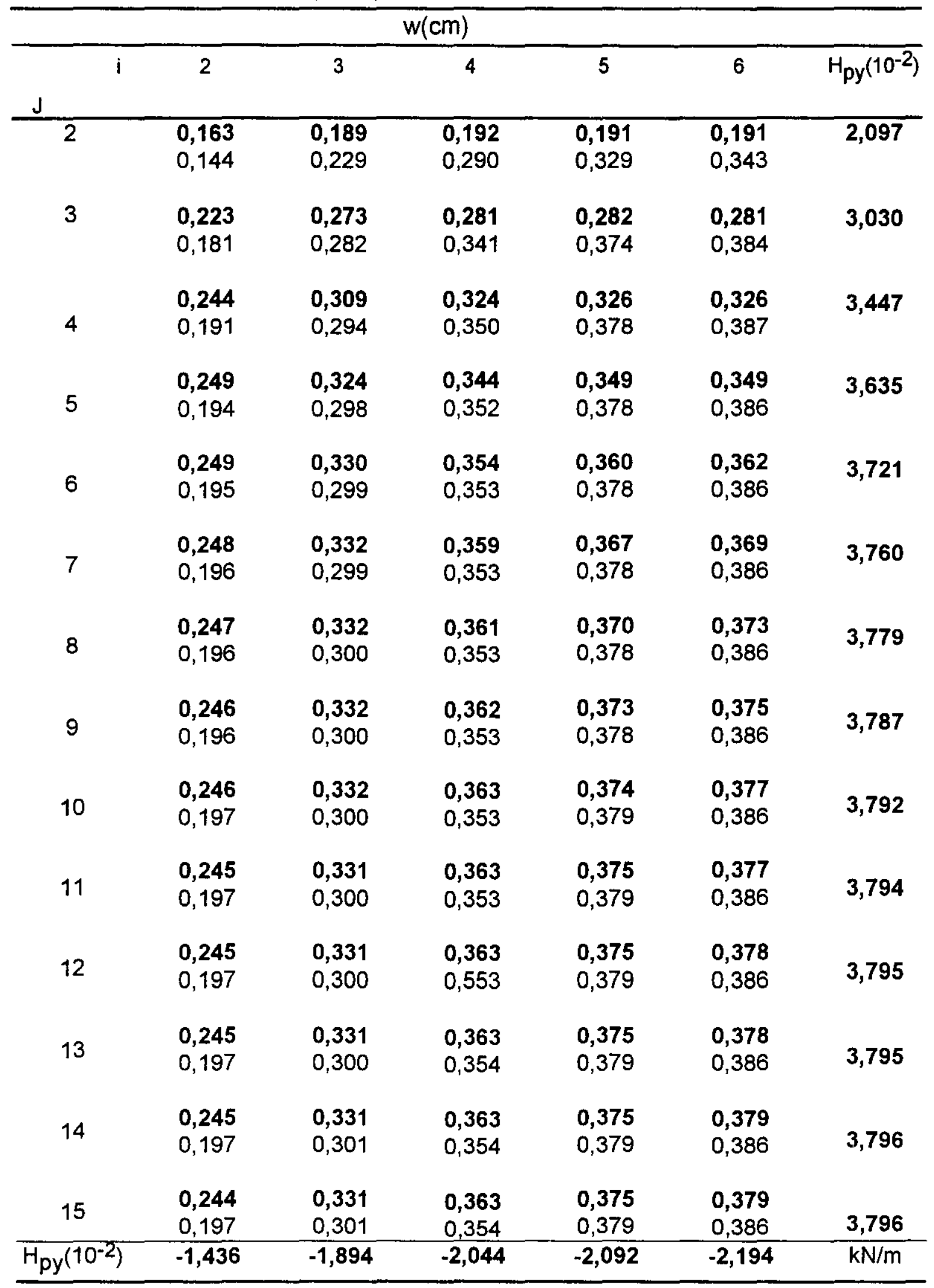


Estes resultados foram comparados com os obtidos através de medidas realizadas em um modelo análogo ao indicado na Figura 4.1 executado no Laboratório de Pesquisa Estrutural da Technical University da Dinamarca. Os testes são descritos com maiores detalhes em ASKEGAARD et al. (1966).

Os resultados obtidos experimentalmente, os obtidos através do cálculo discreto e através do cálculo pela Técnica do Meio Contínuo são mostrados nas Figuras 4.2. e 4.3.

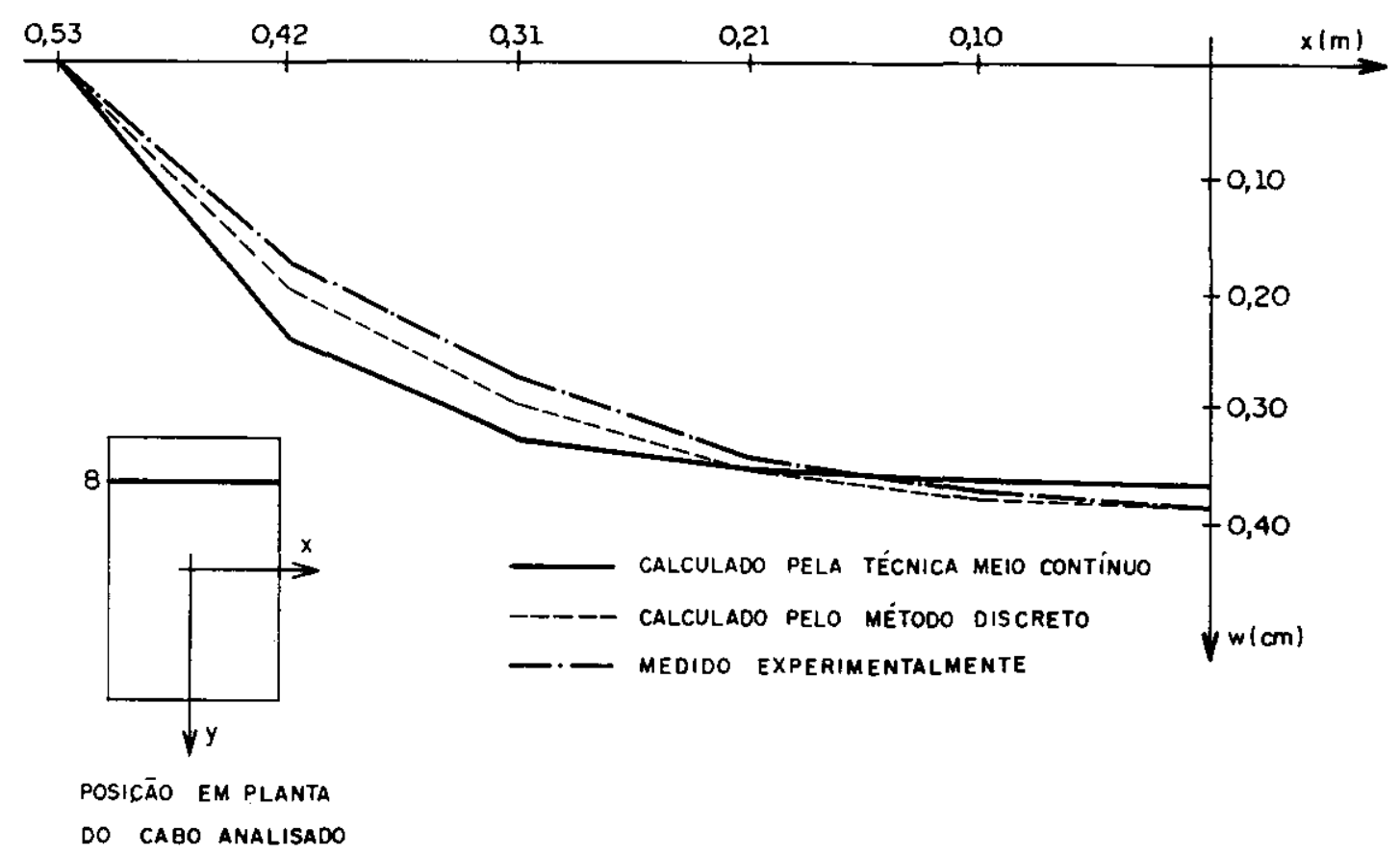

Figura 4.2- Deslocamentos obtidos para $y=0,40 \mathrm{~m}$

Em MøLLMANN (1965) foi analisado o mesmo modelo esquematizado na Figura 4.1 como um sistema contínuo. Desenvolveu-se aí uma solução analítica para uma cesta de cabos com superfície segundo um parabolóide hiperbólico para plantas retangulares e obteve-se assim equações aproximadas e simplificadas para este tipo estrutural específico. 


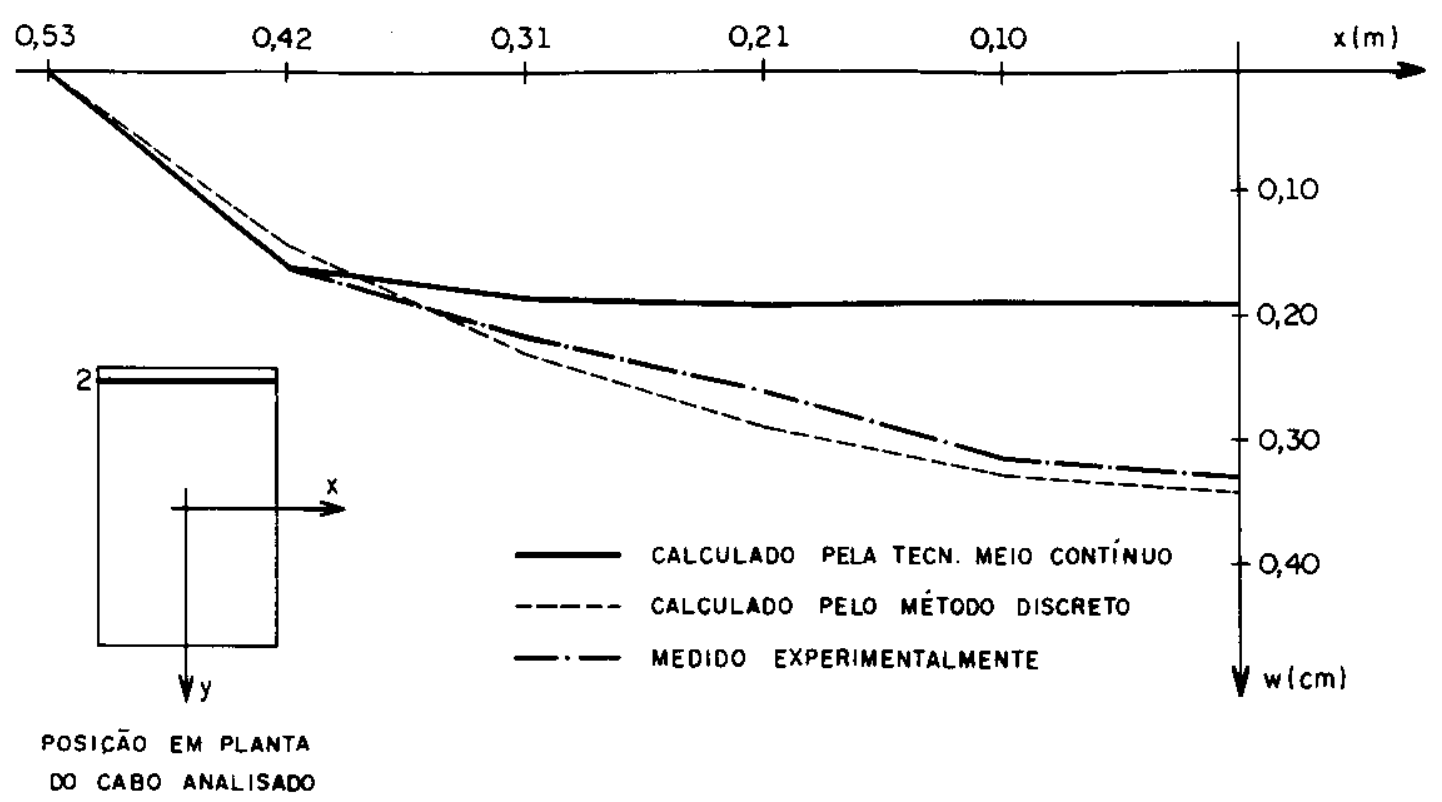

Figura 4.3- Deslocamentos obtidos para $y=0,72 \mathrm{~m}$
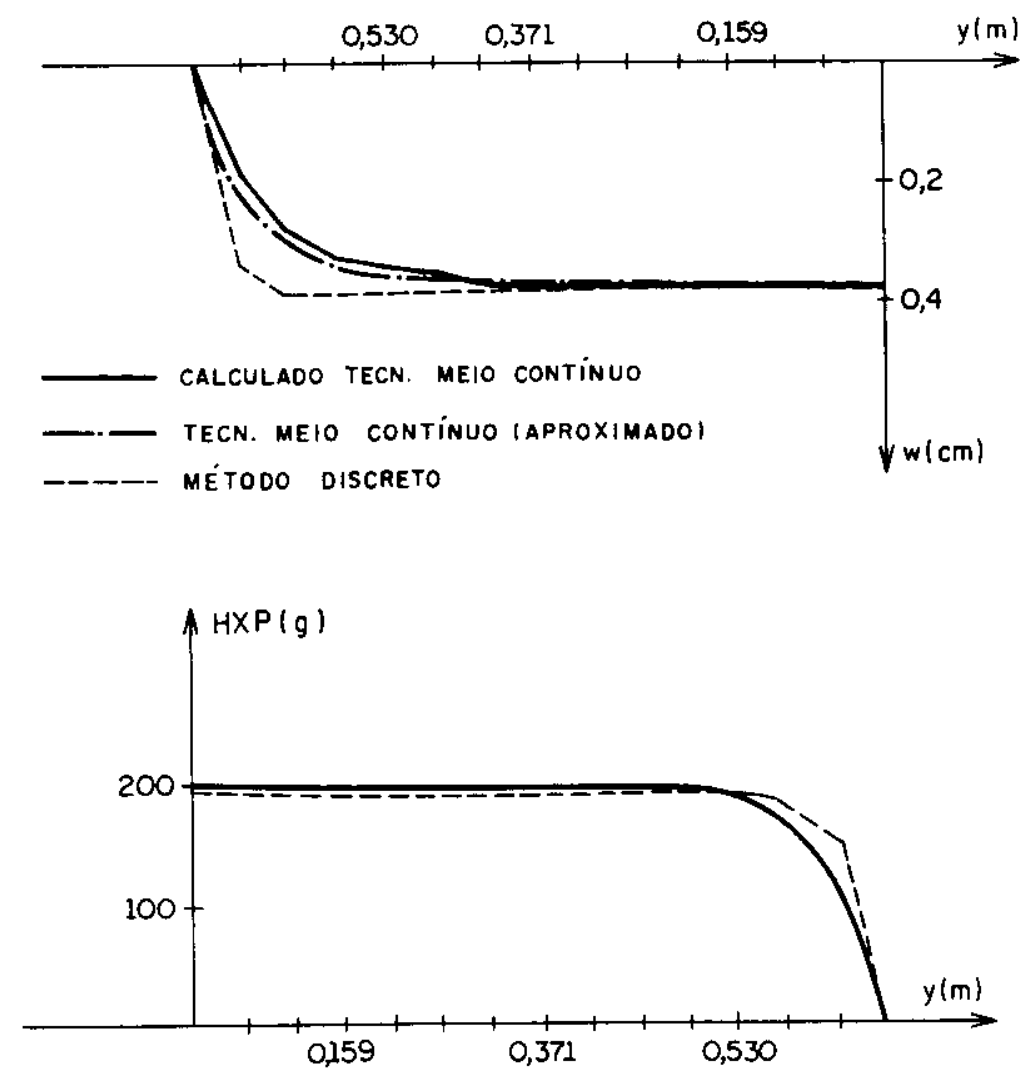

TECN. MEIO CONTÍNUO E TEC. MEIO CONTINUO IAPROXIMADOI MÉTODO DISCRETO

Figura 4.4- Deslocamentos e acréscimos de esforços para $\mathrm{x}=0 \mathrm{~m}$. 

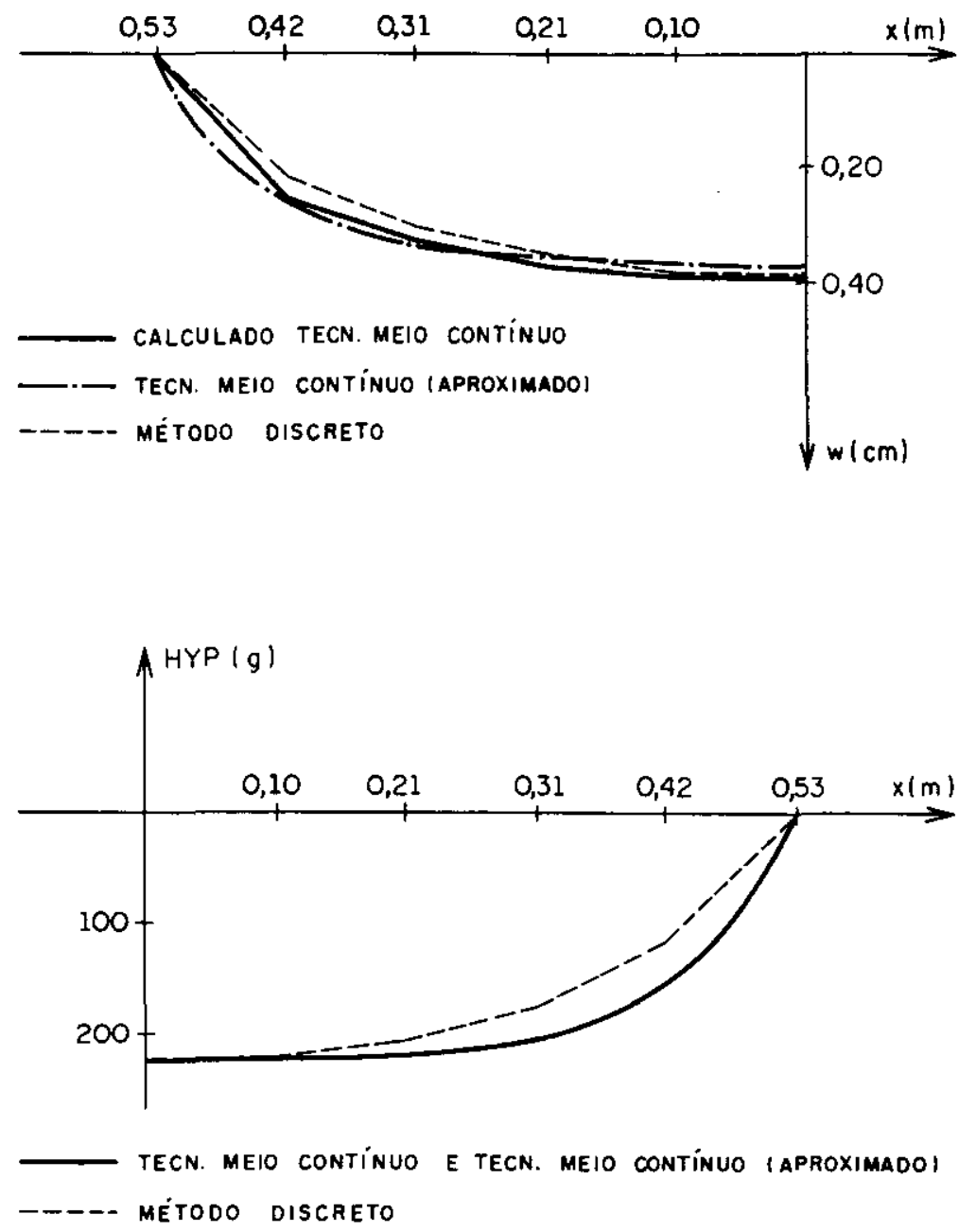

Figura 4.5- Desiocamentos e acréscimos de esforços para y $=0 \mathrm{~m}$

Nas Figuras 4.4 e 4.5 são mostrados os resultados obtidos para deslocamentos e acréscimos dos esforços nos cabos utilizando-se a Técnica do Meio Continuo empregada neste trabalho, os obtidos por MØLLMANN (1965) e por MØLLMANN \& MORTENSEN (1966).

Observa-se que as diferentes técnicas de cálculo utilizadas levaram a resultados extremamente próximos, mas ressalta-se que a formulação apresentada neste trabalho é válida para resolver estruturas suspensas independentemente da forma geométrica da planta a ser coberta, enquanto que a formulação aproximada apresentada por MØLLMANN (1965), embora utilizando Meio Contínuo, resolve apenas um parabolóide hiperbólico com contorno retangular. 


\section{2- Exemplo 3}

A estrutura mostrada na Figura 4.6, cujos dados obtidos em THORNTON \& BIRNSTIEL (1967) é formada por cabos de aço com seção transversal constante igual a $6,45 \mathrm{~cm}^{2}$ e módulo de elasticidade longitudinal igual a $16873,70 \mathrm{kN} / \mathrm{cm}^{2}$.

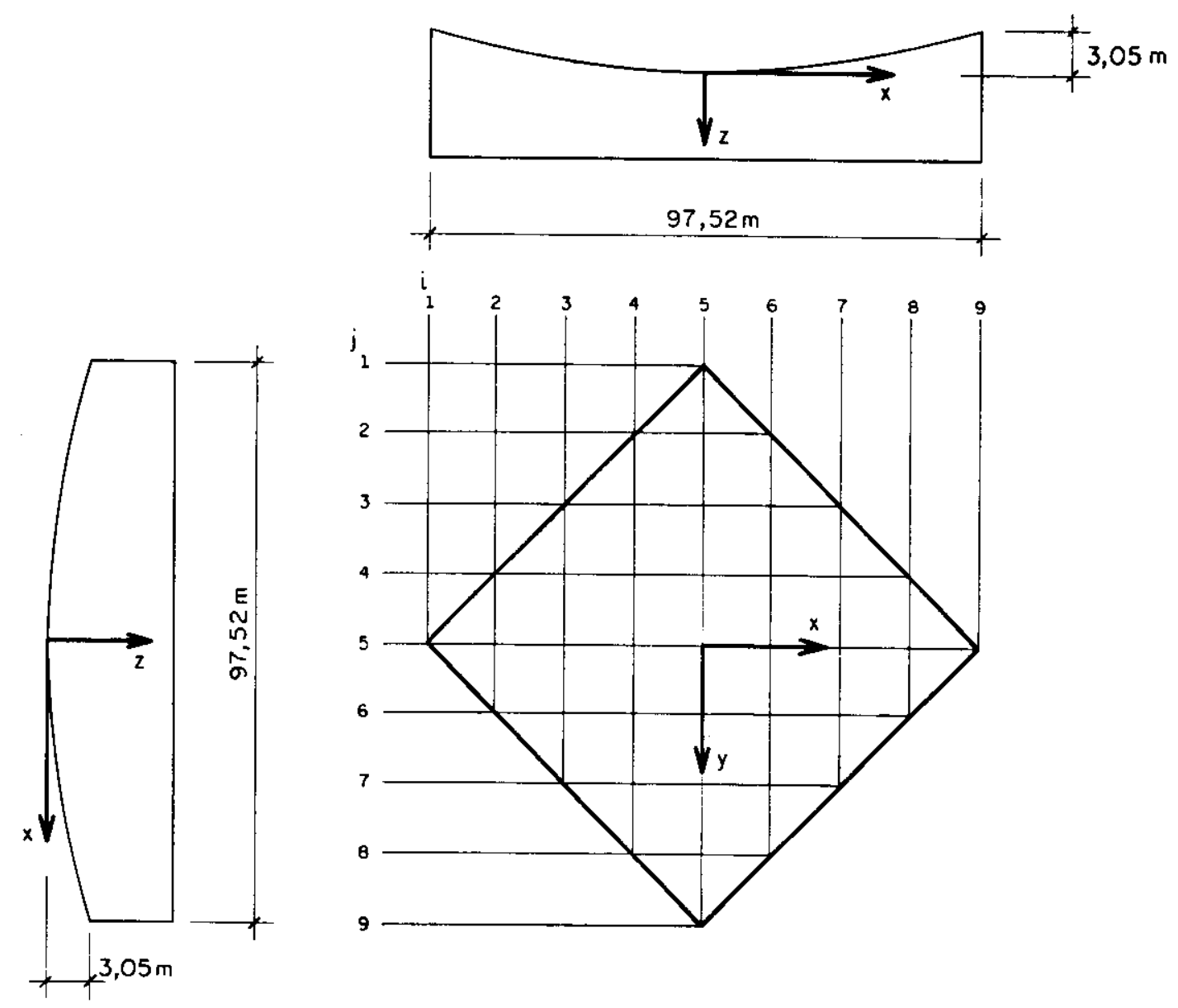

Figura 4.6- Características geométricas e malha arbitrada. Exemplo 3.

Estes cabos estão espaçados entre sí de 12,19 m em ambas direções e os que estão na direção do eixo y receberam um esforço de protensão igual a $18,6 \mathrm{kN} / \mathrm{m}$. Admite-se um carregamento uniformemente distribuido igual a $3,05.10^{-2} \mathrm{kN} / \mathrm{m}^{2}$.

Para a resolução do sistema de equações arbitrou-se uma malha coincidente com a posição dos cabos. 
Na Tabela 4.2 são mostrados os resultados obtidos para a estrutura submetida ao carregamento distribuído.

Tabela 4.2- Deslocamentos e Componentes Horizontais dos Esforços

\begin{tabular}{|c|c|c|c|c|c|}
\hline \multicolumn{6}{|c|}{$w(\mathrm{~cm})$} \\
\hline i & 2 & 3 & 4 & 5 & $H_{p x}$ \\
\hline \multicolumn{6}{|l|}{$J$} \\
\hline 2 & & & & 8,25 & 0,946 \\
\hline 3 & & & 12,79 & 17,56 & 2,469 \\
\hline 4 & & 12,79 & 21,06 & 24,13 & 3,495 \\
\hline 5 & 8,25 & 17,56 & 24,13 & 26,62 & 3,599 \\
\hline$H_{p y}$ & $-0,946$ & $-2,469$ & $-3,495$ & $-3,599$ & $\mathrm{kN} / \mathrm{m}$ \\
\hline
\end{tabular}

Em THORNTON \& BIRNSTIEL (1967) mostrou-se um estudo das estruturas suspensas através de Análise Matricial. A análise envolve a solução de grandes sistemas de equações não lineares.

Foram apresentados dois métodos de cálculo para a resolução do sistema de equações. Um deles, chamou-se de Método da Continuidade, e o outro de Método da Carga incremental. Maiores detalhes sobre os métodos podem ser obtidos neste mesmo artigo.

$\mathrm{Na}$ Figura 4.7 são mostrados os resultados dos deslocamentos obtidos neste trabalho pela Técnica do Meio Contínuo e pelos métodos utilizados em THORNTON \& BIRNSTIEL (1967).

Observa-se que nas diferentes técnicas utilizadas os resultados tiveram pequenas variações; em torno de $1,5 \%$ e 3,0\% entre os obtidos pela Técnica do Meio Contínuo e os obtidos pelo Método incremental de Carga e Método da Continuidade respectivamente. 


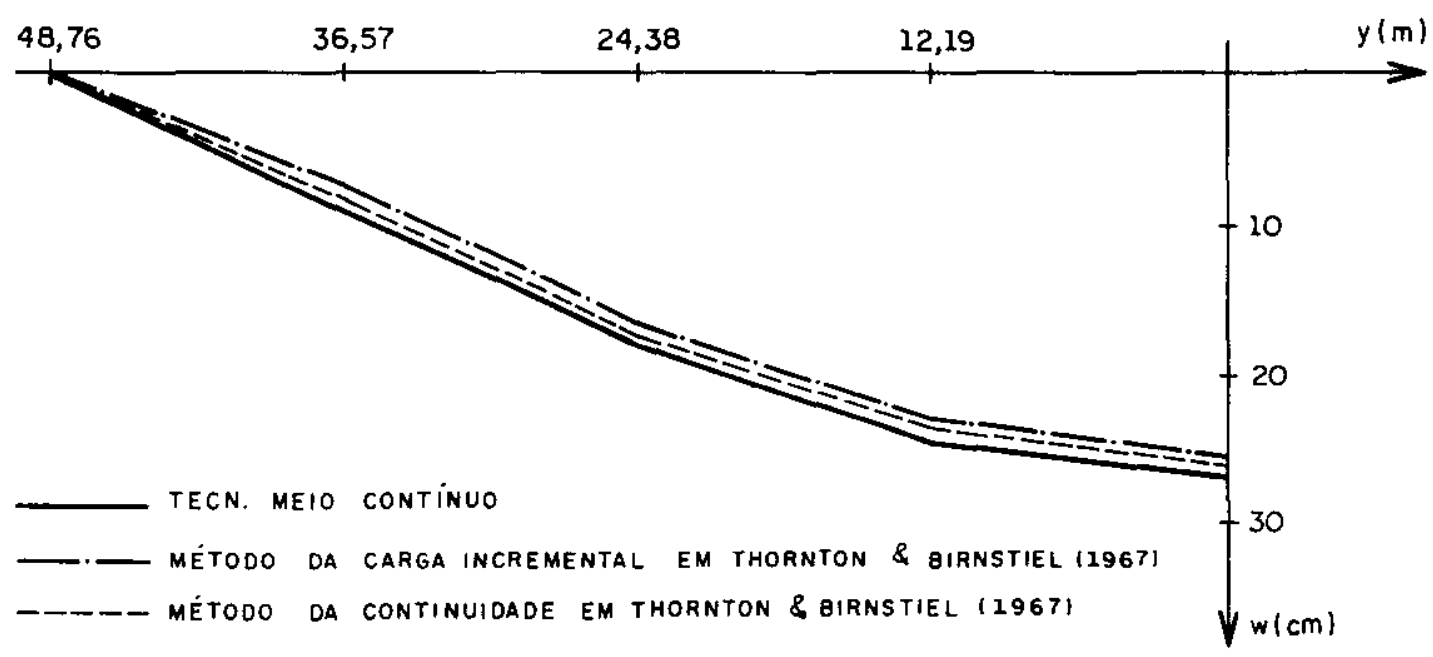

Figura 4.7- Deslocamentos obtidos para $x=0 \mathrm{~m}$. 


\section{CONSIDERAÇÕES FINAIS}

Através dos resultados obtidos neste trabalho evidencia-se a eficiência da Técnica do Meio Contínuo na Análise estrutural das coberturas pênseis. Nota-se que esta técnica é de fácil aplicação, exigindo do pesquisador apenas conhecimentos básicos a respeito da teoria da elasticidade, permitindo de maneira geral o emprego de métodos numéricos.

No entanto o estudo do comportamento estrutural das cestas protendidas por meio desta técnica conduz a um sistema de equações de difícil solução sendo necessário uma série de simplificações que permitam um tratamento não muito complexo do problema.

Estas simplificações iniciaram-se quando se expressou a deformação específica em função dos deslocamentos e de suas variações, equações (2.34) e (2.35)

Nas equações (2.44) e (2.45) descartaram-se as forças de protensão em relação ao módulo de rigidez E.A da membrana; cálculos práticos evidenciam que o valor do produto E.A é muito maior que o valor da protensão.

Para expressar a componente horizontal $\mathrm{H}$ como uma soma algébrica, $H_{0}+H_{p}$, e para levar o valor de $H$ nas equações de equilibrio descartaram-se $u^{\prime}$ e $z^{\prime} w^{\prime}$ e ainda $v^{\bullet}$ e $z^{*} w^{\bullet}$ em relação à unidade. Esta simplificação equivale a desprezar as rotações do elemento de membrana.

Após estas simplificações chegou-se nas equações (2.63.a), (2.63.b) e (2.63.c) que são equações não lineares em $u$, v e w.

Outras simplificações foram feitas no ítem 2.1.5 quando se fez a lineralização das equações de equilibrio (2.63.a), (2.63.b) e (2.63.c); os termos desprezados têm a dimensão de um carregamento distribuido e podem ser considerados como cargas adicionais, $p_{x}^{*}, p_{y}^{*}, p_{z}^{*}$.

Após os valores $H_{p x}, H_{p y}, u$, v e w terem sido determinados de acordo com as expressões já linearizadas, pode-se estimar a influência dos 
termos não lineares desprezados comparando-se as cargas adicionais $p^{*}$ com os valores de carga $p$ existentes.

Assim, determina-se a função $\beta^{*}(x, y)$ através da equação (2.85) considerando-se os valores de $\mathrm{p}^{*}$.

Se $\beta^{*}(x, y)$ não for desprezivel em relação a $\beta(x, y)$, determinam-se correções dadas por $H_{p x}^{*}, H_{p y}^{*}, u^{*}, v^{*}$ e $w^{*}$ que deverão ser acrescentadas aos valores obtidos através das equações lineares.

Cabe ainda observar que só depois de feitas as simplificações e com as equações devidamente combinadas é que chegou-se na equação integro-diferencial (2.75) que foi usada para resolver as cestas protendidas.

Para resolver esta equação empregou-se o Método das Diferenças Finitas utilizando-se um polinômio interpolador de segundo grau.

Todas estas aproximações não conduzem a erros significativos visto que os resultados obtidos neste trabalho, através do emprego de equações linearizadas, e comparados com os obtidos por processos matriciais e por análise experimental são muito próximos.

Os esforços e os deslocamentos da membrana também podem ser obtidos com o emprego da Teoria das Faixas Finitas (grelha). Para isto, divide-se a membrana em faixas de largura unitária dispostas transversalmente a aplicam-se para elas as equações do cabo livremente suspenso. A correspondência de esforços e desiocamentos das faixas e dos cabos é imediata.

O Método dos Elementos Finitos também pode ser empregado para analisar o comportamento da cesta.

Uma observação importante deve ainda ser feita em relação a protensão a ser aplicada inicialmente na cesta. A intensidade desta força deverá ser aquela que mantém a estrutura permanentemente tracionada.

$\mathrm{Na}$ aplicação numérica, exemplo 1 ítem 3.7, observa-se na Tabela 3.6 que houve um destracionamento dos cabos na direção do eixo $x$ quando levou-se em consideração os esforços devidos ao efeito de sucção do vento. Neste caso deve-se adotar um outro valor de protensão, maior do que $o$ anteriormente adotado, repetir o cálculo dos esforços e verificar se os cabos permanecem tracionados.

Assim, é muito importante que se faça uma escolha adequada do valor da protensão a ser aplicada, de maneira que, sob a ação das cargas nenhum cabo seja destracionado; embora em certos carregamentos de curta duração isto possa acontecer sem grandes prejuízos para a estrutura. 
Segundo estudos de BARBATO $(1994)^{\star}$ o valor da protensão pode ser estimado empregando-se as equações do cabo livremente suspenso admitindo-se, por simplicidade, que o tracionamento dos cabos seja feito por meio de deslocamentos impostos às suas extremidades através do uso de esticadores.

Também conforme PULINO (1991) a protensão pode ser introduzida por meio de alongamento de um ou mais cabos. Estes alongamentos são determinados através do processo de minimização da Energia Potencial Total.

Dando continuidade à pesquisa do comportamento das cestas protendidas é necessário que se faça um estudo mais detalhado para determinar a distribuição de forças devidas ao vento; um estudo sobre a deformabilidade do anel de contorno, que neste trabalho foi considerado como rígido; e ainda um estudo sobre o efeito das solicitações dinâmicas.

* BARBATO, R.L. A Estudo das coberturas pénseis. Notas de aulas; trabalho em andamento, 1994. 


\section{BIBLIOGRAFIA}

ASKEGAARD, V.; ALBERS,A.; MORTENSEN, P.L. (1966). Tests on a model of a cable roof. in: INTERNATIONALE TAGUNG FUR EXPERIMENTELLE SPANNUNGSANALYSE, 3, Berlin. Proceedings.

BARBATO, R.L.A. (1972). Sobre o comportamento estático dos cabos de coberturas pênseis. São Carlos. 90p. Dissertação (Mestrado) - Escola de Engenharia de São Carlos, Universidade de São Paulo.

BARBATO, R.L. A. (1991). Emprego de cabos livremente suspensos e cabos-treliça na construção de coberturas pênseis. São Carlos. Tese (Livre-Docência) - Escola de Engenharia de São Carlos, Universidade de São Paulo.

BRITO, J.A.P. (1987). Análise aproximada e não-linear, com visualização gráfica interativa, de estruturas suspensas de cabos protendidos para coberturas de grande vão. Rio de Janeiro. 186p. Dissertação (Mestrado) - Pontifícia Universidade Católica.

CABLE roof structures. (1968). Bethlehem Steel Corp. Bloklet 2318.

CARMO, M.P. (1976). Differential geometric of curves and surfaces. New Jersey, Prentice Hall.

DAVID, R.A.; BARBATO, R.L.A. (1991). Análise de cestas protendidas pelo processo do meio contínuo. In: JORNADAS SUL-AMERICANAS DE ENGENHARIA ESTRUTURAL, 25., Porto Alegre, 1991. Anais. v.2., p. 385-395. 
FRAGOSO, P.R. (1965). Considerações sobre coberturas suspensas. Estruturas, Rio de Janeiro, n. 57, p. 33-60.

IRVINE, H.M. (1991). Cable structures. Cambridge, The Massachusetts Institute of Technology. v.1

KRISHNA, P. (1978). Cable suspended roofs. New York, McGraw-Hill.

MAIER, G. (1963). Le tensostrutture: uno sguardo allo stadio attuale di sviluppo. Costruzioni Metalliche, n. 4, p. 180-189.

MAJOWIECKI, M. (1985). Tensostrutture: progetto e verifica. Milano, Cisia.

MARTINELLI, D.A.O. (1960). A observação da cobertura pênsil da exposição internacional da indústria e comércio. Revista Engenharia, $\mathrm{n}$. 217, p.219-228.

MERRITT, F.S. (1953). Curved roof on cables spans big arena. Engineering News-Record, n.50, p. 31-37.

MØLLMANN, H. (1965). A study in the theory of suspension structures. Copenhagen, Academisk Forlag.

MØLLMANN, H.; MORTENSEN, P.L. (1966). The analysis of prestressed suspended roofs (cable nets). In: INTERNATIONAL CONFERENCE ON SPACE STRUCTURES, Departament of civil Engineering, University of Surrey.

OTTO, F. (1972). Tensile structures. Cambridge, The Massachusetts Institute of Technology. $2 \mathrm{v}$.

PULINO FILHO, A.R. (1991). Contribuição ao estudo das coberturas pênseis. Campinas. 89p. Tese (Doutorado) - Faculdade de Engenharia Mecânica, Universidade Estadual de Campinas. 
SALES, J.J. (1988). Projeto e viabilidade econômica de coberturas pênseis com cabos-treliça. São Carlos. 151p. Dissertação (Mestrado) - Escola de Engenharia de São Carlos, Universidade de São Paulo.

SALVADORI, M.G.; BARON, M.L. (1961). Numerical methods in engineering. 2.ed. New Jersey, Prentice-Hall.

SANTOS NETTO, P. (1975). Contribuição ao estudo das coberturas pênseis cilíndricas não protendidas. São Carlos. 129p. Dissertação (Mestrado) - Escola de Engenharia de São Carlos, Universidade de São Paulo.

SCHLAICH, J.; SEIDEL, J. (1983). Ice skating hall at Munich (Fed. Rep. of Germany). IABSE Structures, n. 4, p. 78-79.

STRUIK, D.J. (1961). Geometria diferencial clasica. 2.ed. Madrid, Aguilar. $256 p$.

SUBCOMMITTEE ON CABLE. (1971). Suspended Structures of the Task Committee on Special Structures, of the Committee on Metals, of the Structural Division. Cable suspended roof construction state of the art. Journal of the Structural Division, ASCE, v.97, n. ST6, Proc. Paper 8190. p. 1715-1761.

THORNTON, C.S.; BIRNSTIEL C. (1967). Three - dimensional suspension structures. Journal of the Structural Division, ASCE, v.93, n. ST2, April, p. $247-270$. 


\section{APÊNDICE}

Programa em linguagem FORTRAN para a resolução de cestas protendidas. 


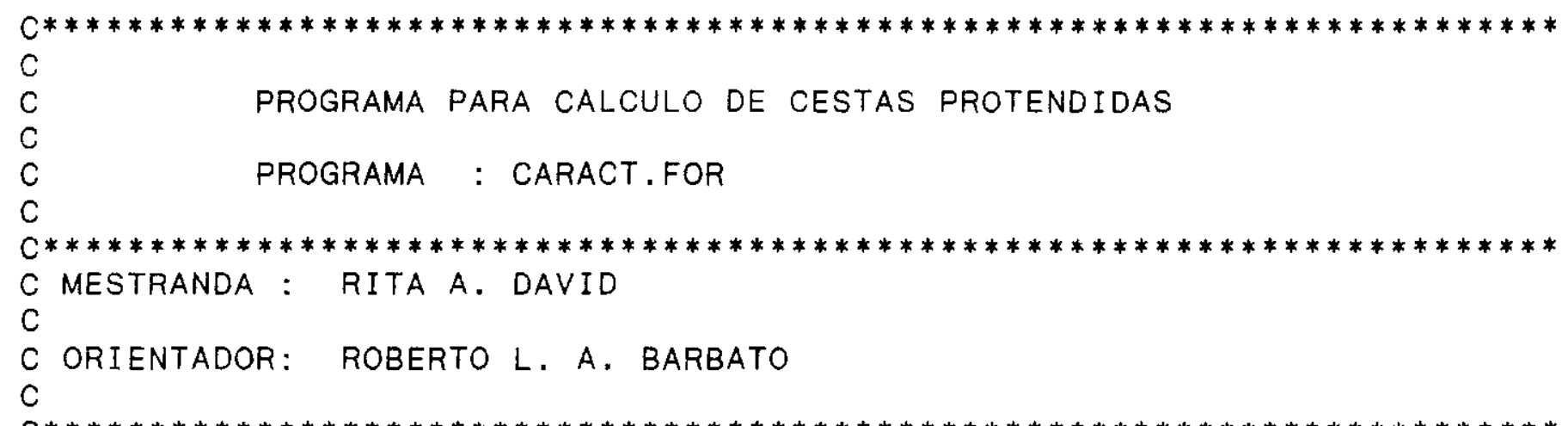

DIMENSION $X(50), Y(50), Z(50,50)$

REAL $a, b, c, d, P X, P Y, S X, S Y, D E L T A X, D E L T A Y, E X, E Y, H X O, G, S N, Q, A L F A T, X$ $\$, Y, Z, Z L, Z P, Z L L, Z P P, K X, K Y, F X, F Y, H Y O, C H I X, C H I Y, H X P, H Y P, H X P N, H Y P N$,

\$ HXPT, HYPT, HXPV, HYPV, RO, TX, TY, CX, CY

INTEGER NX,NY,DELTAT

$\mathrm{C}$

OPEN ( $2, F I L E=$ 'ARQ. DAT', STATUS= 'OLD')

$\operatorname{OPEN}(3, F I L E=$ 'ARQ. SAI', STATUS = 'NEW')

OPEN (UNIT $=4, F I L E=$ 'SAIDA 1 . DAD', ACCESS=' SEQUENT I AL', FORM= 'UNFORMATT $\$ E D^{\prime}$, STATUS= 'NEW')

OPEN (UNIT = 8, FILE= 'SAIDA2. DAD', ACCESS= 'SEQUENT I AL', FORM= 'UNFORMATT $\$ E D$ ', STATUS=' NEW')

OPEN (UNIT $=9$, FILE= 'SAIDA6. DAD', ACCESS=' SEQUENTIAL', FORM= 'UNFORMATT \$ED', STATUS= 'NEW' )

OPEN (UNI T =10, FI LE= 'SAIDA7. DAD', ACCESS=' SEQUENTIAL', FORM= 'UNFORMATT

$\mathrm{C}$ \$ED', STATUS='NEW')

$\mathrm{C}$

$\mathrm{C}$ CARACTERISTICAS GEOMETRICAS E MECANICAS DAS CESTAS

C-

$\mathrm{C}$

$\operatorname{READ}(2,3) a, b, c, d$

C

3 FORMAT ( $4 \mathrm{~F} 6.2)$

WRITE $(3,16)$

16 FORMAT ( $5 X$, 'COEFICIENTES DA SUPERFICIE', //)

WRITE $(3,13) a, b, c, d$

C

13 FORMAT ( $\left.5 \mathrm{X},{ }^{\prime} \mathrm{a}={ }^{\prime}, \mathrm{F} 6.2,3 \mathrm{X}, \mathrm{\prime}^{\mathrm{b}}=\mathrm{\prime}^{\prime}, \mathrm{F} 6.2,3 \mathrm{X},{ }^{\prime} \mathrm{c}={ }^{\prime}, \mathrm{F} 6.2,3 \mathrm{X}, \mathrm{\prime}^{\mathrm{d}} \mathrm{d}={ }^{\prime}, \mathrm{F} 6.2\right)$

$A=a * 2 / c$

$B=b * 2 / d$

C

WRITE $(3,4) \mathrm{A}, \mathrm{B}$

C

$4 \operatorname{FORMAT}\left(/ /, 5 X,{ }^{\prime} A=', F 8.3,5 X, ' B=,, F 8.3\right)$

$\operatorname{READ}(2,5) N X, N Y, P X, P Y$

5 FORMAT (2I3, 2F6.2)

READ $(2,14) T X, T Y$

14 FORMAT (2F6.2)

$C X=P X * T X$

$C Y=P Y * T Y$ 


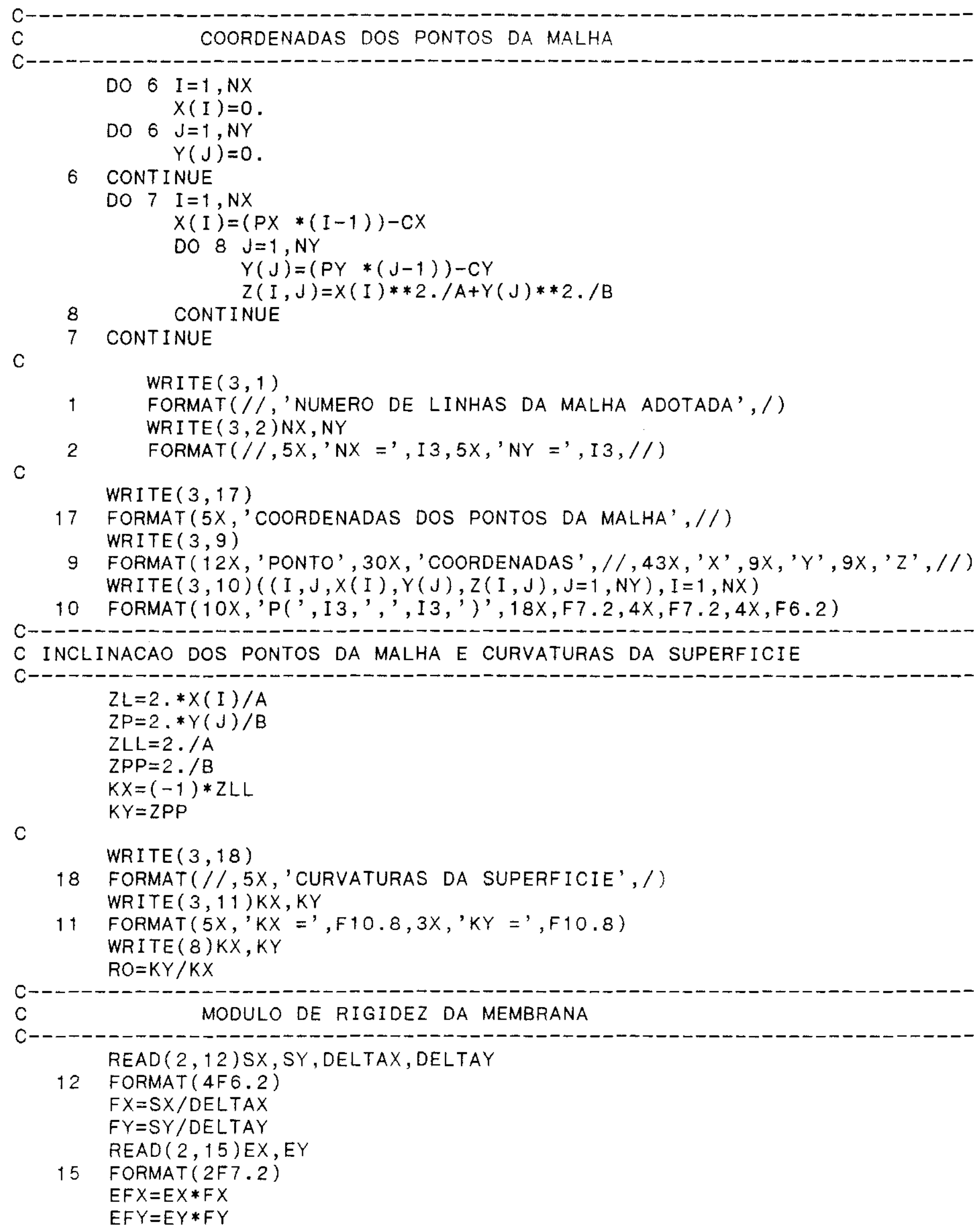




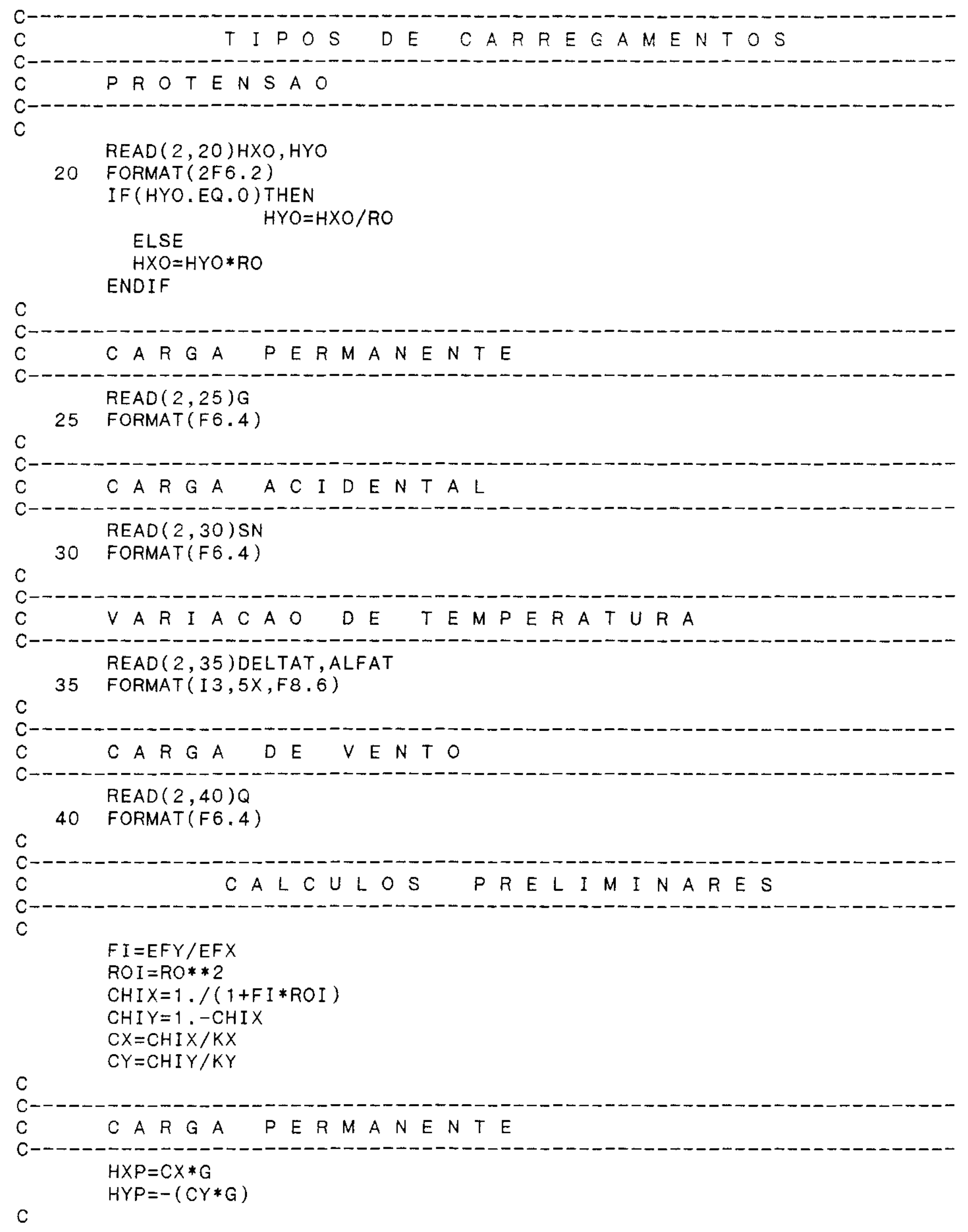




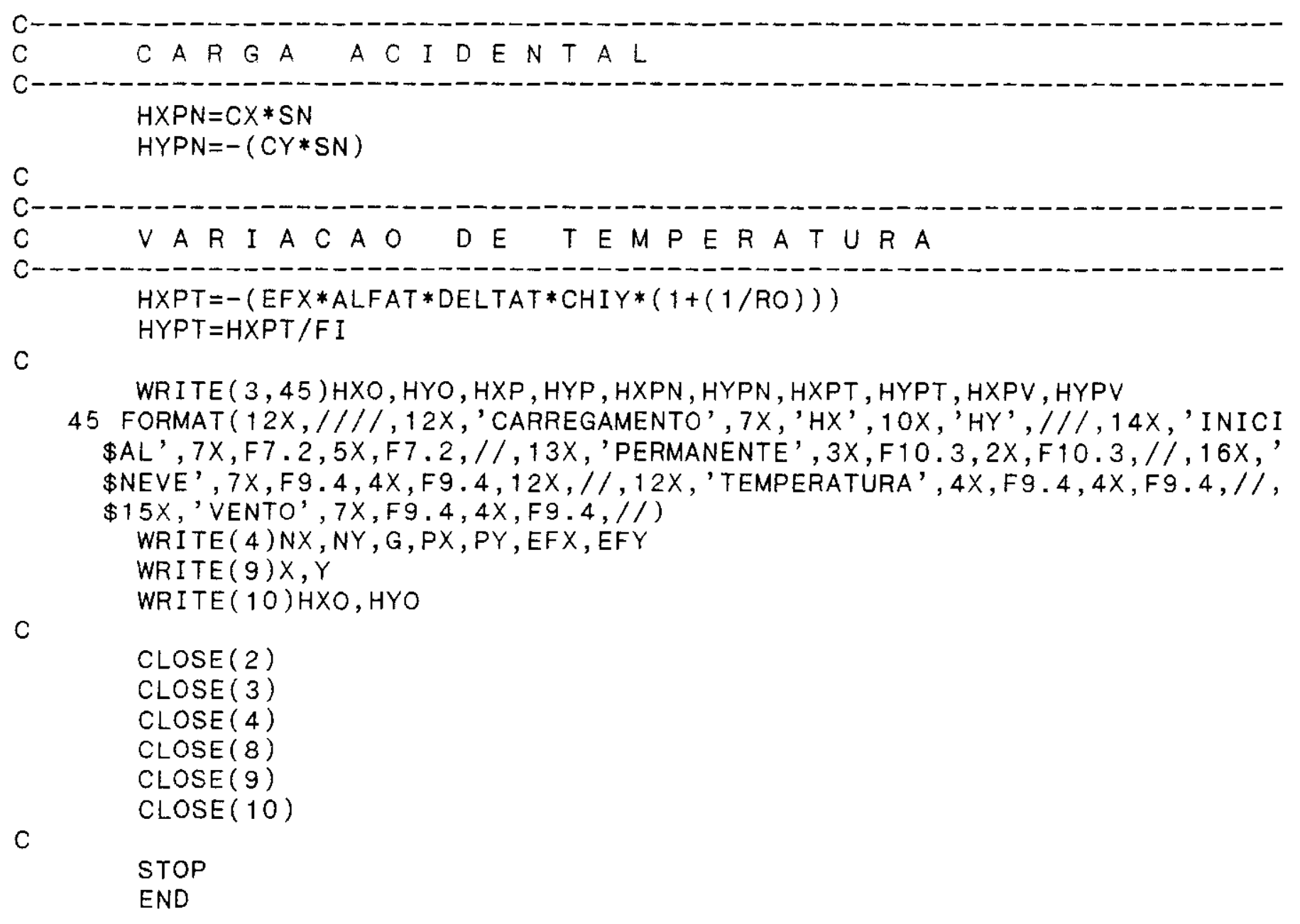




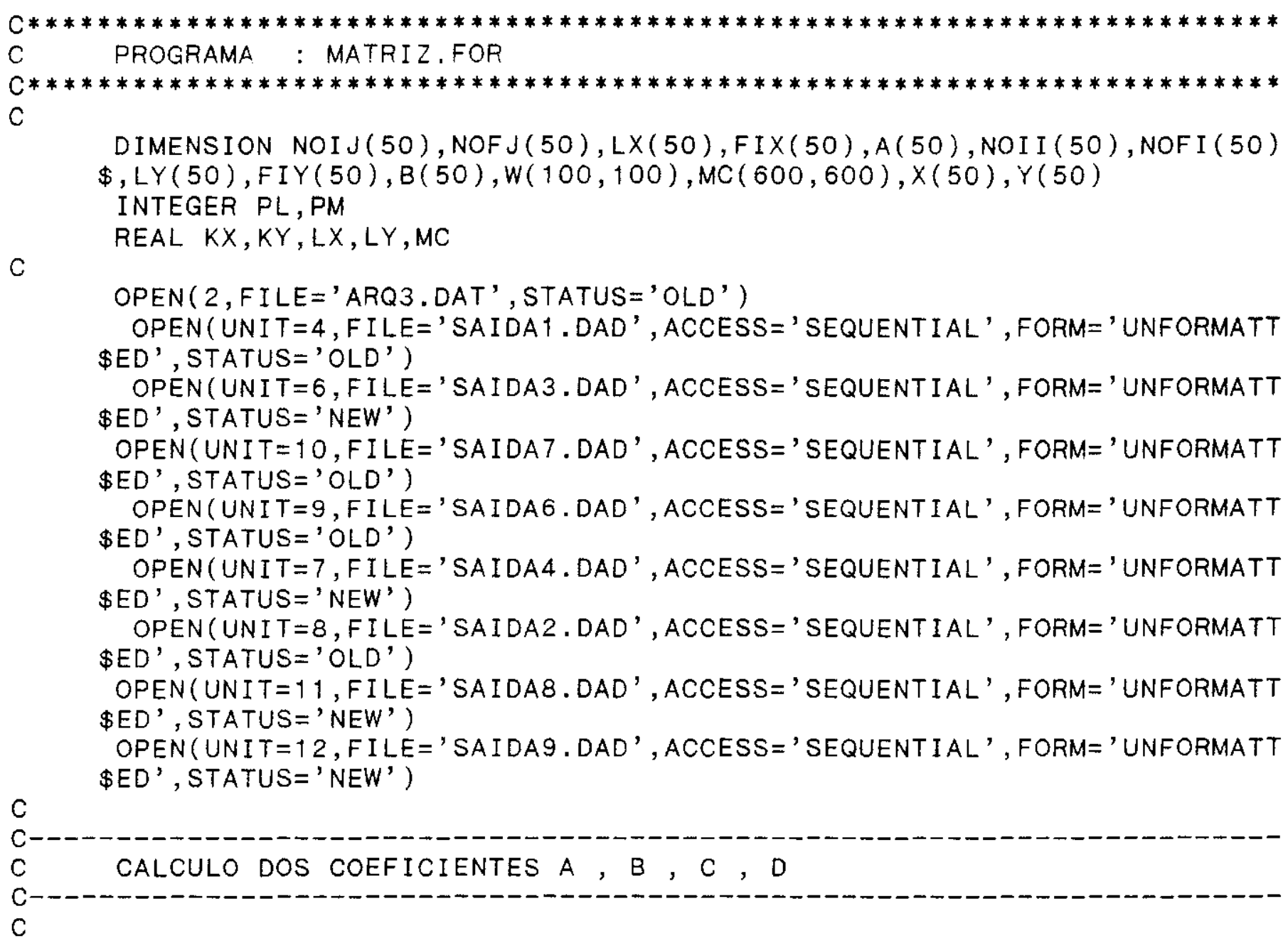

READ ( 4) NX, NY, G, PX, PY, EFX, EFY

$\operatorname{READ}(9) X, Y$

READ ( 10$) \mathrm{HXO}, \mathrm{HYO}$

C

READ ( 8 ) KX, KY

$M=N Y$

NNOST $=0$

DO $100 \mathrm{~J}=2, M-1$

$\operatorname{READ}(2,150)$ NOIJ $(\mathrm{J}), \operatorname{NOFJ}(\mathrm{J})$

FORMAT ( 2 I 3 )

WRITE $(*, *)$ NOIJ $(J), \operatorname{NOFJ}(J)$

C

C

NNOST $=$ NNOST $+(($ NOFJ $(J)-N O I J(J))-1$.

$L X(J)=X(N O F J(J))-X(N O I J(J))$

C

C

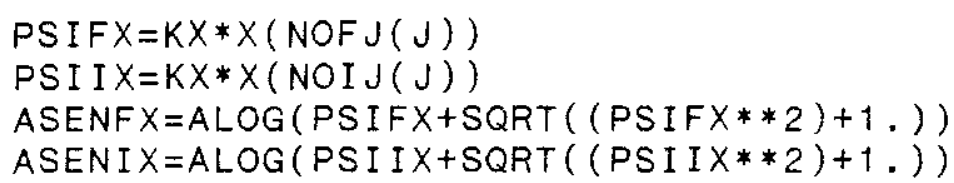


C

PLAMBFX $=(3 . * A S E N F X) /(8 . * P S I F X)+(1 . / 8) *.(5 .+2 . * P S I F X * * 2) * \operatorname{SQRT}(1 .+P$ $\$ S I F X * * 2)$

PLAMBIX $=(3 . * A S E N I X) /(8 . * P S I I X)+(1 . / 8) *.(5 .+2 . * P S I I X * * 2) * S Q R T(1 .+P$ $\$ S I I X * * 2)$

PCABX $=(X(\operatorname{NOFJ}(J)) * P L A M B F X-X(N O I J(J)) * P L A M B I X) / L X(J)$

$F I X(J)=E F X /(L X(J) * P C A B X)$

100 CONTINUE

$$
A(J)=10 . * K X * * 2 * P X * F I X(J)
$$

WRITE $(3,167) \mathrm{J}, \mathrm{A}(\mathrm{J})$

$\mathrm{N}=\mathrm{NX}$

FORMAT $\left(/, 10 X,{ }^{\prime} A(', I 3, ')=', 2 X, F 6.3\right)$

DO $200 \quad \mathrm{I}=2, \mathrm{~N}-1$

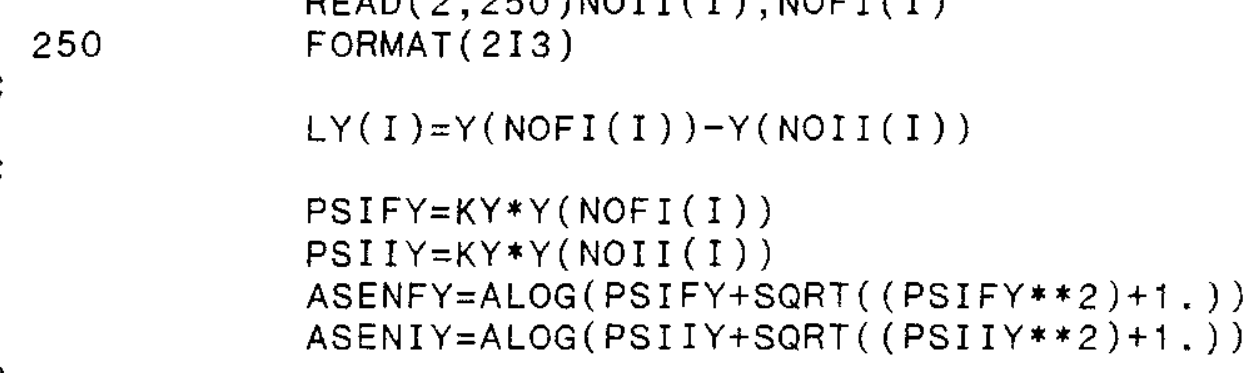

C

PLAMBFY $=(3 . * A S E N F Y) /(8 . * P S I F Y)+(1 . / 8) *.(5 .+2 . * P S I F Y * * 2) * \operatorname{SQRT}(1 .+P$ $\$ S I F Y * * 2)$

PLAMBIY $=(3 . * A S E N I Y) /(8, * P S I I Y)+(1 . / 8) *.(5 .+2$ * *PSIIY**2)*SQRT $(1 .+P$ $\$ S I I Y * * 2)$

PCABY $=(Y(N O F I(I)) * P L A M B F Y-Y(N O I I(I)) * P L A M B I Y) / L Y(I)$

$F I Y(I)=E F Y /(L Y(I) * P C A B Y)$

C

$$
B(I)=10 . * K Y * * 2 * P Y * F I Y(I)
$$

C

200 CONTINUE

c

$\mathrm{C}=(10, * \mathrm{HXO}) / \mathrm{PX} * * 2$

$D=(10 . * H Y O) / P Y * * 2$

C

WRITE (11)A

WRITE (12)B

C

C

MONTAGEM DA MATRIZ MC

C

DO $350 \quad I=1$, NNOST

DO $350 \mathrm{~J}=1$, NNOST

350 CONTINUE $\operatorname{MC}(I, J)=0$.

DO 381 I $3=1, N$

DO 381 J $3=1, M$

$W(13, J 3)=0$.

CONTINUE 


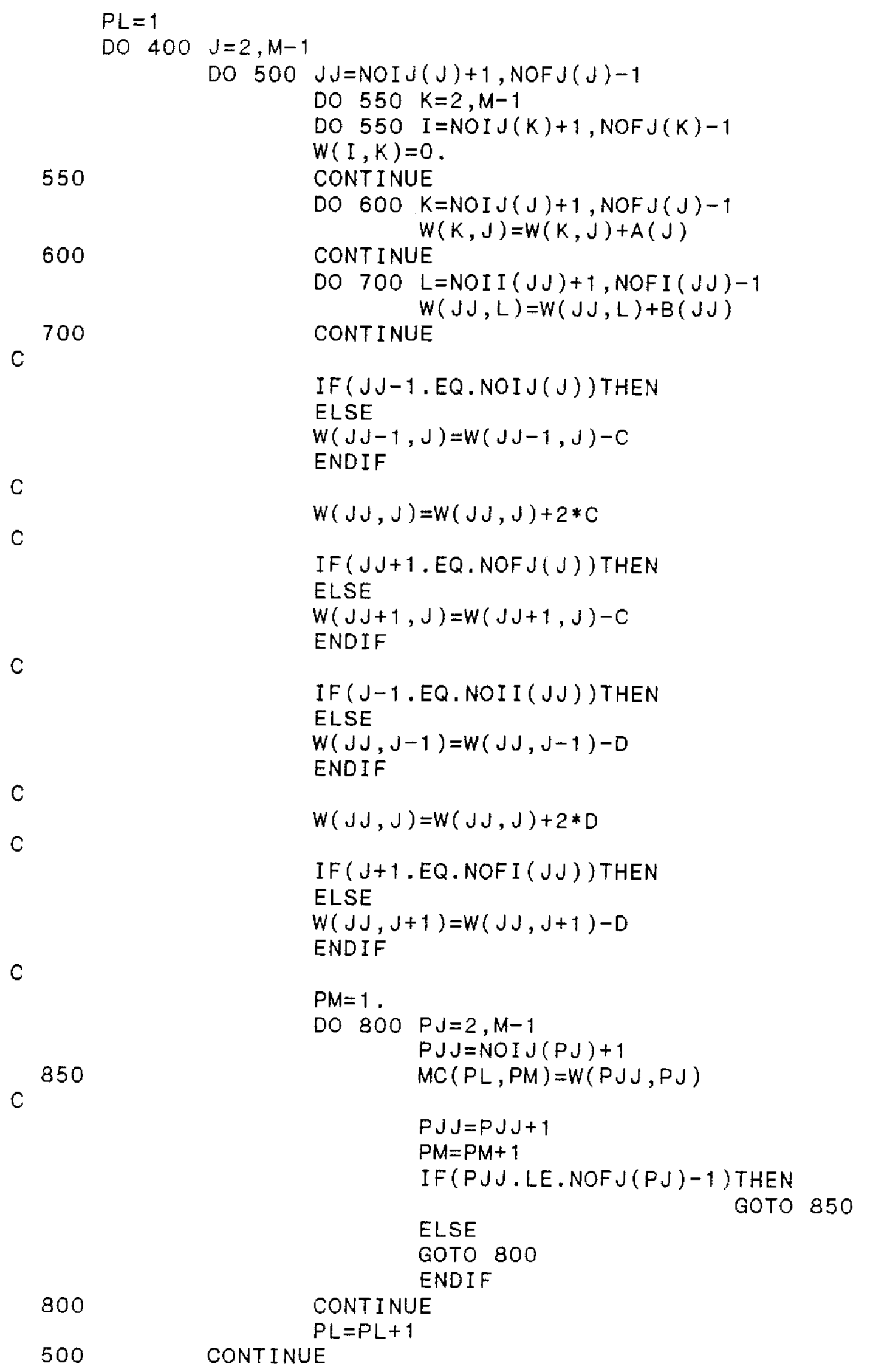




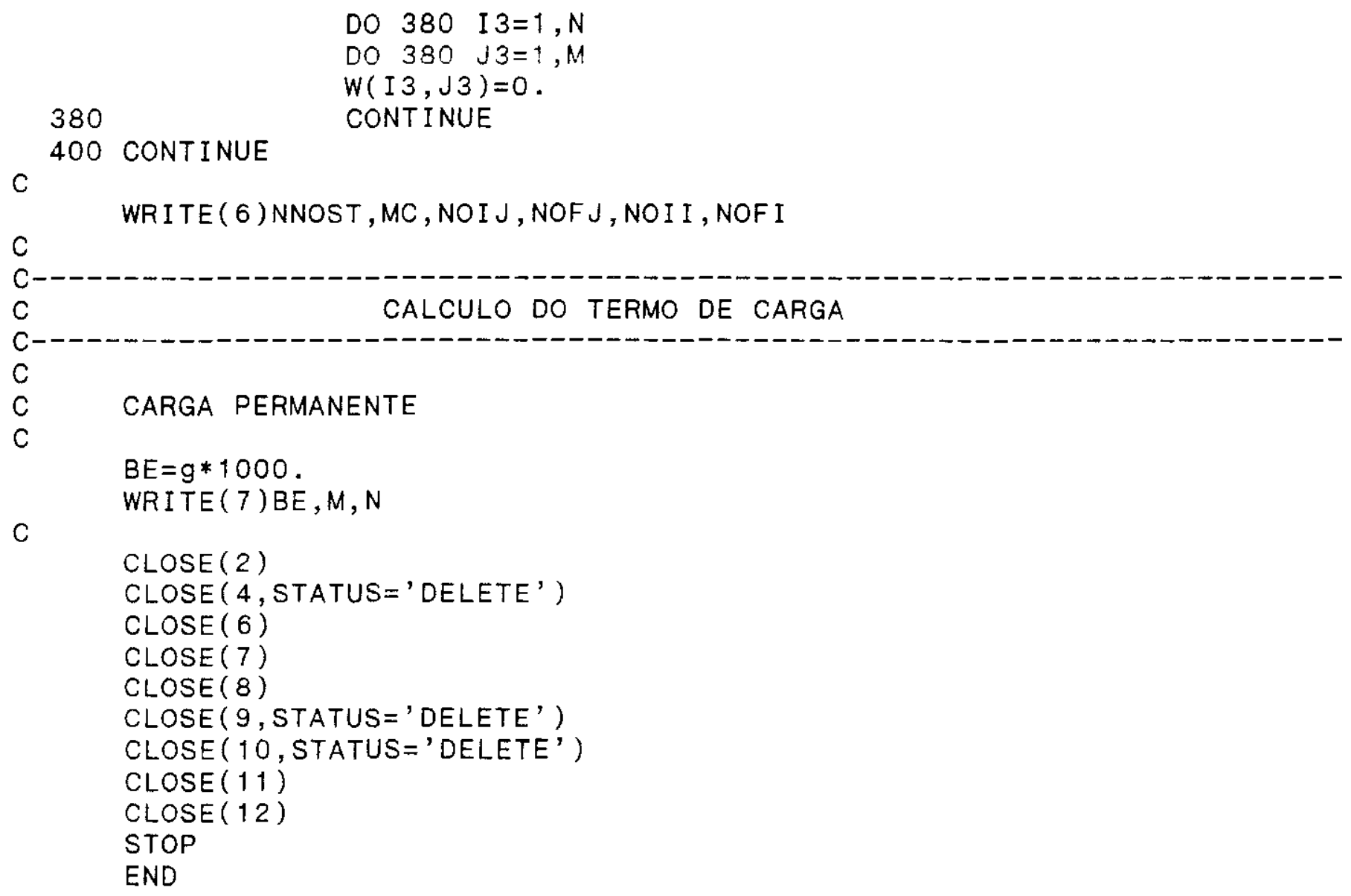




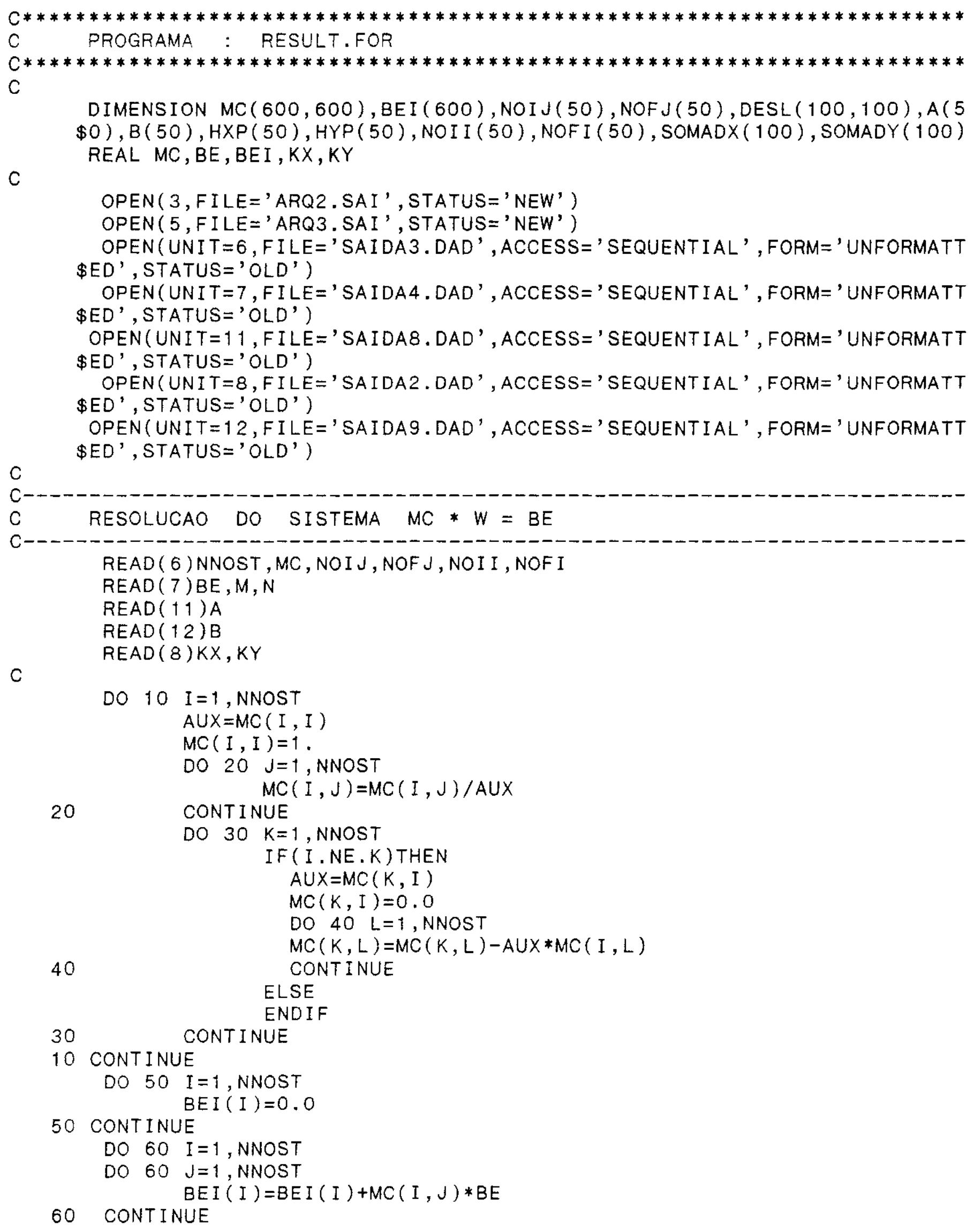




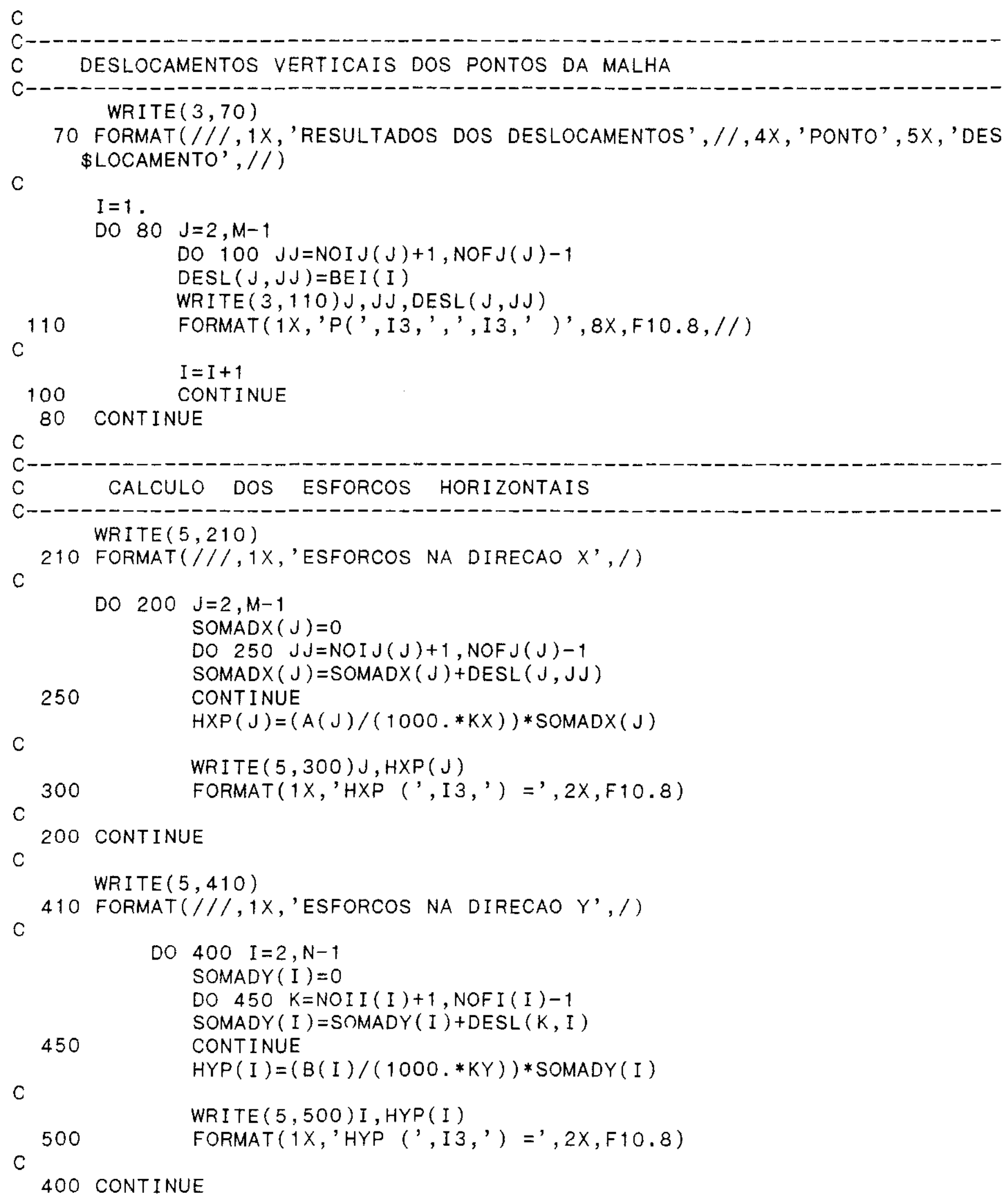




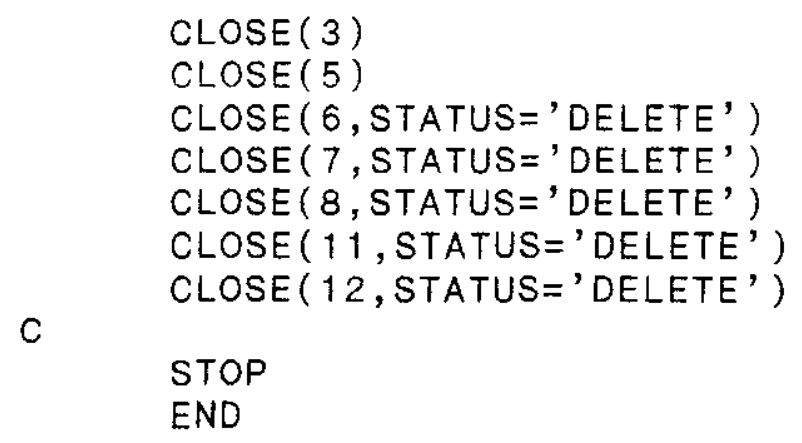

